Portland State University

PDXScholar

2-10-1995

Redefining the Suburban Ideal: An Analysis of Singlefamily Residential Densities in Washington County, Oregon

David Morgan Coughlan

Portland State University

Follow this and additional works at: https://pdxscholar.library.pdx.edu/open_access_etds

Part of the Geography Commons

Let us know how access to this document benefits you.

Recommended Citation

Coughlan, David Morgan, "Redefining the Suburban Ideal: An Analysis of Single-family Residential Densities in Washington County, Oregon" (1995). Dissertations and Theses. Paper 4887.

https://doi.org/10.15760/etd.6763

This Thesis is brought to you for free and open access. It has been accepted for inclusion in Dissertations and Theses by an authorized administrator of PDXScholar. Please contact us if we can make this document more accessible: pdxscholar@pdx.edu. 


\section{THESIS APPROVAL}

The abstract and thesis of David Morgan Coughlan for the Master of Science in Geography were presented February 10, 1995, and accepted by the thesis committee and the department.

COMMITTEE APPROVALS:
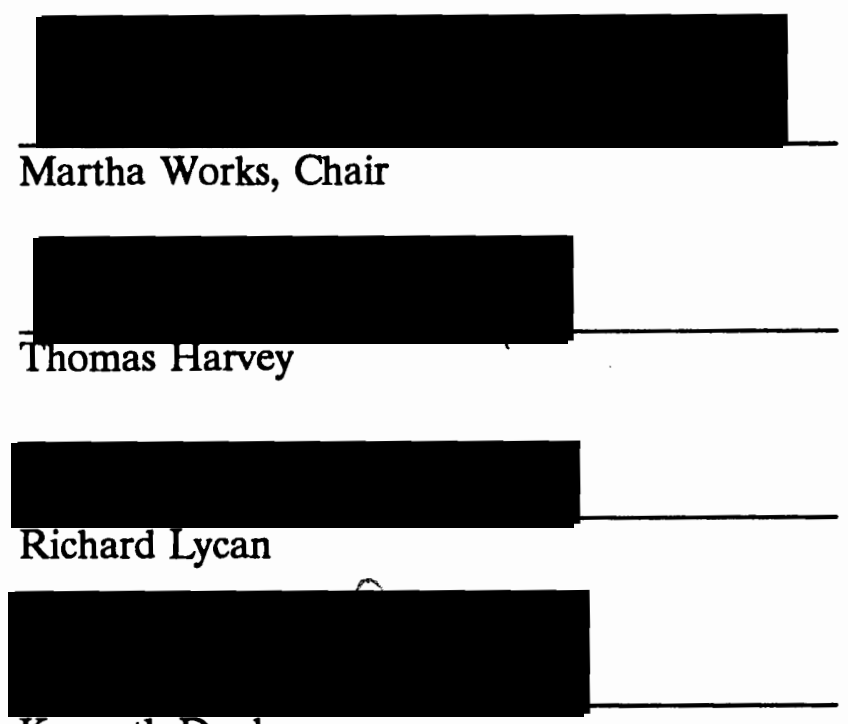

Kenneth Dueker

Representative of the Office of Graduate Studies

DEPARTMENT APPROVAL:

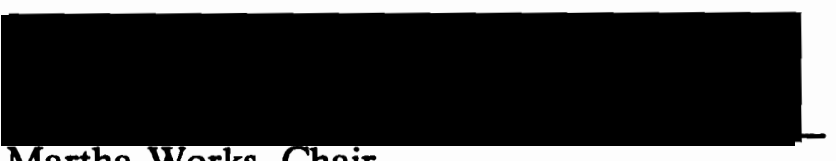

Martha Works, Chair

Department of Geography

ACCEPTED FOR PORTLAND STATE UNIVERSITY BY THE LIBRARY

by

on

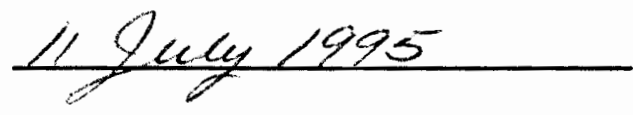




\begin{abstract}
An abstract of the thesis of David Morgan Coughlan for the Master of Science in Geography presented February 10, 1995.

Title: Redefining the Suburban Ideal: An Analysis of Single-Family Residential Densities in Washington County, Oregon
\end{abstract}

The United States' suburban landscape has historically been characterized by low-density residential development. This pattern was shaped by the abundance of developable land in nineteenth century America, and by the emergence of a suburban ideal which romanticized the concept of a spacious home set in a private, garden setting.

For many homebuyers, the realization of the suburban ideal was made possible by continual improvements in intraurban transportation. The commuter rail, the electric streetcar, and ultimately the automobile increased the commuting range of inner-city workers, and contributed to the continual expansion of development on the periphery of cities.

In recent years, economic and population pressures have contributed to accelerated housing costs in many metropolitan areas, necessitating a redefining of the traditional suburban ideal. Rising land costs have prompted developers to build single-family homes at increasingly higher densities. Developers now face 
the challenge of designing and implementing development strategies which maximize land use efficiency, and yet still retain some of the "garden setting" ambiance of the traditional suburban ideal.

This study traces the historical evolution of residential densities in Washington County, through review of 2235 Washington County plat maps dating from 1870 to 1992 . The data reveals a slow growth, low-density development prior to World War II, and a high-growth and increasingly higher-density pattern of development in the post-World War II period.

Since 1980, high-density suburban developments have become an increasingly common feature of the Washington County landscape. Examination of the spatial distribution of these subdivisions suggests a strong correlation between high-density development and land scarcity. Comparison of the different types of high-density subdivisions found in Washington County reveals how common-space developments allow for more effective integration with the natural environment.

The future of subdivision development in Washington County, hinges upon the results of Metro's Region 2040 study. The Region 2040 study will ultimately recommend the extent that the urban growth boundary should be expanded, and thus will directly affect the availability of developable land. The amount, type, ownership, and zoning of these "urban reserves" will be important considerations for future subdivision development in Washington County. 


\title{
REDEFINING THE SUBURBAN IDEAL: AN ANALYSIS OF SINGLE-FAMILY RESIDENTIAL DENSITIES IN WASHINGTON COUNTY, OREGON
}

by

\section{DAVID MORGAN COUGHLAN}

\begin{abstract}
A thesis submitted in partial fulfillment of the requirements for the degree of
\end{abstract}

\section{MASTER OF SCIENCE \\ in GEOGRAPHY}

Portland State University 1995 


\section{ACKNOWLEDGEMENTS}

I would like to thank Tom Harvey for his assistance in the compilation of my literature sources, and for periodically providing a sounding board for my project. I would also like to thank interviewees Robert Cone, and Mark Turpel for helping place residential densities in a governmental planning context, and Von Summers, for providing information on the Portland area homebuilding market.

I would also like to thank Carolyn Perry for her assistance in preparing and formatting the final copy of this thesis. Finally, I would like to thank my advisor, Martha Works, for all her help in this thesis project, and for her continual encouragement and support throughout my graduate program at Portland State. 
ACKNOWLEDGEMENTS $\ldots \ldots \ldots \ldots \ldots \ldots \ldots \ldots \ldots \ldots$ iii

LIST OF TABLES $\ldots \ldots \ldots \ldots \ldots \ldots \ldots \ldots \ldots \ldots \ldots \ldots \ldots$ vi

LIST OF FIGURES $\ldots \ldots \ldots \ldots \ldots \ldots \ldots \ldots \ldots \ldots \ldots \ldots$ vii

\section{CHAPTER}

I INTRODUCTION $\ldots \ldots \ldots \ldots \ldots \ldots \ldots \ldots \ldots \ldots$

II HISTORICAL EVOLUTION OF

RESIDENTIAL DENSITIES ................ 6

The American Suburban Ideal ............ 7

The Commuter Suburbs $\ldots \ldots \ldots \ldots \ldots \ldots \ldots \ldots$

The Subdivision Developers .............. 16

The Recreational Automobile Era 1920-1945 . . . . . . 18

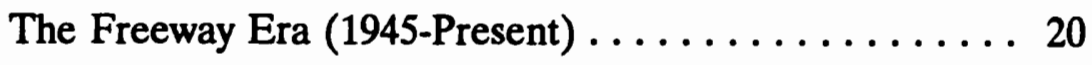

III REDEFINING THE SUBURBAN IDEAL ......... 25

High-Density Subdivision Development . . . . . . 28

Urban Planning Strategies and

High-Density Development ............. 32

High-Density Development Trends

in the Portland Metro Area . . . . . . . . . . . 35

IV METHODOLOGY: CASE STUDY AREA SELECTION AND RESEARCH TECHNIQUES $\ldots \ldots \ldots \ldots \ldots \ldots \ldots \ldots, 40$ 
PAGE

Research Techniques ................. 45

V WASHINGTON COUNTY SUBDIVISION DENSITY

DEVELOPMENT PATTERNS $1870-1992 \ldots \ldots \ldots \ldots \ldots \ldots 52$

Early Subdivision Development 1870-1944 . . . . . . 52

Post World War II Subdivision

Development 1945-1992 .................. 59

VI WASHINGTON COUNTY HIGH-DENSITY

RESIDENTIAL DEVELOPMENT . ............ 73

Spatial Distribution of High-Density Subdivisions ..... 73

Types of High-Density Subdivisions . . . . . . . . 77

VII THE FUTURE OF SINGLE-FAMILY RESIDENTIAL DEVELOPMENT IN WASHINGTON COUNTY . . . . . . 85

Alternative High-Density Development Options . . . . . 87

The Region 2040 Plan . . . . . . . . . . . . . . . 94

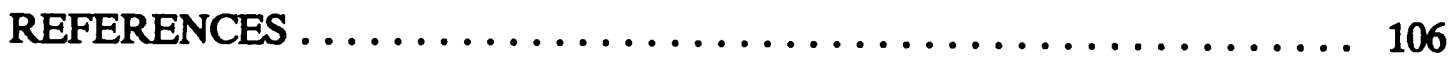

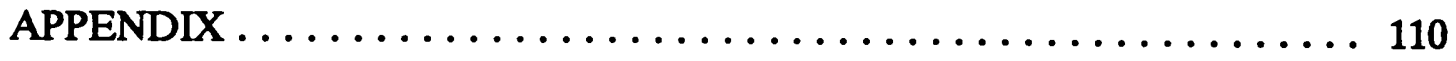




\section{LIST OF TABLES}

TABLE

PAGE

I U.S. Metropolitan Area Housing Costs $1990 \ldots \ldots \ldots \ldots$. . . . 39

II Population of Metropolitan Counties 1940-1990 . . . . . . . . 43

III Population of Washington County Cities $1960-1990 \ldots \ldots$. . . . . 43

IV Washington County Subdivision Data $1870-1992 \ldots \ldots \ldots \ldots 53$

V Washington County Subdivision Density $1870-1992 \ldots \ldots \ldots \ldots 60$ 


\section{LIST OF FIGURES}

1. New York City row houses built in $1845 \ldots \ldots \ldots \ldots \ldots . .9$

2. Romanticized rural environment is evident in $\mathbf{1 8 8 7}$

plan-book home priced at $\$ 3,000 \ldots \ldots \ldots \ldots \ldots \ldots 11$

3. Adams' four-stage evolutionary model $\ldots \ldots \ldots \ldots \ldots \ldots \ldots$

4. Lot layout for streetcar subdivisions in late-nineteenth

century Chicago .................. 15

5. Advertisement for "working man's" subdivision

in late-nineteenth century Chicago $\ldots \ldots \ldots \ldots \ldots 16$

6. Levittown, New York exemplifies large-scale suburban

development patterns in the 1950 s............ 22

7. Z-lot line houses and lot configurations in Westmark

Promenade development in Irvine, California . . . . . . 31

8. Portland's Urban Growth Boundary ............ 36

9. Single-family homes on small lots (average 5,000 sq. ft.) in

Lake Oswego, Oregon ................. 37

10. Map of Washington County $\ldots \ldots \ldots \ldots \ldots \ldots \ldots \ldots, 41$ 
11. Number of Washington County Subdivisions Built $1870-1992 \ldots \ldots \ldots \ldots \ldots \ldots \ldots \ldots \ldots \ldots \ldots$

12. Average Units-Per-Acre of Washington County

Subdivisions: $1870-1992 \ldots \ldots \ldots \ldots \ldots \ldots \ldots \ldots 61$

13. Location of High-Technology Industries in Portland Area ..... 64

14. Percentage of Low, Medium, and High Density

Subdivisions in Washington County 1870-1992 . . . . . 65

15. Birchwood Park Subdivision in Hillsboro, surveyed in 1946,

123 units, average lot size $75 \times 120(9,000$ sq. ft. $) \ldots \ldots 67$

16. Cedar Hills Subdivision in Beaverton, surveyed in 1946,

253 lots, average lot size $80 \times 120$ (9600 sq. ft.) . . . . . 68

17. Catlin Crest 2 Subdivision. Near Intersection of Miller Rd.

and Barnes Rd. Surveyed in 1988, 85 lots, UPA Density:

1.9: average lot size: 15,000 sq. $\mathrm{ft}$. Example of

contemporary high-income housing on large lots . . . . 70

18. Burntwood 2 Subdivision, west of Beaverton. Surveyed in

1983, 35 lots, UPA Density 4.0: Average lot size:

7500 sq. ft. Example of contemporary housing set on

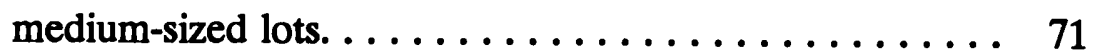

19. Washington County High-Density Subdivisions . . . . . . . . . 74

20. Lot-Size Comparison ................. 78 
21. Amart Summer Lake subdivision located in Tigard. Surveyed in 1979, 135 lots, average lot size: $40 \times 115$ (4600 sq. ft.). . 80

22. Deerfield Subdivision in Rock Creek area. Surveyed in 1989, 99 lots, average lot size: $45 \times 95$ (4275 sq. ft.). . . . . . 82

23. At the Brooks Bend PUD Subdivision. Surveyed in 1984, 20 lots, UPA Density: 5.0: Average lot size: 3900 sq. ft. Example of PUD subdivision incorporating common space around the perimeter of the development...... 84

24. RGC's Town Court Collection at Rancho Santa

Margarita, Calif. . . . . . . . . . . . . . . . 89

25. Canyon Creek courtyard development in Bothell, Wa....... 90

26. Rose Lane TND subdivision in West Linn, Or......... 92

27. Highest rated single-family image in the Visual

Preference Survey $\ldots \ldots \ldots \ldots \ldots \ldots \ldots \ldots \ldots$

28. Typical car-dominant suburban development ......... 96

29. Metro's Region 2040 Analysis of Growth Concept . . . . . . . . 98 


\section{CHAPTER I}

\section{INTRODUCTION}

Suburban land markets have traditionally offered homebuyers the opportunity to own larger pieces of property than they could afford in inner-city locations. Property values generally become lower with increasing distance from the central business district, allowing for larger lot sizes and lower density patterns of development in outlying areas. Although this "sprawling," low density pattern of development has often been criticized by urban planners as wasteful and inefficient, it has also been widely coveted by homebuyers seeking to fulfill their perception of the American "suburban ideal." The lure of large yards and spacious homes prompted millions of Americans to forego the transportation and time-cost advantages associated with inner city locations, and helped spur the suburban exodus which has been the prevailing intra-urban migration pattern for over a century.

The United States' suburban landscape has historically been characterized by low-density residential development. This pattern was shaped by the abundance of cheap, developable land in nineteenth century America, and by the emergence of a suburban ideal which helped define the spatial parameters of the new landscape. This ideal romanticized the concept of a spacious house set on a 
large lot in a natural, wooded setting. The emphasis was on creating large, private spaces that would provide a sense of quietude, and serve as a refuge from the turmoil and congestion of the industrializing inner cities.

The realization of the suburban ideal was made possible by advances in intraurban transportation in the last half of the nineteenth century. The development of the commuter rail, the electric streetcar, and ultimately the automobile allowed for successively larger areas of cities to be suburbanized.

The automobile became the defining force of the suburban landscape after 1920, and its greater range and flexibility generated an increasingly sprawling pattern of development. The emergence of intraurban freeways in the 1950s accelerated this trend by shortening commuting time and allowing for development further from the central city. The suburbs became a middle-class haven during this era, with low interest rates, large-lots, and inexpensive housing prompting millions of Americans to pursue their vision of the suburban dream.

The "golden age" of middle-class suburbia came to a crashing halt in the 1970s and 1980s. Increasing energy costs, high interest rates, and population pressures resulted in a squeezing out of the middle-income homebuyer in many metropolitan areas. The escalating cost of land prompted subdividers to design innovative high-density residential developments in the hope of recapturing the middle-income housing market. These "planned-unit-developments" and "zero-lotline" designs attempted to create the impression of a suburban setting on lots 
ranging between 3,000 and 5,000 square feet--an area less than half the lot size of the typical 1950s suburban home.

The new high-density developments represent a substantial departure from the traditional large-lot suburban home. Their emergence marks a new era of compromise, one that requires middle-class homeowners to reconcile their perception of the suburban ideal to the spatial realities of the new landscape. The challenge for developers is to design and implement high-density development strategies which enhance long-term livability and retain some of the "garden setting" ambiance of the traditional suburban ideal. Innovation and thoughtful design will be a critical component in selling the new high-density concept to a generation of homebuyers accustomed to the traditional low-density pattern of development.

This thesis examines the evolution of subdivision densities in Washington County, Oregon, with particular focus on high-density development trends. The purpose of the study is to identify the principal factors which have helped shape the residential density patterns of the Washington County suburban landscape, and to use this information to help project future development density trends.

Washington County was chosen as a case-study area because its dramatic economic and population growth in recent decades have contributed to an accelerated high-density development pattern. The county has been experiencing a substantial increase in land costs in recent years, fueled both by its emergence as 
a premier high-technology center and by its increasing popularity as a Portlandarea residential site. These factors, combined with the approaching saturation of developable land within the urban growth boundary, have prompted Washington County developers to build subdivisions at increasingly higher densities.

The thesis begins with a review of the literature on suburban processes, with particular emphasis on the United States' residential density development patterns. The intent of the review is to provide a broad historical and theoretical context in which to evaluate Washington County's development density trends. The review examines the key variables which have influenced national residential density patterns, including the transportation revolution, the rise of the subdivision builders, FHA housing standards, and the 1970s' energy crisis.

The tracing of the historical evolution of residential densities in Washington County, involved review of $\mathbf{2 2 3 5}$ Washington County subdivision plat maps dating from 1870 to 1992 . The data collected from this process allows for detailed analysis of the county's residential density history, and provides a quantifiable means of explaining physical changes in Washington County's suburban landscape. The data reveals historical variations in subdivision lot size and prompts examination of specific factors which may have contributed to those variations.

One of the focal points of this study is the analysis of how high-density subdivision development is changing the shape and appearance of the Washington County landscape. Examination of the spatial distribution of high-density 
subdivisions in Washington County reveals variables which encourage or discourage high-density development. Review of the various types of high-density subdivisions in Washington County allows for comparison of design characteristics, and evaluation of how closely each type adheres to the traditional suburban ideal.

Finally, I consider the future of Washington County residential development, with special attention given to the expected impact of Metro's Region 2040 study. The Region 2040 study will ultimately recommend the extent that the urban growth boundary should be expanded, and thus will directly affect the availability of developable land. The amount, type, ownership, and zoning of the land in these designated "urban reserves," will be important considerations for future residential development in Washington County. 


\section{CHAPTER II}

\section{HISTORICAL EVOLUTION OF SUBURBAN RESIDENTIAL DENSITIES}

The United States' urban structure differs from the rest of the world in several important respects. In the United States, affluent and middle-class people generally live in suburban areas that are located far from their central-city work

places. In most countries, affluent and middle-class people prefer to live close to their places of work, and their residences tend to be clustered in the central parts of cities. In American suburbs, residents usually own their homes which are situated on lots that are much larger than the world average. In the rest of the world, high-density development patterns dominate and homeownership is the exception rather than the rule (Jackson, 1985, p. 6).

The unique patterns of residential development in the United States can be at least partly attributed to the availability of space. The development of suburbia in the nineteenth century coincided with the expansion of the American frontier, and this "limitless space" mentality is reflected in the low-density development patterns of the suburban landscape. Land costs in the United States have been traditionally low by world standards, and this factor has allowed more flexibility in the shaping of the American suburban ideal. The concept of a spacious home in a garden setting evolved naturally in the American public conscienceness, 
unhindered by the spatial constraints confronting residents of more densely populated regions.

The emerging American perception of suburbia as an ideal living environment represented a significant departure from traditional views of suburban areas. In pre-industrial times, land located on the outskirts of cities was considered undesirable because it was inconveniently removed from the commercial activities of the central city. Since wealthier families could afford to pay the higher land costs in the inner city locations, their residences tended to be clustered close to the city's commercial heart. The poorer groups, however, were priced out of the inner city and forced to locate in the outlying areas. This often resulted in a suburban landscape which was comprised of substandard housing and inadequate sanitary facilities. The slum-like characteristics of these suburbs prompted scorn by inner city residents, and even the word suburb became associated with "inferior manners, narrowness of view, and physical squalor" (Jackson, 1985, p. 19).

\section{The American Suburban Ideal}

In the United States, the negative public perception of the suburb began to change in the early nineteenth century. The advent of the steam engine ushered in the transportation revolution and precipitated the transformation of the structure of American cities. 
Throughout the nineteenth century, advances in transportation made the peripheral areas of cities more and more accessible. Ferries, steam railroads, and electric streetcars all helped expand the urban environment by providing relatively inexpensive and convenient transportation service to outlying areas.

The transportation revolution was instrumental in helping transform the public residence ideal from high-density inner city to low-density suburban. Early nineteenth-century "walking cities" were characterized by extreme congestion. The need to be within walking distance of jobs, shopping, and social activities, prompted residents to crowd together at density levels far higher than is common today. Densities in walking cities normally exceeded 75,000 per square mile, and were rarely less than 35,000 per square mile, which was about the density level in New York City in the 1980s. (Jackson, 1985, p. 14).

The individual residences of inner city dwellers reflected the premium placed on high density development. Lot sizes were usually less than twenty feet wide and houses were close to the curb. Row houses (Figure 1) were a common residential structure in walking cities and the rear areas of these houses were usually less than twenty-five feet deep (Jackson, 1985, p. 56). Private space was at a premium in these crowded conditions, and it was only by relocating to suburban locations that homeowners could realize the increasingly popular ideal of a spacious house with a large yard. 


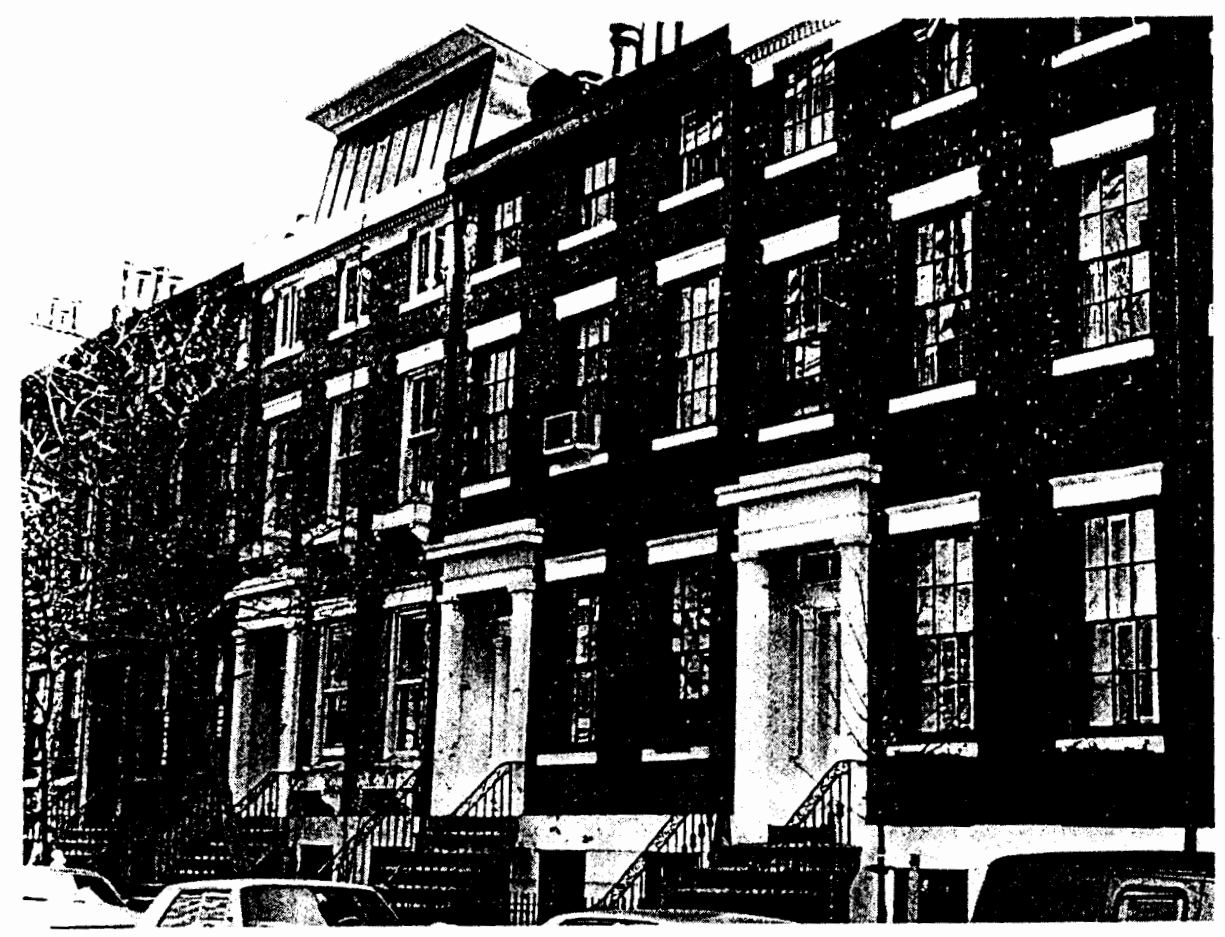

Figure 1. New York City row houses built in 1845 (Source: Jackson, 1985).

According to Zelinsky, the nineteenth century suburban ideal had its roots in the Jeffersonian perception of democracy, specifically in its interpretation of the agrarian doctrine of the eighteenth-century Enlightenment (Zelinsky, 1973). This ideal was based on the belief that the rural life is best for the soul, and that the country stood for life "in the fruits of the soil, in green growing things, in the healthy human family, and in the freedom from arbitrary political and social constraints" (Tuan, 1974, p. 236). Thomas Jefferson was the first mainstream political theorist to create a "schematic spatial representation of a national ideal of 
democracy" (Hayden, 1984, p. 19). His preference for the model family farm over the model village is reflected in the layout of his National Survey, which was designed to divide the landscape into small farms so that every man could own the means of agricultural production (Hayden, 1984, p. 19).

In the last half of the nineteenth-century the outdoors began to be increasingly viewed as a "healthy and invigorating" place to be (Rowe, 1991, p. 93). The traditional colonial view of nature as hostile and threatening was replaced with a romanticized perception of the rural environment (Figure 2). This change in attitude toward nature was reflected in the change in public tastes in housing. The walking city's row houses and crowded conditions had at one time offered a sense of fortification against the wilderness. Now the increasing appeal of detached houses in a rural setting revealed how the city itself was becoming something from which people sought refuge.

As the United States became increasingly industrialized in the last-half of the nineteenth-century, the suburban ideal became more attractive to city dwellers. By 1890 , the United States had become the world's leading industrial nation and its population was already one-third urban (Jackson, 1985, p. 47). The industrialization process tended to depersonalize the inner-city character of American cities, and prompted people to seek private living spaces as a refuge from the noise and congestion of the central city. The suburban home and family came to be viewed as a personal bastion against society, a place where people could renew their spirit in a serene and natural setting. 


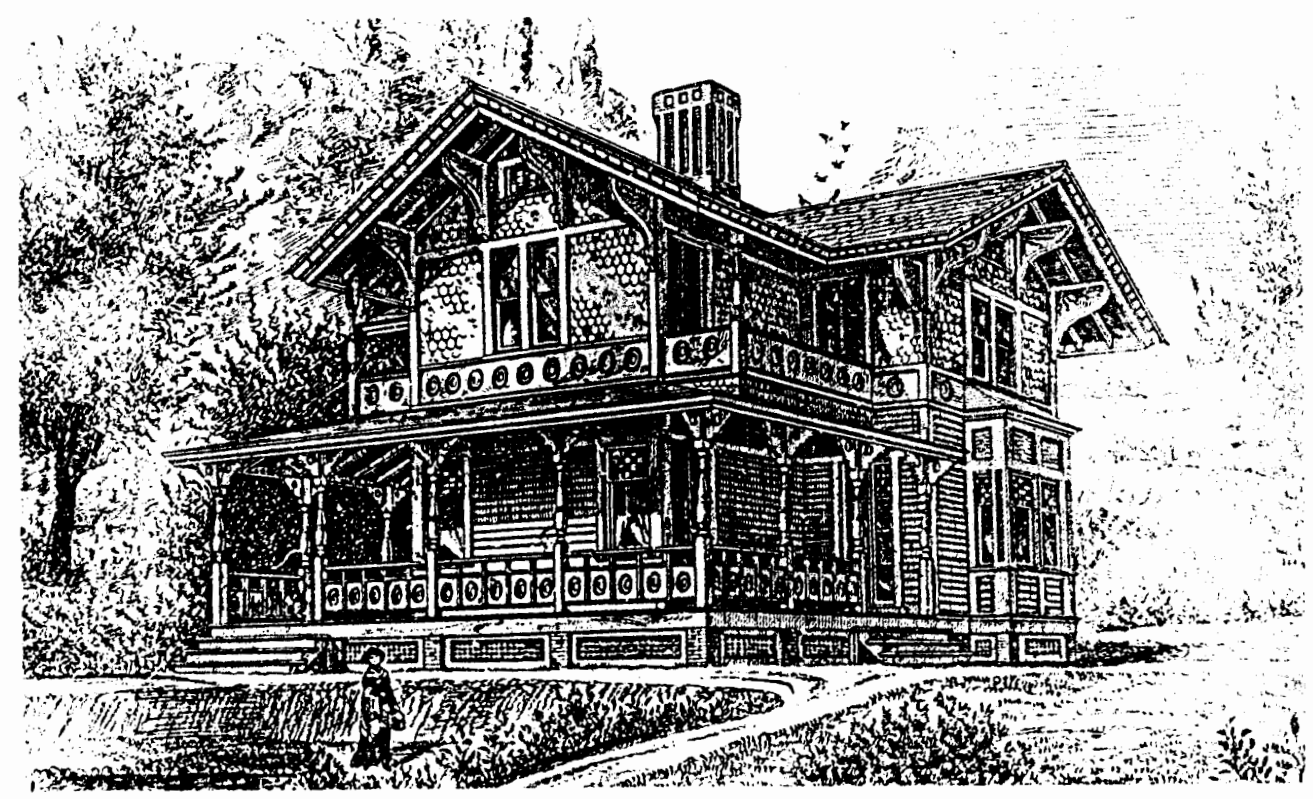

Figure 2. Romanticized rural environment is evident in 1887 plan-book home priced at \$3,000 (Source: Shoppell, 1887).

One of the key features of the new suburban ideal was the enlargement of open areas. Prior to 1875 , a large home on a extremely small lot was considered a perfectly acceptable residence for a high-status family (Jackson, 1985, p. 55). The transportation revolution, however, made the cheaper land on the periphery of the city much more accessible and allowed for a substantial increase in residential lot sizes. The row houses and small-lot homes of the inner city were no longer considered appropriate for this new suburban environment. Instead, the detached home set in the middle of a large, manicured yard became the suburban 
ideal (Clark, 1986, p. 100), and provided the blueprint for a suburban development pattern that has endured to this day.

\section{The Commuter Suburbs}

The emergence of the first commuter suburbs in the nineteenth century was largely attributable to the development and expansion of commuter rail lines. These rail lines opened up the outlying areas primarily to the wealthy, who were the only people who could afford the time and fare costs associated with rail travel.

The first affluent suburbs were developed around New York, Boston, and Philadelphia after the Civil War (Donaldson, 1969, p. 24). Developers catered to the luxurious tastes of their wealthy clients and created beautiful "garden" suburbs in the true spirit of the Jeffersonian ideal. The homes in these developments were spacious and set on huge, carefully landscaped lots ranging from 1/2 acre $(21,780$ square feet) to $11 / 2$ acre (65,340 square feet), (Jackson, 1985 , p. $80-83)$.

Although the commuter rail lines made pursuit of the suburban ideal a reality for wealthy families, it had relatively little effect on the residential living patterns of the burgeoning middle-class. This all changed, however, with the introduction of the electric streetcar in the early 1890 s. The streetcar offered low commuter fares, and its relatively high speeds allowed the middle-class to commute much further than had been possible before.

The Electric Streetcar Era represented the second stage in John S. Adams' four-stage evolutionary model which describes how major innovations affect 
movement and spatial organization in the metropolis (Figure 3),(Adams, 1970). The four stages are: 1) Walking-Horsecar Era (pre 1850 to late 1880s), 2) Electric Streetcar Era (late 1880s to 1920), 3) Recreational Automobile Era (1920 to 1945), and 4) Freeway Era (1945 to the present).

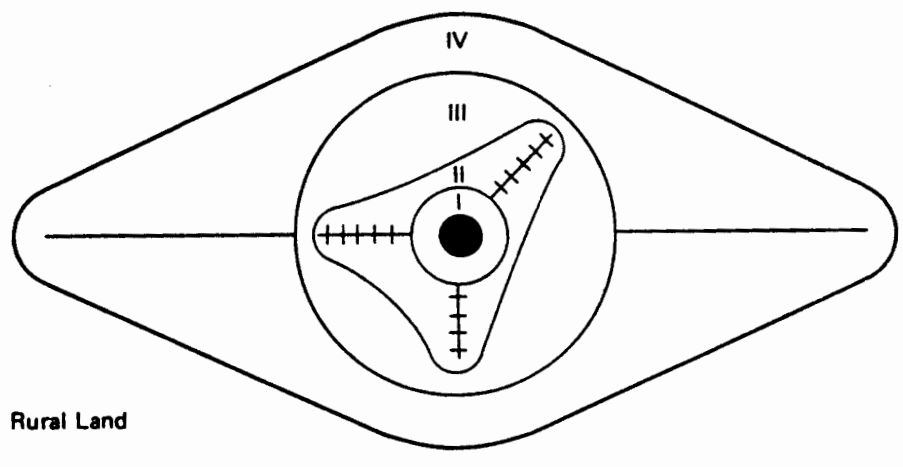

Figure 3. Adams' four-stage evolutionary model (Source: Adams, 1970).

The advent of the Electric Streetcar Era was particularly significant to the middle-class because it lowered commuting costs and substantially expanded the developable areas in cities. The average trolley speeds of 15 to $18 \mathrm{mph}$ were three times that of horsecars, and allowed for a significant increase in commuting range. The streetcar extended the urban development radius to up to 10 miles from the city core. This meant that at least five times the surrounding area of the horsecar city was now within 30 minutes of the CBD (Muller, 1981, p. 30). 
The broadening of cities' commutable areas coincided with the steady expansion of the middle-income urban population after 1890. The result was a dramatic growth in streetcar suburbs and the beginnings of the mass intraurban migration pattern which has characterized U.S. cities for over a century.

The middle-class suburbs were developed in a manner only partially consistent with the suburban ideal. The lower costs of suburban land allowed for a more lavish use of space and permitted middle-class families to realize the dream of a detached house and a yard (Muller, 1981, p. 30). The lot sizes in these new suburbs, however, fell somewhat short of the romanticized suburban ideal. The typical streetcar suburb featured one- or two-family homes on lots of about three thousand to six thousand square feet (Figure 4.), (Jackson, 1985, p. 136). Although these dimensions were generous by inner-city standards, they were a far cry from the $1 / 2$ acre to $11 / 2$ acre lots typical of the wealthier suburbs.

The compactness in middle-income suburbs occurred because the streetcar required a certain volume of traffic for profitable operation. This meant that the trolley line could only be extended to areas that had relatively high residential densities (Jackson, 1985, p. 136). So, although the streetcar opened up the suburbs to the middle-class, its economies of scale necessitated certain compromises by the beneficiaries of its service. Middle-income families gained the advantages associated with being removed from the inner city, but did not fully realize the yard space objectives implicit in the Jeffersonian rural ideal (Figure 5). 


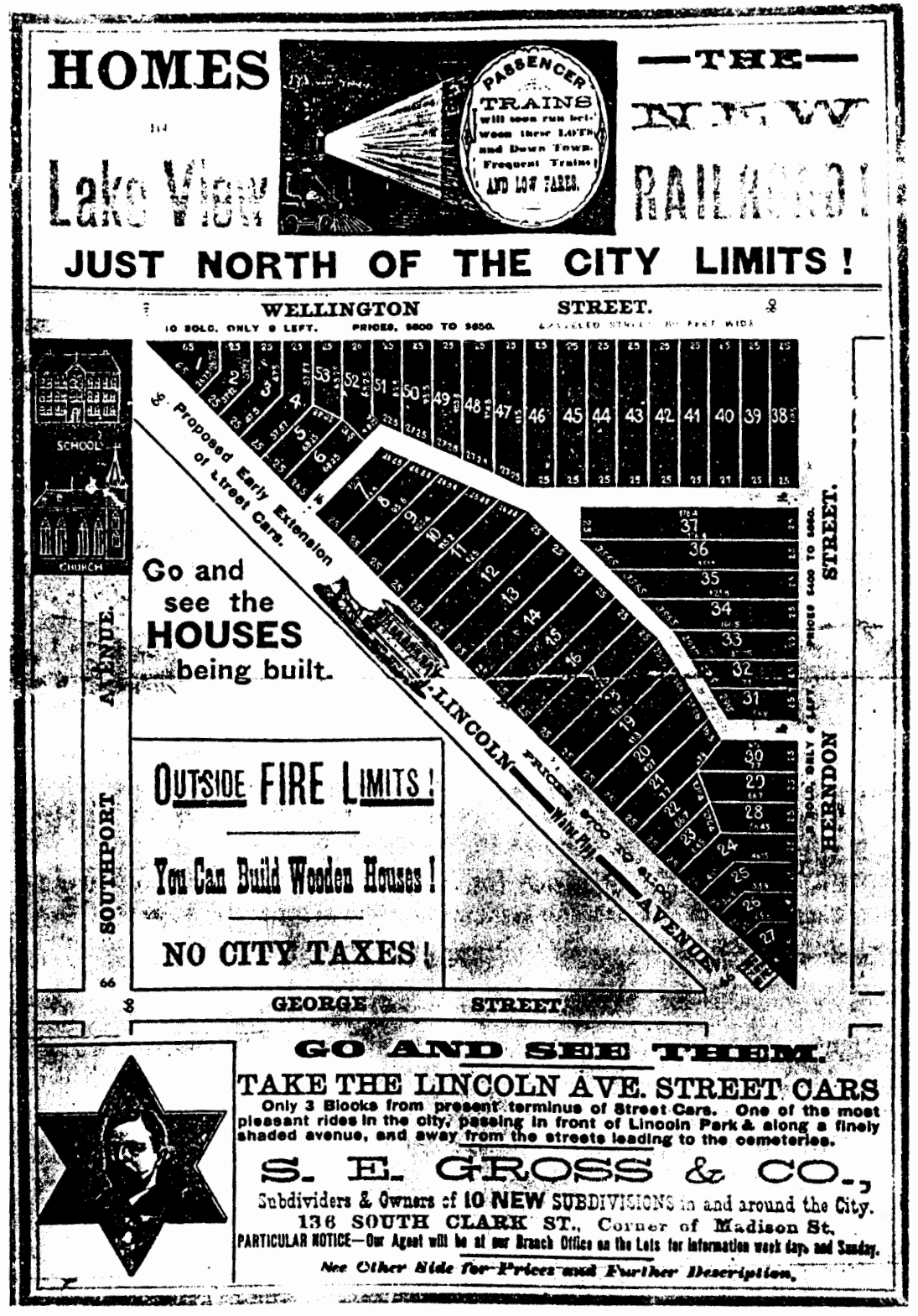

Figure 4. Lot layout for streetcar subdivisions in late-nineteenth century Chicago (Source: Muller, 1981). 


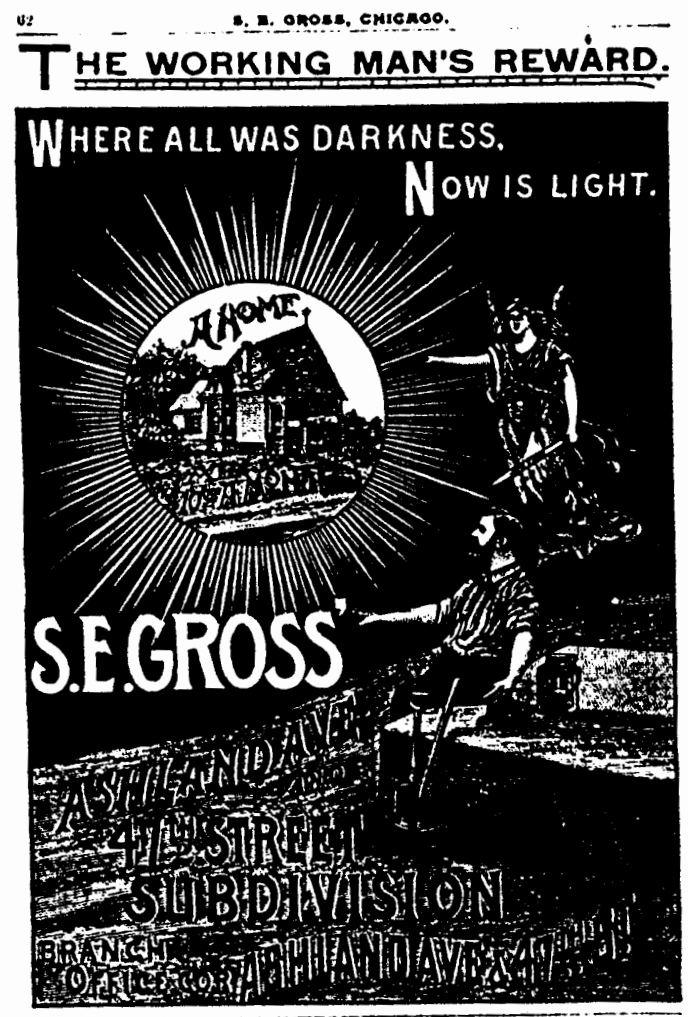

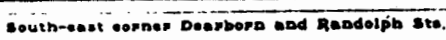
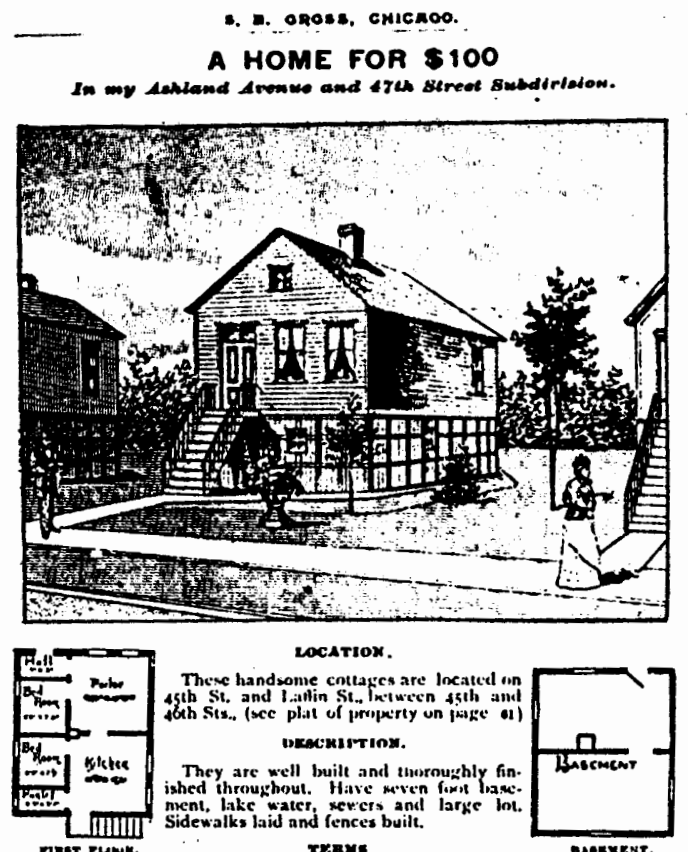
- Price gijojo to \$1,500: S100 cawh, balance on tong time and monthly paym.ntnkexce orrter Axb now ro art ruxas.

Branch Office comer of 47th St. and Ashland Ave. Open every disy. T.lk

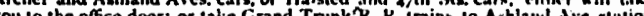
and go two blucks north: or call at Main Uffice and you will be tatien free to sce the properiy,

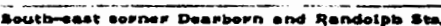

Figure 5. Advertisement for "working man's" subdivision in late-nineteenth century Chicago (Source: Clark, 1986).

The Subdivision Developers

The expansion of streetcar service provided a great impetus for subdivision development. Subdividers purchased multiple acreage of undeveloped land next to the streetcar lines, and "subdivided" the land into individual building lots (Weiss, 1987, p. 40). The common development pattern was a grid of residential streets laid out on either side of the commercial corridors paralleling the streetcar lines. This pattern represented the easiest development pattern for subdividers, 
but was often criticized at the time for its lack of aesthetic appeal (Jackson, 1985, p. 75).

Subdividers played a key role in the transformation of the American suburban landscape. The large-scale subdividers were often actually community builders who insured neighborhood continuity by requiring all lot and home purchasers to abide by long-term deed restrictions. In addition to these covenants, the community builders also established uniform front and side yards, and imposed minimum housing standards and construction costs (Weiss, 1987, p. 45). These early attempts to standardize suburban development were met with great receptivity from the buying public. Homebuyers liked the idea that their investment would be protected by these covenants, and no doubt the exclusive nature of these restrictions held a certain appeal. These early community builders correctly assessed the appeal of standardization to the buying public, and their interpretation of the suburban ideal still lives on in the modern suburban landscape.

Community builders developed vast, contiguous parcels of land and were thus more inclined than the small subdivider to assume a broad land-use planning approach (Weiss, 1987, p. 51). According to Weiss, these developers regarded land-use planning as a means of rationalizing the cost of land and building development, and of protecting their investment over the life of the project. The developers shared many of the same planning interests with government planners and these two groups quickly established the basis for a cooperative relationship. 
Plat control became a central issue for both subdividers and planners, and one of the main objectives of this control was to establish a minimum lot size (Weiss, 1988) The idea was to prohibit the selling of "lots of such small dimensions as to constitute a fraud by misleading the buyer concerning the cheapness of the lot" (N.P. Dodge, 1925, p. 302-3 as cited in Weiss, 1987).

According to Weiss, the shared planning interests between developers, realty boards, and government planners helped facilitate the growth of public regulation of suburban land. As the urban development emphasis shifted from the inner city to the periphery, increasing pressure was applied by real estate developers to establish suburban zoning regulations. By 1914, the attention of city planning had begun to shift away from the downtown and into the suburban areas. Private suburban land-use began to be regulated through zoning laws and public review of subdivision plots (Weiss, 1987, p. 54). The developers' standardization of the suburban ideal was now increasingly reinforced by zoning restrictions, and this assured the continuation of low-density urban development patterns.

\section{The Recreational Automobile Era 1920-1945}

The increased use of the automobile in the 1920 s contributed to a substantial expansion of the developable areas of cities. The increased range and flexibility that the automobile provided meant that prospective homebuyers were no longer restricted to locations along the commuter rail and streetcar lines. The unbuilt areas lying between suburban rail axes were opened up and eventually transformed into the first automobile suburbs. 
The relatively cheap land in these newly accessible areas attracted developers away from the densely settled streetcar corridors (Muller, 1981, p. 40), and encouraged development at unprecedentedly low density levels. The increased use of the automobile meant that the operational economies of the streetcars and rail lines could no longer dictate the spatial distribution and densities of residential developments. The automobile had become the new defining force of the suburban landscape, and its mobility and range would play a major role in perpetuating the low density development trends in suburban areas.

According to Meinig, the physical elements of the car-oriented landscape-widely dispersed housing tracts, curvilinear streets, and residential driveways and garages--were first exhibited in southern California in the 1920s (Meinig, 1979). The California lifestyle as depicted in Hollywood movies appealed to filmgoers throughout the country, and the California suburb became the specific expression of the suburban ideal (Muller, 1981, p. 49). The rest of the country began to imitate southern California's housing styles, including the southern California bungalow, Spanish architectural styles, and the low-roof ranch house popularized in the 1930s and 1940s (Muller, 1981, p. 49).

The siting of houses in middle-income subdivisions became increasingly standardized in the Recreational Automobile Era. Houses were placed in what Rowe refers to as a "standard tract configuration," which means they were situated toward the center and front third of a rectangular lot. The lot was 50 to 55 feet in width, and 100 to 120 feet in depth, with the total square footage ranging from 
5000 to 6500 square feet. This configuration was economically efficient because the relatively narrow, deep lots minimized infrastructure investments. It also divided the site into a front and back yard with smaller side yards, thus creating standardized public and private spaces (Rowe, 1991, p. 92).

The larger lot size and standardized siting practices of these subdivisions, represented a significant evolutionary step from the streetcar suburbs. The Recreational Automobile Era allowed many middle-income families to edge closer to the large-lot suburban ideal long enjoyed by their wealthier neighbors. It would not be until after World War II, however, that the Freeway Era and government mortgage subsidies would usher in the true "golden age" of middle-class suburbia.

\section{The Freeway Era (1945-Present)}

The post-World War II suburban boom was greatly facilitated by the creation of FHA housing standards in the 1930s. The introduction of Federal Housing Administration mortgage insurance was instrumental in transforming residential development practices during this period. The FHA's underwriting standards and land planning policies resulted in an upgrading and further standardization of subdivision development. These policies proved to be highly favorable to the community builders who had been searching for a suitable method for enforcing strict land planning standards. Since mortgage insurance was only granted on properties that met FHA's minimum standards, disreputable subdividers were forced out of business (Weiss, 1987, p. 142). Thus the creation 
of FHA standards assured that the community builders and small reputable subdividers gained complete control of the suburban housing market.

The community builders begin to flourish in the late 1930s and their largescale development approach often translated into increased affordability for middle-income homebuyers. In fact, a 1938 U.S. Department of Labor survey of 72 cities concluded that large-scale builders dominated construction of "mediumcost" single-family houses. The study revealed that all of the builders who built more than 100 houses a year operated in cities of more than 500,000 population, and nearly all of the houses produced by these builders were valued at between $\$ 2,500$ and $\$ 7,500$, the "middle-priced" range (Bureau of Labor Statistics, September 1940, p. 735).

The FHA's greatest contributions to middle-income homebuyers was raising the standards of design in less expensive subdivisions (Hare, 1939, p. 157), and providing an inducement to lenders to finance long-term mortgage loans. Mortgage insurance provided a major impetus for the post-World War II housing boom, and the FHA's emphasis on suburban development was one of the key factors propelling the middle-class suburban exodus.

The scale of suburbanization reached unprecedented levels in the postWorld War II period. Years of pent-up demand combined with modest prices and easy financing to generate a prodigious spurt in homebuilding. The large-scale builders began to dominate the construction industry, resulting in increased affordability for middle-income buyers. According to Muller, housing affordability 
was further enhanced through improvements in house prefabrication technology, repetition of large numbers of identically designed houses, and concentration on developing large but relatively inexpensive outlying tracts (Figure 6), (Muller, 1981, p. 54).

The development of high-speed freeways in the 1950s contributed to the ever-widening sprawl of residential development. The freeways further expanded intrametropolitan flexibility, and substantially broadened the range of residential locational choices (Muller, 1981, p. 52). The automobile assumed complete dominance in defining the suburban landscape during the Freeway Era, and its

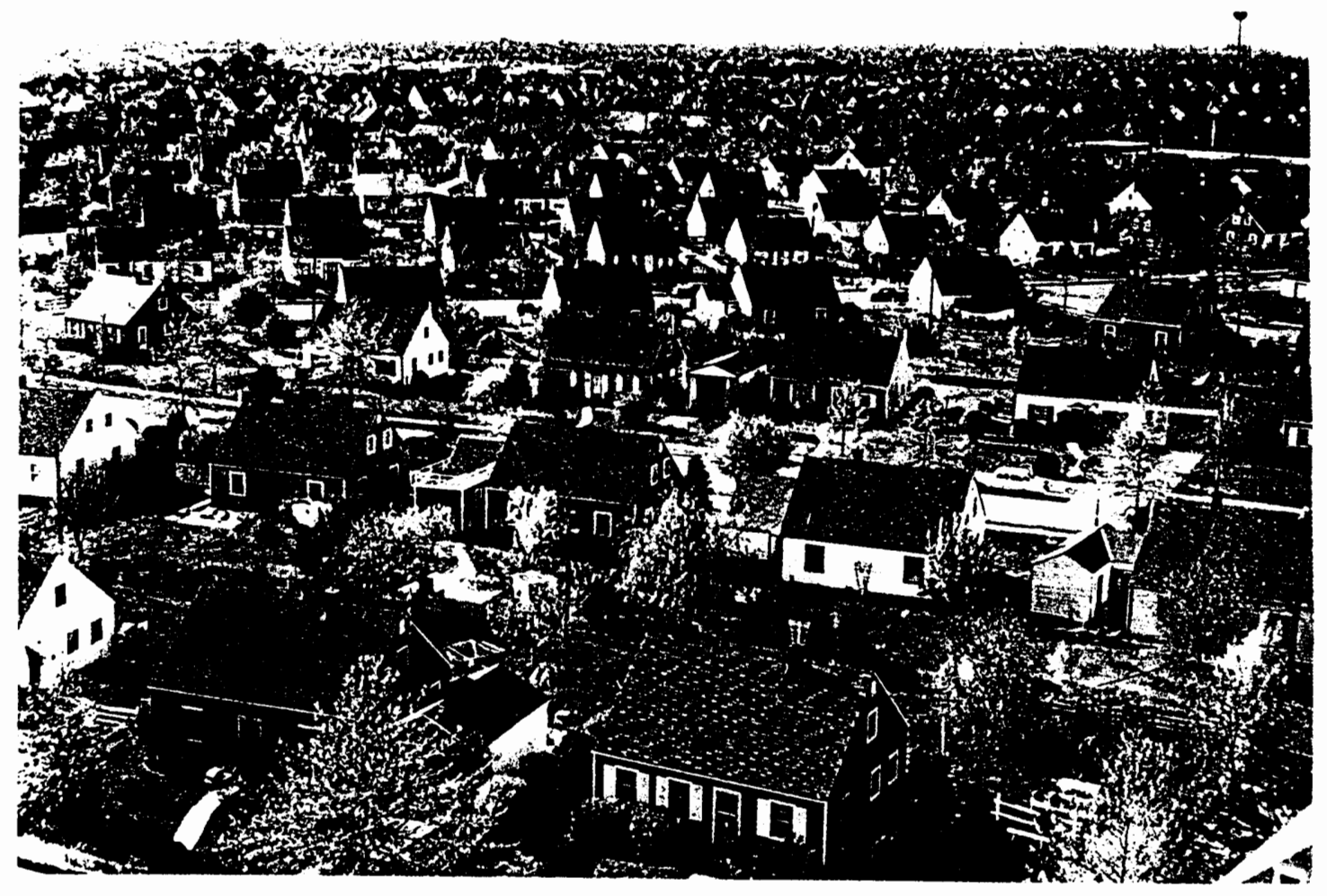

Figure 6. Levittown, New York exemplifies large-scale suburban development patterns in the 1950s (Source: Clark, 1986). 
increased popularity resulted in an acceleration of low-density residential development patterns.

The new freeways increased the urban commuting range and opened up new areas to residential development. The relatively low cost of this outlying land allowed middle-class subdivision development densities to reach an all-time low. Lots in newly developed middle-income areas were often 10,000 square feet or larger (Clark, 1986, p. 228), providing more than enough space for full front and back yards. The 1200 square foot ranch house on a large lot became the standard for many middle-income Americans by the 1960 s (Clark, 1986, p. 224), and helped define the material and spatial expectations of the burgeoning baby boomer generation.

Interestingly, although lot size increased substantially in the post-war era, a 1950 survey conducted by the federal government's Housing and Home Finance Agency, revealed that middle-income homebuyers still felt dissatisfied with their amount of space. Most buyers indicated they would prefer a larger lot for privacy than the 11,100 square foot lot which was the median in the survey year (Clark, 1986, p. 228).

The lot configurations of middle-income subdivisions began to change in the 1950s. Increasing emphasis on the recreational use of the yard necessitated an overall increase in the dimensions of lots. According to Rowe, landscape designs were often characterized by "large expanses of lawn, shrubbery, and sweeping horizontal lines" (Rowe, 1991, p. 94). Lots became wider across the front and the 
integrated appearance was often enhanced by "irregular or curvilinear lots which complemented the flowing lines of the dwelling environment" (Rowe, 1991, p. 94).

The 1950s and 1960s were in many respects the "golden age" for the middle-income suburban homebuyer. Low interest rates, inexpensive housing, and an expanding economy assured that the suburban lifestyle could be realized by an increasing proportion of middle-income Americans. Land on the periphery of cities was still relatively cheap and low gasoline costs enabled middle-income homebuyers to commute increasingly greater distances. These economies encouraged a marked acceleration in sprawling, low-density patterns of development, and contributed to an ever increasing dependence on the automobile as the sole source of commuter travel. 


\section{CHAPTER III}

\section{REDEFINING THE SUBURBAN IDEAL}

During the 1970s and 1980s, dramatic changes in the world economy prompted a redefining of the American suburban ideal. High interest rates, rising energy costs, and population pressures caused a squeezing out of the middleincome homebuyer in many metropolitan areas, reversing a century-old trend of increased affordability. The realities of the world economy necessitated a revising of the traditional American "frontier mentality" approach to residential land use. The golden age of expanding spatial and material acquisition was drawing to a close for many middle-income Americans, to be replaced by a new era of compromise and diminished expectations.

During the 1970 s and 1980s, middle-income homebuyers in many cities were forced to accept a compromise on the traditional suburban ideal. Increasing housing costs meant that middle-income buyers were often either priced totally out of the market, or were restricted to older homes in less desirable neighborhoods. Middle-income families seeking new housing were usually limited to modest houses on small lots ranging from 3000 to 5000 square feet, a space less than half that of the average suburban lot size in the 1950 s and 1960 s. The American middle-income suburban experience had seemingly come full circle from 
its streetcar suburb roots, returning to the pattern of spatial compromise that typified the first middle-class suburban communities a century earlier.

The changing characteristics of suburban development prompted studies on maximum density limits and the aesthetic values of the higher-density suburban landscape. Alexander (1993) examined the measurement and practical limits of residential density, discussing how quantitative attributes of the built environment are expressed in "measured density." Measured density includes the number of dwellings in an area, the number of potential occupants or users, and the proportion of a site that is built upon (Alexander, 1993, p. 184).

Alexander also identified qualities of the built environment which are not measurable but play an important role in shaping our perception of density. These qualitative factors include the height, relative spacing, juxtaposition, and diversity of structures and buildings, as well as lighting levels and type and extent of landscaping (Alexander, 1993, p. 184).

In his analysis of single-family residential densities, Alexander established that single-family detached housing is "subject to a clear maximum density limit of 10 units per acre." He indicated, however, that this density level can be exceeded by "unconventional" development such as "carpet" layouts with enclosed patios or zero-lot-line development (Alexander, 1993, p. 194).

As lot sizes diminish, it becomes increasingly challenging to retain privacy and usable yard space. Marcus, Francis, and Meunier (1987), comment on how 
yard space in lower-priced, San Francisco Bay area suburban developments, is almost always minimal, allowing for only very limited ornamental gardening. The small dimensions of these yards limit their utility and inhibit childrens' active play options. The authors point out the irony of people moving to the suburbs to escape the congestion of urban life, only to find that the small lots and layout of suburban developments actually place them in closer proximity to neighbors than the urban neighborhoods they left behind (Marcus, Francis, and Meunier, 1987).

The trend toward narrower lots combined with widening garages has resulted in a streetscape which appears as if it were designed more for cars than people. Southworth and Owens (1993) examine the evolution of the suburban streetscape, noting how the pedestrian-oriented porch-dominated streetscape has been displaced by garage-dominated developments (Southworth, and Owens, 1993, p. 283). In many subdivisions, front porches have disappeared altogether, which reinforces the car-dominant impression, and tends to discourage neighborly interaction (Southworth, and Owens, 1993, p. 283).

Although there are numerous design challenges associated with high-density developments, it is clear that they do offer distinct economic advantages. As Clay (1982) asserts, clustering homes, eliminating side yards, and shortening utility runs all save money (Clay, 1982, p. 72). However, conventional garage-dominant suburban designs do not seem well-suited for high densities. Placing relatively large, garage-dominated homes on 4000 square foot lots usually results in a stark, congested landscape with limited private and recreational space. The solution of 
course is not to return to lower densities, but to reconsider suburban subdivision design. The next section examines several innovative subdivision designs that redefine the spatial parameters of the traditional suburban development.

\section{High-Density Subdivision Development}

One of the subdivision developers' strategies for making new housing affordable to middle-income families, was to reduce the square footage of the house or the land or both without making the final product seem "impoverished or peculiar" (Langdon, 1984, p. 48). The concept of "planned-unit" developments became increasingly popular in California and other areas experiencing rapid acceleration in housing prices. According to Langdon, planned-unit developments are large suburban tracts built up at more than the customary suburban density, but laid out to fit the terrain and incorporating open space reserved for common use. These developments were often facilitated by local government cooperation, which freed the developer from such zoning requirements as lot sizes and street widths. The developer, in return, pledged to develop the land more imaginatively than was characteristic of typical subdivision development (Langdon, 1984, p. 49).

One of the more extreme high-density residential development concepts is the zero-lot-line (ZLL) which has been used by developers since the late 1960 s. In a ZLL development, each unit is built at or near one side of a long and narrow lot, leaving a long yard on the other side (Richardson, 1988, p. 15). The side of the yard hugging the boundary has no windows, so that each house's wider side yard has privacy (Langdon, 1984, p. 51). 
A study of a ZLL subdivision in Irvine, California reveals the high level of density characteristic of these types of developments. The Irvine Vista Filare development offers two-story detached houses set on lot sizes averaging thirty-six by eighty-six feet, or 3100 square feet (Langdon, 1984, p. 51). These houses cost between $\$ 133,000$ and $\$ 158,000$ in 1985 , which by Irvine's standards were quite affordable (Langdon, 1984, p. 50).

The ZLL configuration does have its detractors, however. According to Richardson, critics of the ZLL design have argued that cars are not wellaccommodated on extremely narrow lots. When twenty-foot wide, two-car garages are part of houses on thirty-five foot wide lots, the streetscape is dominated by garage doors and driveway aprons. In this setting, houses and landscape fade into the background. Richardson asserts that this "monotonous series of garage doors gives the subdivision an image of attached housing" (Richardson, 1988, p. 15).

The ZLL configuration also poses interior design problems which arise from the presence of the long windowless side wall at the property line. This usually means that the front door opens into a dark interior space, and rooms located along the windowless wall lack direct outdoor light (Richardson, 1988, p. 16).

An alternative to the zero-lot-line development is the Z-lot approach, where the house is laid out on the diagonal between its front and back yards (Figure 7). The Z-lot configuration allows for more flexibility in design than the zero-lot-line. Entrance yards can be arranged on alternating sides of the houses, 

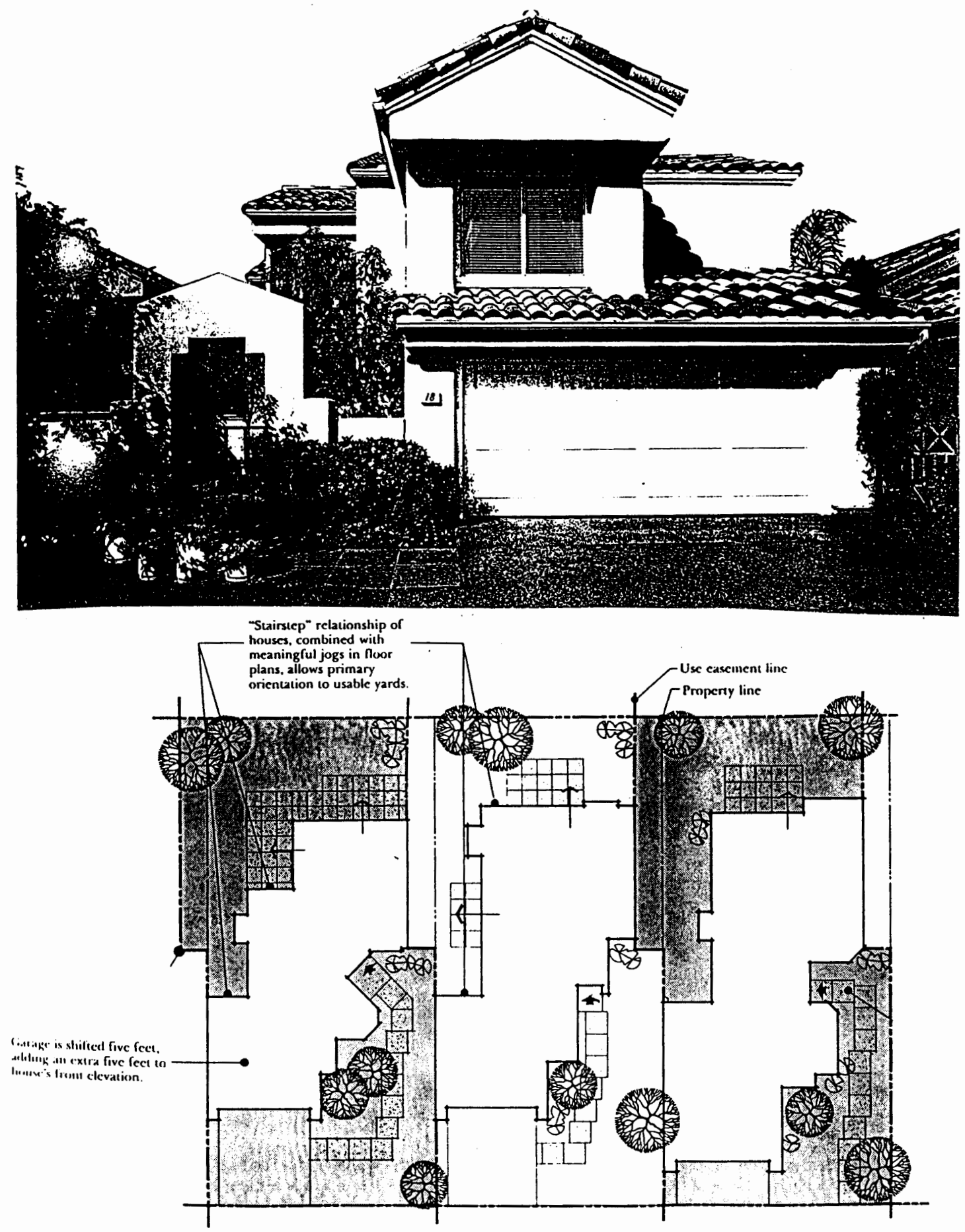

Figure 7. Z-lot line house and lot configurations in Westmark Promenade development in Irvine, California (Source: Richardson, 1988). 
thereby varying the streetscape. The Z-lot approach also provides more usable yard space. Since the Z-lot house's side yard is on the side of the house opposite the entry, the yard can "borrow" space from the adjacent lot through an easement (Richardson, 1988, p. 16).

The Z-lot approach typically requires a slightly lower development density than the zero-lot-line. Z-lot advocates, however, claim that this is more than offset by the advantages gained in improvements in neighborhood aesthetics and house design. The Westmark Promenade development in Irvine exemplifies how innovative design can create the impression of spaciousness in high-density subdivisions. The Westpark Promenade development's lots are only 42 wide by 90 feet in length with a total of 3780 square feet. Yet, the Z-lot configuration allows for maximum utilization of these tiny dimensions, with each site offering a generous entrance courtyard, plenty of light, and considerable privacy in the outdoor areas (Richardson, 1988, p. 18).

According to Richardson, there has been a tendency among some developers to become somewhat overzealous in their application of high-density development designs. In areas with extremely high land costs, developers have been tempted to put inappropriately large houses on increasingly smaller lots. This approach substantially reduces yard space, decreases ambient light, and negates many of the other advantages gained through innovative design. 
Detached housing, adequate yard space, and an open, airy setting have always been key features of the suburban ideal. The building of large houses on tiny lots represents a fundamental disregard for this tradition, and could very well translate into reduced long-term liveability and salability in these types of developments (Richardson, 1988, p. 20).

\section{Urban Planning Strategies and High-Density Development}

The OPEC oil embargoes in the 1970s revealed how dangerously dependent the United States had become on foreign oil and prompted critical scrutiny of American's sprawling suburban landscape (Popenoe, 1977, p. 14). Urban sprawl was increasingly attacked because it forced residents to travel farther to most activities, using more energy resources and producing more air pollution (Ottensmann, 1977, p. 389). Planners became increasingly sensitive to the negative external economies associated with low-density residential development, and urban growth control strategies were implemented to discourage "wasteful" low-density development patterns. Urban sprawl was no longer perceived as a logical landscape manifestation of the suburban dream, but instead viewed as a wasteful use of land which seriously compromised public transportation and service efficiency.

The suburban growth control programs implemented in the 1970s and 1980 s were designed to either discourage growth altogether, or to restrict development within prescribed boundaries. The programs in the California cities of Davis and Petaluma, employed direct restrictions on the number of housing 
units permitted. Other cities, such as Boulder, Colorado and Boca Raton, Florida, set specific population or housing caps (Rosenbaum, as cited in Schwartz, Hansen and Green, p. 303, 1981).

A key objective of growth control programs is to maximize public service efficiency by discouraging the "leapfrog" development patterns characteristic of sprawling suburban landscapes. By restricting the outward boundaries of urban growth, urban containment systems assure an eventual infilling of undeveloped land within the designated boundaries. The end result is a well-defined border between urban and rural areas, and continuity in development which greatly enhances the efficiency of public transportation and utility networks (Portland Urban Growth Boundary Findings, 1979).

Because urban growth control strategies restrict the amount of developable land on the periphery of cities, they provide an additional impetus to the current trend of increasing costs of residential land. The city of Petaluma, California provides an extreme example of how growth control strategies can greatly accelerate increases in the cost of housing. Petaluma implemented a growth limitation policy in 1972 after experiencing a 77 percent increase in population between the 1960 and 1970 census. The growth strained the capacity of the sewerage system and caused severe overcrowding in the schools. The city sought to remedy the situation by establishing a housing quota of 500 new units a year (Schwartz, Hansen, and Green, 1984, p. 110). 
The Petaluma growth control policy had an immediate effect on the cost of housing. In Schwartz, Hansen, and Green's study "The Effect of Growth Control on the Production of Moderate-Priced Housing," the authors compared sale prices of new houses sold in Petaluma and nearby Santa Rosa between 1970 and 1976. The increasing contrast between the two markets during this period was striking. In Petaluma the percentage of houses that sold for less than $\$ 25,000$ (1970 dollars) was between 48.3 percent and 56.7 percent before growth control; after growth control it dropped to 15.2 percent in 1974, 2.3 percent in 1975, and 3.3 percent in 1976. In Santa Rosa between 32.9 percent and 43.1 percent of the houses sold for less than $\$ 25,000$ over the entire $1970-76$ period. Thus the percentage of middle-income housing dropped from about 50 percent to less than 5 percent in Petaluma but remained at nearly 40 percent in Santa Rosa (Schwartz, Hansen, and Green, 1984, p. 112).

The growth control policies adopted by Petaluma greatly discouraged middle-income housing development. Since development options were so severely limited, the superior architectural design and construction quality of the more expensive houses assured they received preferential consideration in the allocation process. The city council's preference for high-quality subdivisions resulted in the virtual elimination of new middle-income housing developments in the city of Petaluma (Tarr, 1978, as cited in Schwartz, Hansen, and Green, 1984, p. 112-113). 
High-Density Development Trends in the Portland Metro Area

Although Petaluma's growth controls resulted in a substantial increase in the price of new housing, there is evidence to suggest that in certain circumstances, urban containment systems do not always produce this effect. As part of a statewide land use planning program, Portland, Oregon adopted an urban growth boundary (UGB) in 1984, that connected the outer edges of the city's metropolitan sprawl into a large circle (Figure 8), (Stacey, 1987, p. 12). Vacant areas within the circle could still be developed, but areas outside the boundary would be protected from urban encroachment (Portland Metropolitan Services District (METRO), 1989).

Although the urban growth boundary was expected to result in an eventual rise in the costs of remaining developable land, special planning provisions had been made to enhance housing affordability. The implementation of the Metropolitan Housing Rule in the early 1980 s removed zoning constraints to development of lower-cost housing (1000 Friends of Oregon, and HBAMP, 1991, p. 4). This factor, combined with a sluggish real estate market, helped keep new housing relatively affordable in the Portland area throughout the 1980 s.

The Metropolitan Housing Rule helped offset the residential land costs increases associated with the inception of the UGB. Developers could still build affordable, middle-class housing providing they increased the residential densities of their subdivisions. After the implementation of the Housing Rule, about 


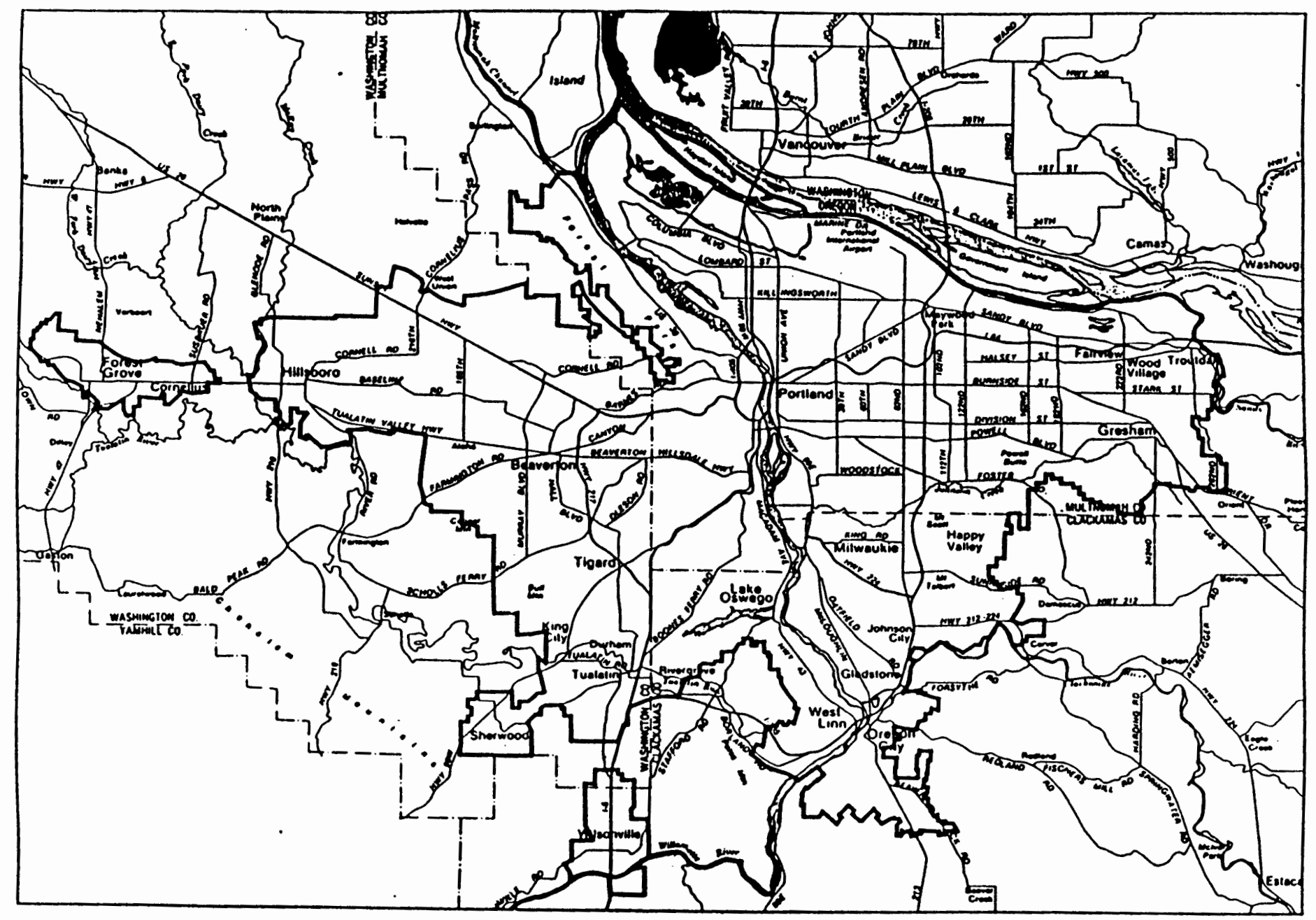

Figure 8. Portland's Urban Growth Boundary (Source: Portland Metropolitan Services District (METRO), 1989). 
two-thirds of the new homes were built on lots smaller than 9,000 square feet, and half of these were on lots smaller than 7,000 square feet (Figure 9). This compares to an average lot size of 13,000 square feet allowed under pre-Housing Rule plans. The correlation between small lot size and housing affordability is quite pronounced, with homes on lots smaller than 7,000 square feet costing on average only half as much as homes on lots larger than 9,000 square feet (1000 Friends of Oregon, and HBAMP, 1991, p. 10).

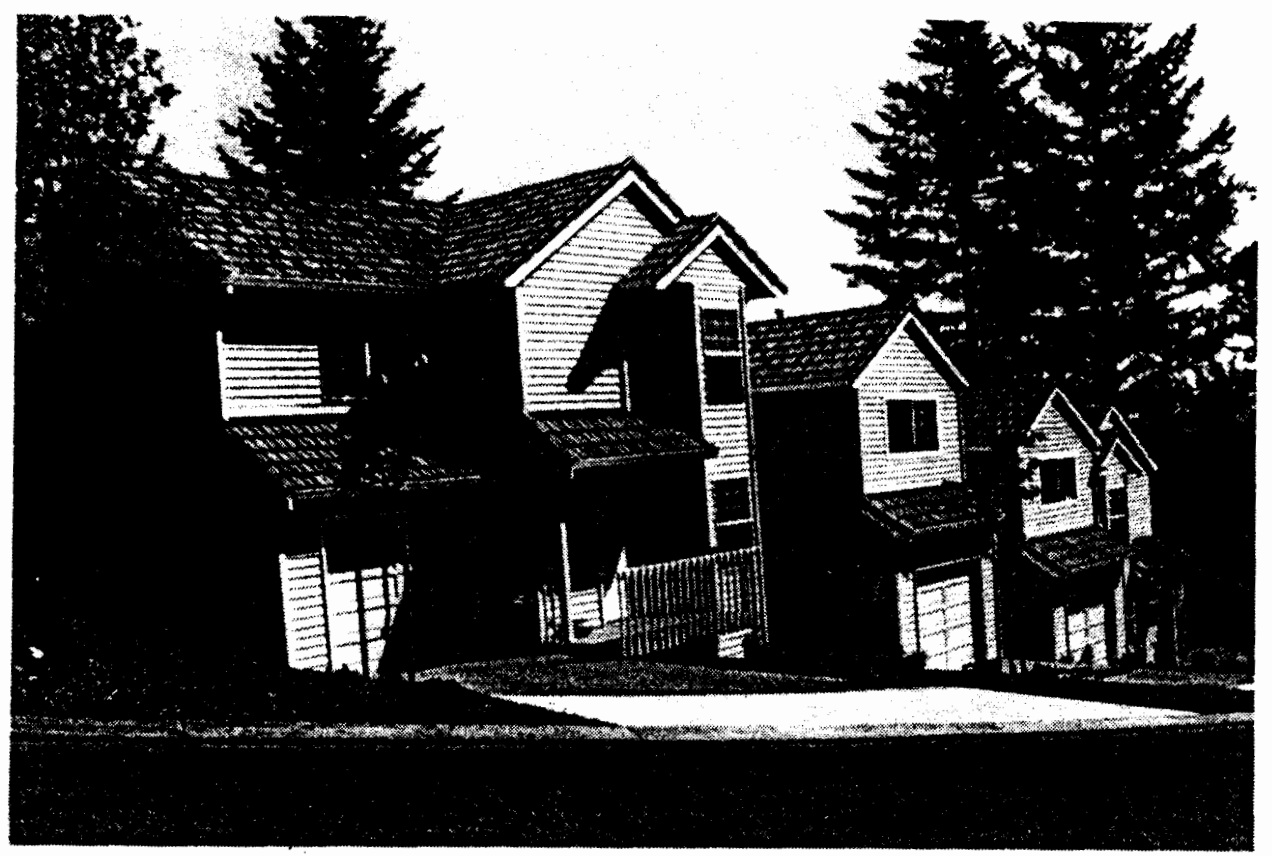

Figure 9. Single-family homes on small lots (average 5,000 sq. ft.) in Lake Oswego, Oregon (Source: 1000 Friends of Oregon, and HBAMP, 1991).

The reduction of average lot sizes kept new housing relatively affordable in the Portland area, especially compared with other U.S. cities (Table I). Still, only 25 percent of regional households could afford a new home on a small lot 
(less than 7,000 square feet) in 1989, and only 2 percent could afford a new home on a lot larger than 9,000 square feet (1000 Friends of Oregon, and HBAMP, 1991). Even in the relatively "affordable" 1989 Portland real estate market, the middle-income suburban ideal was becoming increasingly difficult to realize.

The trend in Portland is likely to be continually higher development densities for middle-income homebuyers, with fewer people able to afford new housing. Portland has been experiencing substantial housing price increases since 1989 due to a strong economy, renewed in-migration into the metro area, and a decrease in the number of homes on the market (1000 Friends of Oregon, and HBAMP, 1991, p. A-31). This decreasing affordability trend will only be exacerbated by the fact that in many areas the Portland urban growth boundary is approaching saturation development levels. 
TABLE I

U.S METROPOLITAN AREA HOUSING COSTS 1990

\begin{tabular}{|c|c|c|c|c|}
\hline $\begin{array}{l}\text { METROPOLITAN } \\
\text { AREA }\end{array}$ & $\begin{array}{r}\text { MEDLAN-PRICED } \\
\text { EXISTING SF } \\
\text { HOME }\end{array}$ & $\begin{array}{l}\text { MORTAGE } \\
\text { RATE \%** }\end{array}$ & $\begin{array}{r}\text { MEDIAN } \\
\text { HOUSEHOLD } \\
\text { INCOME }\end{array}$ & $\begin{array}{l}\text { QUAIIFYING } \\
\text { INCOME** }\end{array}$ \\
\hline Baltimore, MD & $\$ 108,400$ & 10.25 & $\$ 34,198$ & $\$ 37,301$ \\
\hline Boston, MA & 175,900 & 10.28 & 36,914 & 60,678 \\
\hline Chicago, IL & 122,000 & 10.10 & 32,266 & 41,459 \\
\hline Cleveland, OH & 83,900 & 10.22 & 30,748 & 28,798 \\
\hline Dallas, TX & 90,800 & 10.17 & 33,153 & 31,037 \\
\hline Denver, CO & 87,800 & 9.76 & 34,120 & 28,991 \\
\hline Detroit, MI & 77,500 & 10.22 & 33,697 & 26,602 \\
\hline Houston, TX & 72,200 & 10.33 & 34,037 & 25,009 \\
\hline Indianapolis, IN & 75,800 & 10.37 & 30,712 & 26,343 \\
\hline $\begin{array}{l}\text { Kansas City, } \\
\text { MO/KS }\end{array}$ & 75,800 & 10.26 & 30,708 & 26,036 \\
\hline Los Angeles, CA & 211,400 & 9.67 & 28,858 & 69.268 \\
\hline Miami/Hialeah, FL & 91,300 & 10.06 & 26,712 & 30,923 \\
\hline Milwaukee, WI & 85,900 & 10.03 & 32,386 & 29,020 \\
\hline $\begin{array}{l}\text { Minneapolis/ } \\
\text { St. Paul, MN }\end{array}$ & 88,200 & 9.98 & 36,580 & 29,672 \\
\hline $\begin{array}{l}\text { NYCNewark/ } \\
\text { Long Island }\end{array}$ & 176,700 & 9.93 & 26,368 & 59,195 \\
\hline Philadelphia, PA & 118,700 & 9.96 & 31,163 & 39,866 \\
\hline Phoenix, AZ & 85,800 & 10.20 & 30,611 & 29.402 \\
\hline Pittsburgh, PA & 73,100 & 10.28 & 28,244 & 25,217 \\
\hline Portland, OR & 78,000 & 10.25 & 32,422 & 26.837 \\
\hline San Diego, CA & 186,600 & 9.47 & 29,421 & 60,094 \\
\hline $\begin{array}{l}\text { San Francisco Bay } \\
\text { Area, CA }\end{array}$ & 261,600 & 9.42 & 34,192 & 83,882 \\
\hline St. Louis, MO & 82,500 & 9.94 & 32,117 & 27,661 \\
\hline $\begin{array}{l}\text { Washington, } \\
\text { DCMMD/VA }\end{array}$ & 153,200 & 9.98 & 43.763 & 51,540 \\
\hline
\end{tabular}

(Source: Home Sales, National Association of Realtors, 1990). 


\section{CHAPTER IV}

\section{METHODOLOGY: CASE STUDY AREA SELECTION AND RESEARCH TECHNIQUES}

The dramatic economic and population growth of Washington County during the last four decades, makes it a suitable area to study high-density subdivision development trends. The county began attracting residential development on a large scale after World War II, when expansion and upgrading of highway arterials in the county made it easier to commute from Washington County to Portland. The transformation of Washington County from an agricultural to a suburban area was accelerated during this period, as large tracts of farm land were converted to residential communities (Figure 10).

Washington County's proximity to Portland and its abundance of developable land were instrumental in the expansion of its suburban landscape in the post-World War II era. However, it is likely that the true catalyst for the county's phenomenal population growth was the arrival of high-technology industry in the 1950s. The founders of Washington County's first high-tech firm, Portlandbased Tektronix, were attracted to the inexpensive industrial land available in Washington County during the early 1950s. This factor, combined with recognition of the "pleasant housing developments" that had begun to appear since 


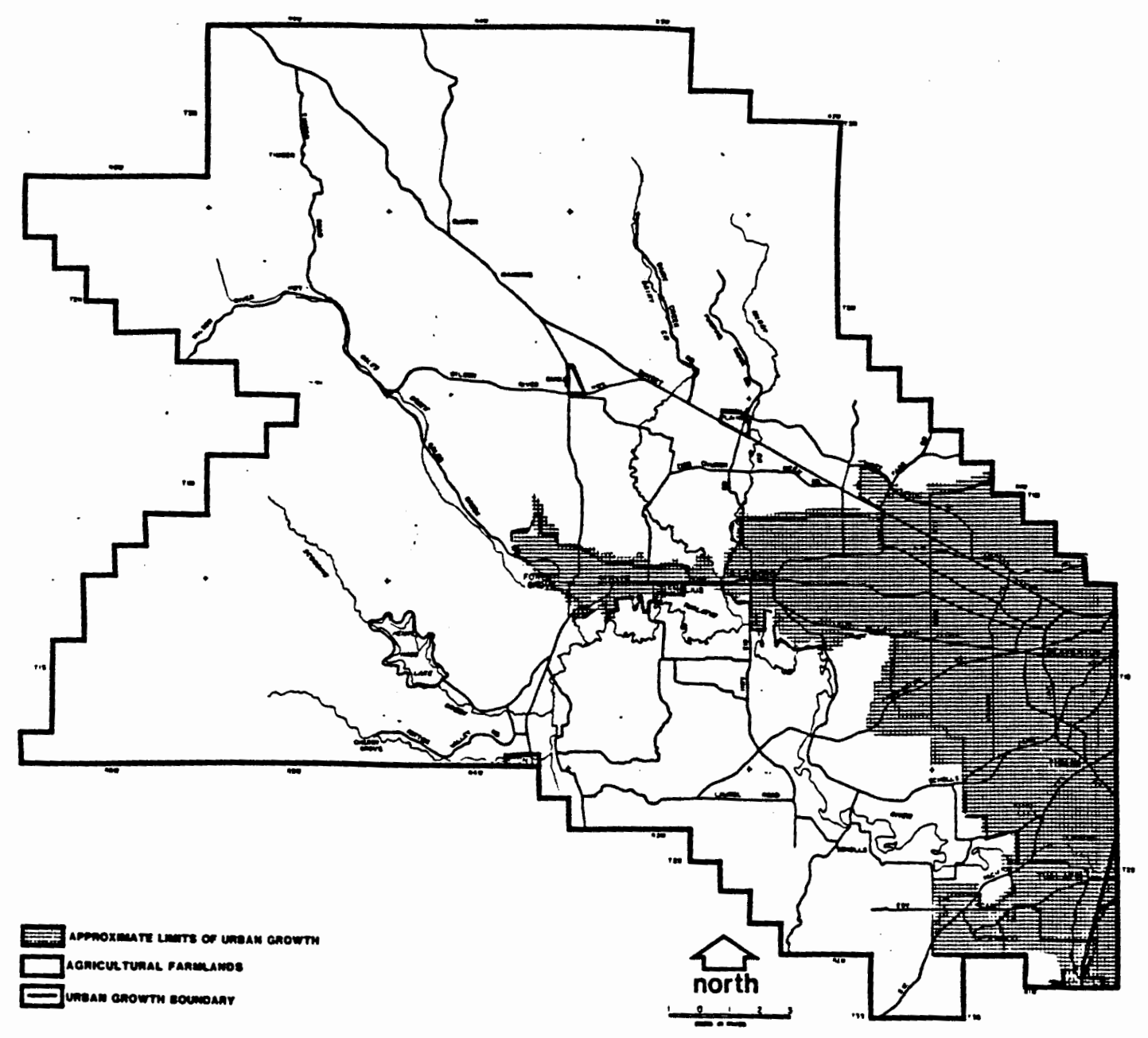

Figure 10. Map of Washington County (Source: Washington County Planning Department, 1981). 
World War II, prompted Tektronix to relocate to Washington County in 1951 (Dodds and Wollner, 1990, p. 34).

The relocation of the Portland-based firm, Electro Scientific Industries (ESI), to Washington County in 1962 , helped strengthen the foundation for the development of high-tech agglomeration economies. By the 1970s, Washington County had attracted the attention of two Silicon Valley high-technology giants, Intel and Hewlett-Packard, both of which opened plants in Washington County in the latter half of that decade. By the 1980s, Washington County had emerged as one of the premier high-technology centers in the country, and its continued economic and population growth (Tables II \& III), helped fuel the rampant expansion of the county's subdivision development.

The population pressures which have arisen from this high-technology economic boom are reflected in the increasing cost of land in the county. This increased demand for land has prompted developers to build subdivisions at increasingly higher densities, a development pattern which parallels other Western high-growth metropolitan areas such as Los Angeles and San Francisco.

The type of growth dynamic which spawned innovative, high-density developments in Los Angeles and the Bay area, is just beginning to surface in the Washington County area. Property values in these California cities are still two to three times as high as Washington County, but the gap appears to be closing quickly. The soft California economy in recent years has fueled a steady stream of 
TABLE II

POPULATION OF METROPOLITAN COUNTIES 1940-1990

$\begin{array}{lrrrrrr}\text { County } & 1990 * * & 1980 * & 1970 * & 1960 * & 1950 * & 1940 * \\ \text { Washington } & 311,554 & 245,808 & 157,920 & 92,937 & 61,269 & 39,194 \\ \text { Multnomah } & 583,887 & 562,640 & 554,668 & 522,813 & 471,517 & 355,099 \\ \text { Clackamas } & 278,850 & 241,919 & 166,088 & 113,038 & 86,716 & 57,130\end{array}$

\section{Growth Rate \&}

$\begin{array}{lrrrrrr}\text { Washington } & 26.7 & 55.7 & 71.2 & 50.5 & 56.3 & 29.4 \\ \text { Multnomah } & 3.8 & 1.4 & 6.1 & 10.9 & 32.7 & 5.0 \\ \text { Clackamas } & 15.3 & 45.7 & 46.9 & 30.4 & 51.8 & 23.6\end{array}$

* Source: 1980 Census of Population: Number of Inhabitants, 1981.

** Source: State and Metropolitan Area Data Book 1991, 1991.

TABLE III

POPULATION OF WASHINGTON COUNTY CITIES 1960-1990

City

$1990 * * 1980 * 1970 * 2960 *$

$\begin{array}{lrrrr}\text { Aloha } & 34,254 & 28,353 & - & - \\ \text { Beaverton } & 48,026 & 30,582 & 18,577 & 5,437 \\ \text { Hillsboro } & 36,136 & 27,664 & 14,675 & 8,232 \\ \text { Sherwood } & 3,093 & 2,386 & 1,396 & 680 \\ \text { Tigard } & 29,212 & 14,286 & 6,499 & - \\ \text { Tualatin } & 13,255 & 7,307 & 750 & 350\end{array}$

* Source: 1980 Census of Population: Number of

Inhabitants, 1981 .

** Source: 1990 census of Pourilation and housing: Summary Population and Housing Characteristics. oregon, 1991. 
in-migration from California to Oregon, and this has accelerated the trend toward rising housing prices in the Portland area. The median price of a new home in the Portland area doubled from the low $\$ 70,000$ range in 1988 , to $\$ 143,000$ in 1993, and some forecasters project prices could double again in the next five years (Potter, 1993).

The increasing demand for land in Washington County is illustrated in a comparison of growth rates and residential density among the three counties in the Portland area. From 1960 to 1990, Washington County's population increased 238 percent, compared to 12 percent for Multnomah County and 147 percent for Clackamas County (Table II). The effects of Washington County's higher growth rate are reflected in the higher-density development patterns of its suburban landscape.

A recent study revealed that the proportion of homes built on small lots (less than 7,000 sq. ft.) in the Portland metropolitan area between 1985 and 1989 was 32 percent (1000 Friends of Oregon, and HBAMP, 1991). While Clackamas County had the lowest small lot average of 29 percent, Washington County far exceeded the region average with 41 percent of its new homes built on small lots during this period (1000 Friends of Oregon, and HBAMP, 1991). The results of this study suggest that Washington County's residential development patterns more closely parallel the development trends found in other high-growth regions of the United States, and thus the county represents the best local case study area for examining high-density development patterns. 


\section{Research Techniques}

The study of the evolution of Washington County's single-family residential development densities was conducted through review of 2235 subdivision developments surveyed from 1870 to $1992 .{ }^{1}$ The subdivision information is available on microfilm sheets at the Washington County Tax Assessment Office in Hillsboro, Oregon. The 2235 subdivisions reviewed represent a large ( 80 percent) sampling of the approximately 2800 total Washington County subdivisions surveyed between 1870 and 1992 . My intent was to collect a sufficiently large sampling to allow for an accurate representation of the proportion of subdivisions built in specific time intervals, as well as the percentage falling in low, medium, and high density categories. Although a smaller sampling would likely have been sufficient for my purposes (preliminary totals after 770 subdivisions were reviewed revealed distribution patterns that did not differ significantly from the final data totals), I collected a larger sampling to enhance accuracy of the data analysis and representation.

Each Washington County sheet contains a plat map of a surveyed subdivision with dimensions of the individual lots. There is a high degree of variability in the amount of detail provided on each sheet, with the newer sheets

${ }^{1}$ Sample pages of the data set are located in the appendix. The complete data set is on file in the Portland State University Geography Department. 
generally providing more usable data. The newer sheets (post-1975) usually list the total acreage of the subdivision and indicate the acreage of the portions not currently being utilized for housing development. By dividing the total number of housing units into the developed acreage, I was able to obtain a "units per acre" (UPA) gross density figure for most of the subdivisions built after 1975. Since one of the central themes of this study is the increase in Washington County highdensity residential development during the 1975-1992 period, I felt the units per acre method would provide the most objective data for evaluating and comparing residential density levels during this period.

Some of the pre-1975 sheets also provide the total acreage of the subdivision, but it was usually necessary to rely on the lot dimension data to compare densities of different subdivisions built prior to 1975 . Since many Washington County subdivisions have some variability in their lot's sizes and configurations, it was necessary to choose a sample lot which best typified the density pattern of the subdivision as a whole. Since corner lots, cul-de-sac lots, and lots on curves are generally atypical of subdivision standard lot sizes (Peiser, 1989, p. 195), I avoided these lots as sample lots. Instead I chose the most uniform, regularly shaped lot which was either the most common lot configuration in the subdivision or which was closest to the median size.

Subdivision lots are normally numbered, beginning with lot number one and ranging up as high as number 400 . Usually the number one lot is a corner lot and unsuitable for use as a sample lot. The number two lot, however, is often a 
rectangular shaped, inside lot which in many instances can be representative of the subdivision as a whole. Whenever possible, I chose the number two lot as the subdivision sample lot. I felt that by choosing the number two lot whenever it met the sample lot requirements, I would be minimizing the amount of subjective selection in my study. Of course, if a subdivision's number two lot was irregularly shaped or in any way out of character with the rest of the subdivision, I would instead choose the next lot which best fulfilled the sample lot criteria.

If a subdivision contained primarily irregularly shaped lots or had too high a degree of variability in its lot size, I indicated "irreg" on my data tables (see sample data table pages in appendix) and excluded it from my density study. In all, less than nine percent of the subdivisions studied fell into the irregular category.

A previous study on residential densities conducted by the 1000 Friends of Oregon and The Home Builders Association of Metropolitan Portland, categorized lot sizes as small; less than 7,000 sq. ft., medium; 7000 to 9000 sq. ft., and large; more than 9,000 sq. $\mathrm{ft}$. These intervals were cited by the study's advisory committee members as being "representative of 'natural breaks' in the single family housing market" (1000 Friends of Oregon, and HBAMP 1991, p. 34). For this research project I used the same intervals to group Washington County subdivisions. However, since the density levels of most of the post-1975 subdivisions were figured in units per acre rather than lot size, I had to establish correlative intervals for these subdivisions. 
In order to establish correlative intervals, it was first necessary to determine what the conversion factor was for converting sample lot size to units per acre. Units per acre density levels divide the total number of units into the total developed acreage. This means that sidewalks, streets, and other public easements are included in the UPA density figures. Sample lot figures, however, reflect only private property and do not include sidewalks and streets.

Consequently, it is not accurate to assume, for example, that a 5,000 square foot sample lot would translate into a units per acre density of 8.7 (using the formula 43,560 sq. ft. per acre, divided by the sample lot size of 5,000 sq. ft., equals 8.7 units per acre). This approach does not make allowances for the land consumed by streets and sidewalks, which can represent as much as $\mathbf{3 0}$ percent of a subdivision's developed land.

In order to obtain an accurate conversion factor it is necessary to employ the following formula (using a sample subdivision with a 6.2 units per acre density and a 5,000 square foot sample lot):

$$
43,560 / 6.2=7026 \text { sq. } \mathrm{ft} \text {. }
$$

7026 sq. ft./ 5000 sq. ft. $=1.4$ conversion factor

The 1.4 conversion factor represents the 2026 sq. ft. difference between the 5,000 sq. ft. net sample lot size and the 7026 sq. ft. gross figure which includes streets and sidewalks. By collecting both units per acre and lot size data from 79 
subdivisions surveyed between 1980 and 1992 , I was able to determine that the average conversion factor for the sampled subdivisions was approximately 1.4 . I then was able to obtain correlative unit per acre densities from pre-1975 subdivision data, by simply multiplying the sample lot sizes of each subdivision by the 1.4 conversion factor and then dividing that figure into 43,560 square feet. This meant that a 6,000 sample square foot lot would translate into 5.2 units per acre density by using the following formula:

$$
\begin{array}{r}
6,000 \times 1.4=8400 \\
43,560 / 8400=5.2
\end{array}
$$

By using this method I was able to establish correlative intervals between units per acre categories and lot size categories. These break down as follows:

small lots/high density: 7000 sq. ft. / >4.5 UPA medium lots/medium density: $7000-8999$ sq. $\mathrm{ft} . / 3.5$ to 4.4 UPA large lots/low density: more than 9000 sq. ft. / <3.5 UPA

Since all the subdivisions with obtainable units per acre figures also displayed lot dimensions, I was able to continuously verify the correlation between these two methods of evaluating subdivision density. With reassuring regularity, subdivisions with small sample lots fell into the corresponding high-density UPA category, medium sample lots into the medium density UPA category, and large 
sample lots into the corresponding low-density UPA category. Occasionally, a subdivision might have a 4.6 UPA (high-density) level, for example, but all or most of its lots would fall within the 7,000-8,999 square feet (medium-density) range. If this occurred I indicated "al-md" (meaning "all lots-medium density") or "ml-md" (meaning "most lots-medium density) in the data tables, and included that subdivision in the middle density category. These instances were rare, however, and less than one percent of the subdivisions studied deviated from their expected UPA categorization.

In recent years, there have been an increasing number of subdivisions built in Washington County which incorporate common areas into the development plan. Usually the individual lots in these types of developments are quite small (3000-4000 sq. ft.), but the addition of common space areas contributes to a lowering of both physical and perceived density levels. Although the amount of common space in these developments is usually minimal in comparison to the total developed area, careful placement can often contribute to the perception of lower density levels than the actual measurable physical density would suggest. This means, for example, that a common-space planned-unit-development with a 5.5 UPA may give the impression of lower density than a conventional subdivision with the same UPA figure.

Although perceived density is an important consideration in subdivision design, it is a highly subjective variable which is difficult to quantify. For that reason I chose to categorize Washington County's subdivisions based strictly on 
their measurable densities. Common-space developments' densities are determined by adding the common area acreage to the individual lot acreage and dividing the total by the number of housing units. Sample individual lot sizes are also included for informational purposes, but do not influence density categorization. Although this approach precludes categorizing common-space and conventional developments together strictly by lot size, it does allow for their categorization based on units-per-acre density levels. The need for a common basis for categorization of all types of subdivisions provided further impetus for using units-per-acre instead of lot size as the primary measure of Washington County subdivision densities. 


\section{CHAPTER V}

\section{WASHINGTON COUNTY SUBDIVISION DENSITY DEVELOPMENT PATTERNS 1870-1992}

Washington County subdivision survey records date back to 1870 , allowing for analysis of over a century of the county's subdivision development patterns. The analysis is divided into two eras, $1870-1944$, which is predominantly a slowgrowth, low-density period, and 1945-1992, which is a period characterized by fast growth and higher density development (Table IV \& Figure 11).

\section{Early Subdivision Development 1870-1944}

Generally, Washington County subdivisions built before World War II were extremely low density, with lot sizes generally ranging from one to ten acres. The relatively high-density streetcar era development patterns which were characteristic of large eastern cities such as New York and Chicago, were not in evidence in Washington County during this period. This was due to the fact that most of Washington County was still too far removed from Portland to be considered a viable commuting suburb for that city. The burgeoning neighborhoods in the more accessible Portland east-side were better situated for commuter access, and during this period these areas experienced high density development patterns which more closely resembled the subdivision growth in Eastern cities. 
TABLE IV

WASHINGTON COUNTY SUBDIVISION DATA 1870-1992

Interval Subdivision Data Totals* Density Category Category Pct.

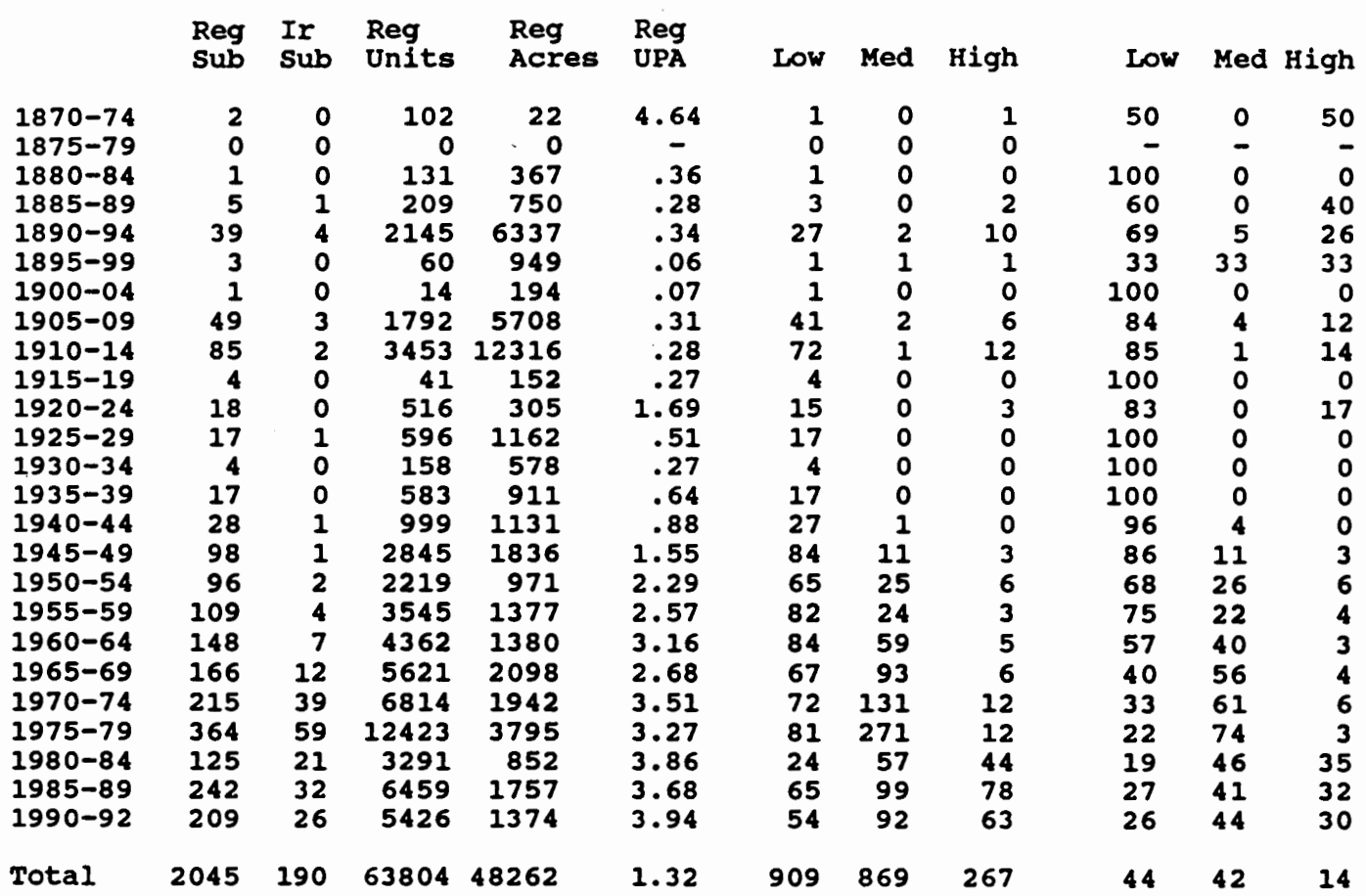

*Key to Subdivision Data Totals Iabels

Reg Sub: Total subdivisions with regularly shaped lots.

Ir Sub: Total subdivisions with irregularly shaped lots.

Reg Units: Total housing units in subdivisions with regularly shaped lots.

Reg Acres: Total acreage in subdivisions with regularly shaped lots.

Reg UPA: Units-per-acre average of subdivisions in regularly shaped lots. 


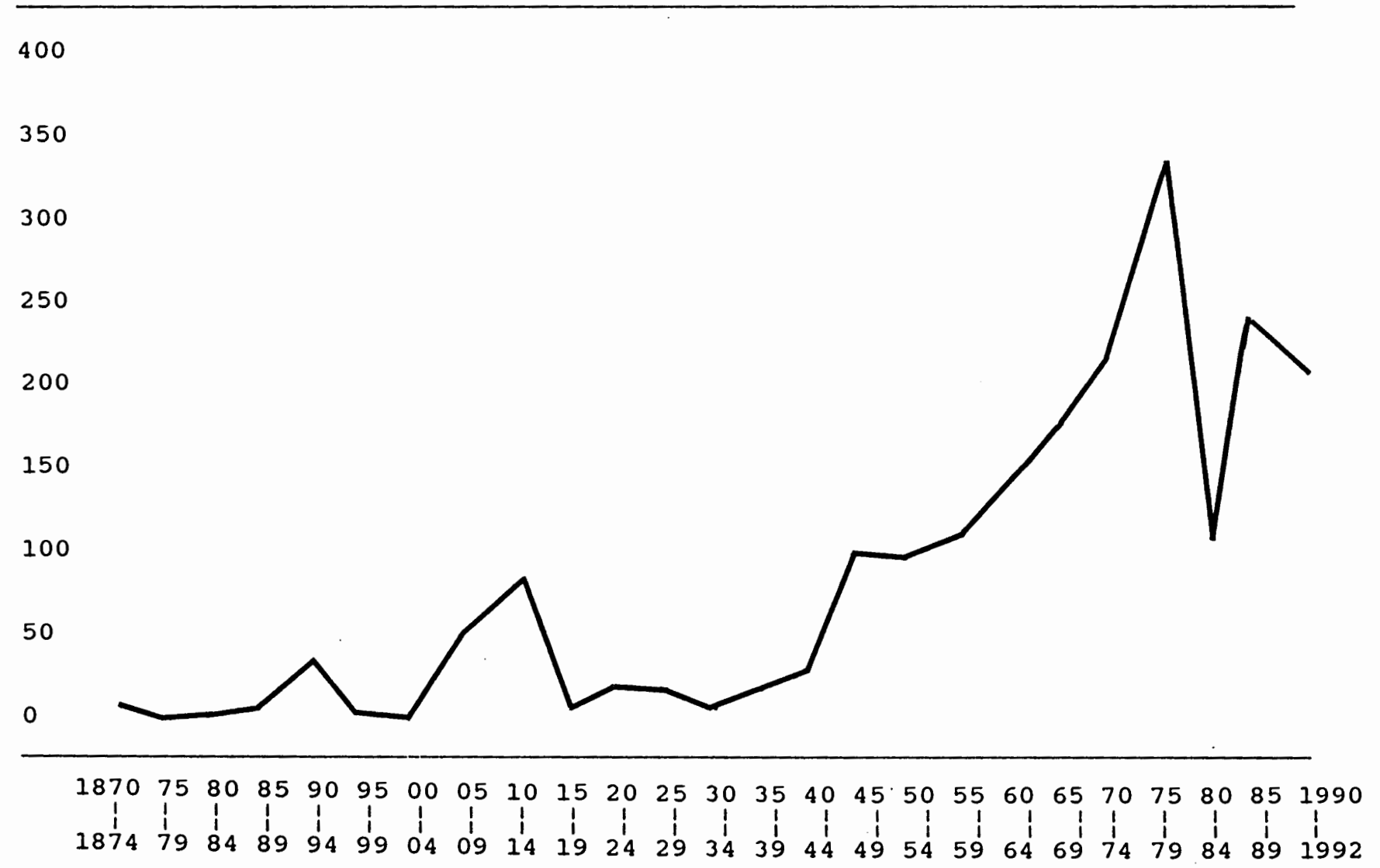

Figure 11. Number of Washington County Subdivisions Built: 1870-1992. 
Although the vast majority of the pre-1945 Washington County subdivisions were extremely low density by 1992 standards (Table IV), there were a few isolated developments in the county which fit the higher density subdivision pattern characteristic of the streetcar suburb era. One of these was Brown's Subdivision, built in Hillsboro in 1892. This subdivision was located on Hazel and 14th Street, contained 38 lots, with average lot dimensions of $50 \times 100$ or 5,000 square feet. The small lot sizes in this development were presumingly a reflection of the higher land costs associated with its close proximity to the downtown core of Hillsboro. Similar high-density developments in Forest Grove (Baber Addition, 1911, 48 lots, avg. 5750 sq. ft.), and Sherwood (City View, 1911, 32 lots, avg. 5000 sq. ft.), were also situated close to their respective city centers. The density and lot configuration of these subdivisions were more typical of the traditional $50 \times 100$ lots found in Portland developments (Dotterer, 1974), and were not representative of the prevailing Washington County suburban development patterns during this period.

The variation in property values between city and county parcels during this era, is illustrated in F. M. Heidel's real estate pamphlet entitled "Oregon Farms Partial List of Washington Co. Farms - For Sale By F.M. Heidel, Hillsboro, Oregon, April 25, 1904." According to Heidel's pamphlet, vacant lots within the city of Hillsboro ranged from $\$ 75$ to $\$ 500$ according to location, and improved city property was priced from $\$ 500$ to $\$ 5000$. Acreage in Hillsboro ranged in price from $\$ 100$ to $\$ 500$ per acre (Heidel, 1904). 
Property located outside of Hillsboro, however, was substantially less expensive. A 74 acre parcel located just one and one-half mile from Hillsboro, and described as "well-suited for subdivision," was priced at \$3300. This translates into $\$ 45$ per acre, which is less than half the cost of the least expensive acreage within the city limits. The importance of close proximity to city centers during this period is revealed in the fact that advertised property values dropped dramatically with increasing distance from Hillsboro. Parcels located five miles from Hillsboro were usually priced at just a fraction of similar-sized parcels within a mile of the city (Heidel, 1904).

Although the price of residential land varied substantially depending on its location, the houses found on suburban properties were usually quite similar to their inner-city counterparts (Mooberry, 1961). The primary difference was that the typical suburban home was set on five to ten acres of land and there was appreciably more space available for gardening, livestock, or other outdoor activities. The houses built in Washington County during this era were usually two stories in height and set on a brick wall or cedar blocks. Ceilings were high and windows were long and narrow with at least one bay window. Most homes had a large adjoining woodshed, and it was not uncommon for residents to have a barn, a chickenyard, and a garden spot on their property (Mooberry, 1961).

The following excerpt from F.M. Heidel's real estate pamphlet is representative of a typical early twentieth century Washington County suburban property: 
"8 acres - Two and one-half miles from Hillsboro, all in cultivation, fine lot of bearing fruit, well-finished 6-room house, beautifully located on a Knoll, surrounded by maple and fir shade trees, Price \$1,400."

The $\$ 1400$ price for this property was relatively affordable for the average wage-earner in the early 1900 s. Washington County farm hands were paid on average $\$ 30$ per month, and could earn the $\$ 1400$ price in approximately four years. The average mechanic earned approximately $\$ 75$ per month (Heidel, 1904), and could earn the price of this property in one and one-half years. For the sake of comparison, the modern equivalent of these occupational incomes would likely range between $\$ 15,000$ and $\$ 40,000$ annually, but would require twice as long (eight and three years respectively), to earn the $\$ 120,000$ price of the average 1994 Washington County property.

Prior to World War II, Washington County subdivision development was characterized by periods of building booms and busts. For example, during the twenty year period $1870-89$, only nine of the sampled subdivisions were built in the county. The following five year period 1890-94, however, saw construction "boom" to a total of 43 subdivisions. This was followed by another ten year "bust" period, 1895-1904, when only four of the sampled subdivisions were developed (Table IV).

In the period 1905-1914, Washington County experienced a surge of development which would remain unsurpassed until after World War II. In this ten year period, 139 of the sampled subdivisions were developed, an amount which far surpassed the total of 55 subdivisions built in the previous 35 year period 1870-1904, and which also easily exceeded the total of 90 subdivisions 
developed in the subsequent 30 year period 1915-44. This high level of development combined with extremely low densities (average lot size during this period exceeded 100,000 square feet), resulted in a rate of land consumption that has never been equaled in Washington County. From 1870 to 1992, the total amount of land converted to subdivisions in the sample was 48,262 acres. Of this total, over 18,000 acres or 37 percent were converted in the $1905-1914$ period. (Table IV).

World War I brought an abrupt halt to the building boom, and during the years 1915-1919 only four of the sampled subdivisions were built in Washington County. In the 1920s there was a slight resurgence of subdivision building, but development was still substantially less than in the 1905-1914 period. This was the beginning of the Fecreational Automobile Era in the United States, and many cities were experiericing an unprecedented expansion of their suburban landscapes. Washington County, however, remained largely unaffected by this trend. It had yet to emerge as a true commuting suburb for the city of Portland, and it would not be until the post-World War II era that it would begin to assume this role.

The Great Depression years of the 1930s contributed to continued stagnation in the building industry in Washington County. During the 1930-1939 period, only 21 of the sampled subdivisions were built. The low-growth, lowdensity development pattern continued through the World War II years of 19401945. The end of the war, however, marked the beginning of Washington County's emergence as an important Portland area suburban center. 
Post-World War II Subdivision Development 1945-1992

The post-war period 1945-1949 brought a dramatic resurgence of subdivision development in Washington County. Ninety-eight of the sampled subdivisions were built during this period, the highest five-year total in the county's history to that point (Table IV). Improvements in existing roads and the creation of new highway systems helped make Washington County increasingly accessible as a commuting suburb. These improvements in transportation networks, combined with high housing demand and attractive FHA and VA financing, helped spur subdivision growth to unprecedented levels (Dotterer, 1974).

In the 1950-1959 period, subdivision construction in Washington County continued at a pace comparable to that experienced in the five years after World War II. In the 1960s, however, subdivision growth rates increased substantially as Washington County began to establish itself as a high-technology center. The sustained high level of demand for land translated into increasing residential densities during this period, with unit per acre levels climbing from 1.3 in the 1940 s, to 2.45 in the 1950 s, and up to 2.87 UPA in the 1960 s (Table V \& Figure 12).

Washington County's emergence as a high-technology center can be traced to the early 1950s, when the Portland-based electronics firm, Tektronix, relocated to Washington County. The firm initially relocated on a four acre parcel at the intersection of Barnes Rd. and Highway 26. Tektronix quickly outgrew this location, however, and by 1957 had relocated on a 313 acre site west of 
TABLE V

WASHINGTON COUNTY SUBDIVISION DENSITY 1870-1992*

$\begin{array}{lrrrrrrrrrrr}\text { Interval } & \begin{array}{r}\text { Tot } \\ \text { Sub }\end{array} & \text { Units } & \text { Acres } & \text { UPA } & \text { Avg Lot } & \begin{array}{l}\text { Low } \\ \text { Den }\end{array} & \begin{array}{l}\text { Med Hi } \\ \text { Den Den }\end{array} & \text { LDz } & \text { MDz } & \text { HDz } \\ 1870-99 & 50 & 2647 & 8424 & .31 & 100,369 & 33 & 3 & 14 & 66 & 6 & 28 \\ 1900-09 & 50 & 1806 & 5902 & .31 & 100,369 & 42 & 2 & 6 & 84 & 4 & 12 \\ 1910-19 & 89 & 3494 & 12468 & .28 & 111,122 & 76 & 1 & 12 & 85 & 1 & 14 \\ 1920-29 & 35 & 1112 & 1467 & .76 & 40,939 & 32 & 0 & 3 & 91 & 0 & 9 \\ 1930-39 & 21 & 741 & 1490 & .50 & 62,229 & 21 & 0 & 0 & 100 & 0 & 0 \\ 1940-49 & 126 & 3844 & 2967 & 1.30 & 23,394 & 111 & 12 & 3 & 88 & 11 & 2 \\ 1950-59 & 205 & 5764 & 2348 & 2.45 & 12,700 & 147 & 49 & 9 & 72 & 24 & 4 \\ 1960-69 & 314 & 9983 & 3478 & 2.87 & 10,841 & 151 & 152 & 11 & 48 & 48 & 4 \\ 1970-79 & 579 & 19237 & 5737 & 3.35 & 9,288 & 153 & 402 & 24 & 26 & 69 & 5 \\ 1980-92 & 576 & 15176 & 3982 & 3.81 & 8,166 & 143248 & 185 & 25 & 43 & 32 \\ & & & & & & & & & & & \\ \text { Total } & 2045 & 63804 & 48262 & 1.32 & 23,571 & 909869 & 267 & 44 & 42 & 14\end{array}$

\section{* Key to Labels}

Tot Sub: Total subdivisions surveyed during interval

Units: Total number of housing lots surveyed during interval

Acres: Total acreage of subdivisions

UPA: Units-per-acre

Avg Lot: Average lot size

Low Den: Number of low-density subdivisions

Med Den: Number of medium-density subdivisions

Hi Den: Number of high-density subdivisions

LDt, MDt, HDt: Percentage of low, medium, and high-density subdivisions 


$$
4.0
$$

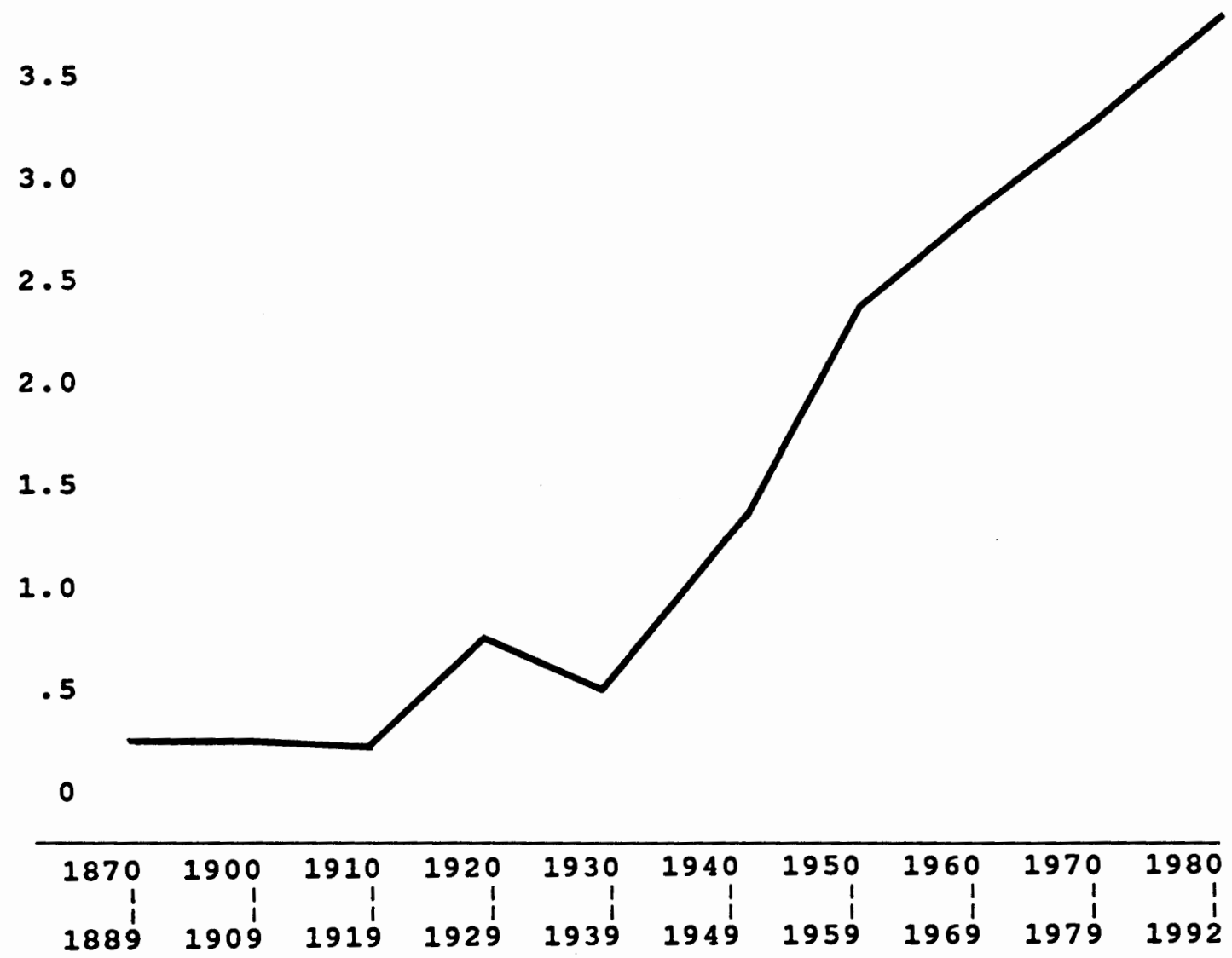

Figure 12. Average Units-Per-Acre of Washington County Subdivisions: 1870-1992. 
Beaverton. Here the firm created a large high-technology industrial "campus" which was to serve as a prototype for future high-technology companies' facilities in Washington County (Dodds and Wollner, 1990, p. 34).

In 1962 the Portland-based electronics firm, ESI, bought 100 acres near the junction of Murray Road and Highway 26. Here the company built the Sunset Science Park, which was designed to attract light manufacturing industries to an environment modeled on a university campus. The park concept was based on the Stanford University Science Park (Dodds and Wollner, 1990, p. 18), which had served as a catalyst to electronic industry growth in Silicon Valley.

The founders of ESI were enamored with the prospect of relocating their science park close to the burgeoning suburban communities in Washington County. They envisioned an idealized work/home spatial arrangement, where employees could live in pleasant surroundings within a short commute to their workplace (Dodds and Wollner, 1990, p. 19).

The ESI Sunset Science Park helped foster an interactive, creative atmosphere conducive to the formation and success of spin-off companies. One such spin-off firm, Floating Point Systems, was so successful in the 1970s that it became one of the largest employers in the county. The success of these spin-off firms, combined with the established presence of firms like Tektronix and ESI, prompted interest from two out-of-state high technology firms, Intel and HewlettPackard. The arrival of these firms in the late 1970s solidified the county's 
reputation as a high-technology center, and contributed to an accelerated level of subdivision growth through the end of the 1970s.

The availability of land, adequate supplies of good water, and a well-trained and hardworking labor force were some of the key features which attracted hightech firms to Washington County. Employers found it was easy to attract and retain employees because of reasonable housing costs, good schools, and the state's recreational opportunities (Dodds and Wollner, 1990, p. 56). These factors contributed to the continued influx of high-technology firms to Washington County, and by 1985 there were over 23,000 people employed in the county's hightechnology industry (Figure 13), (Hamilton, 1987, p.176). The expansion of Washington County's high-tech industry has been a key factor in the county's phenomenal population growth in the last four decades, and has been instrumental in shaping the increasingly high-density nature of the county's suburban landscape.

Subdivision development in Washington County continued to grow dramatically from 1945 through 1979 (Figure 11 \& Table IV). Table IV shows that except for the 1950-1954 period, each successive five year interval experienced higher subdivision totals than the previous interval. These were the extreme high growth years for Washington County, with 1320 of the sampled subdivisions being built during this $1945-1979$ period, a figure which represents 59 percent of the total built between 1870 and 1992. This high level of growth 


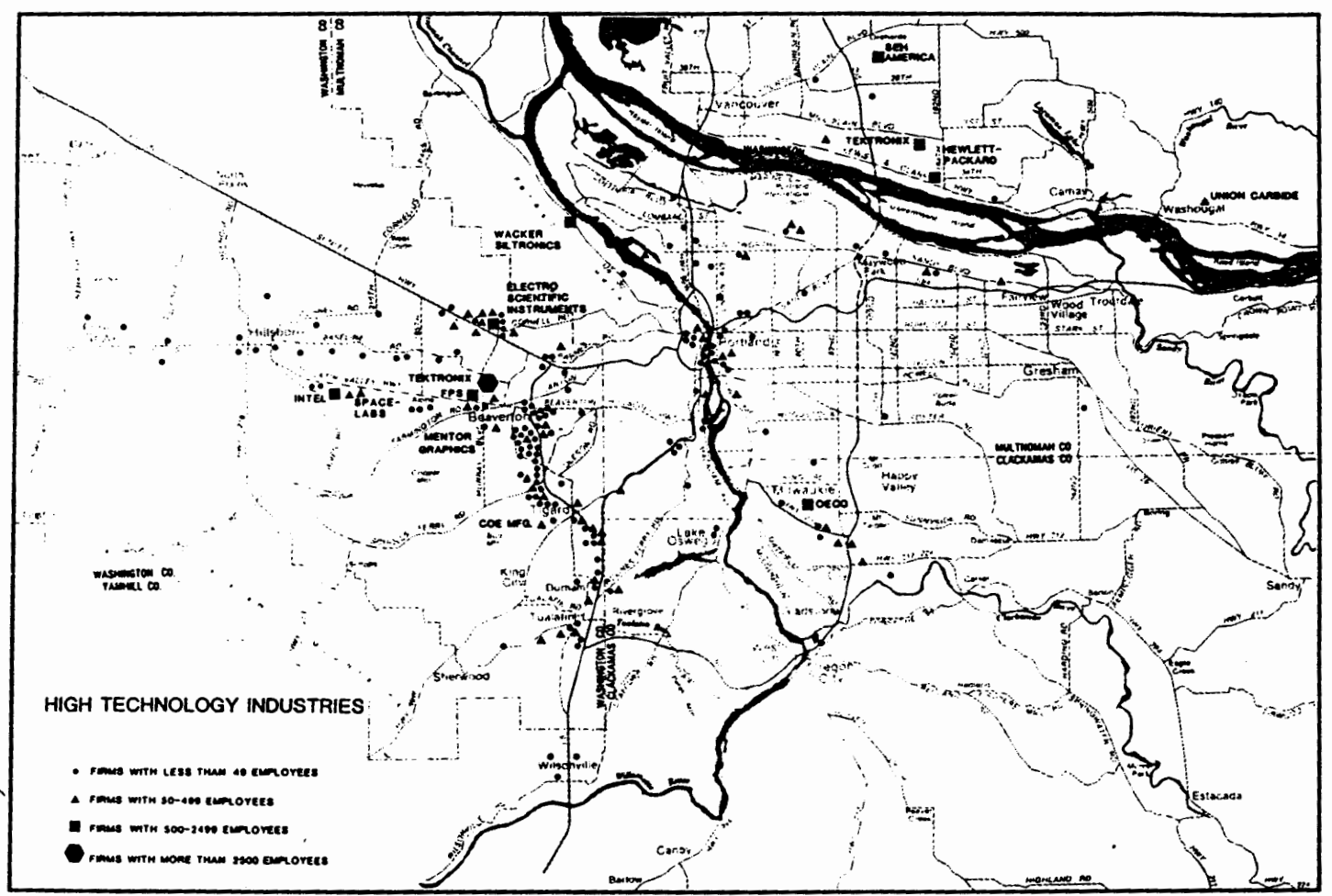

Figure 13. Location of High-Technology Industries in Portland Area (Source: Hamilton, 1987, p.177).

translated into increasingly higher development densities throughout the 1970s, when the average lot size decreased to 9288 square feet and the units per acre increased to 3.35 . This trend continued into the 1980 s and early 1990 s with the average lot size decreasing further to 8166 square feet, and the units per acre rising to 3.81 (Table V \& Figure 12).

The post-World War II era also ushered in the rise of the middle-sized lot (Figure 14). Prior to 1940, only six of the sampled subdivisions were built at middle density levels. The high levels of demand in the post-war era, however, 


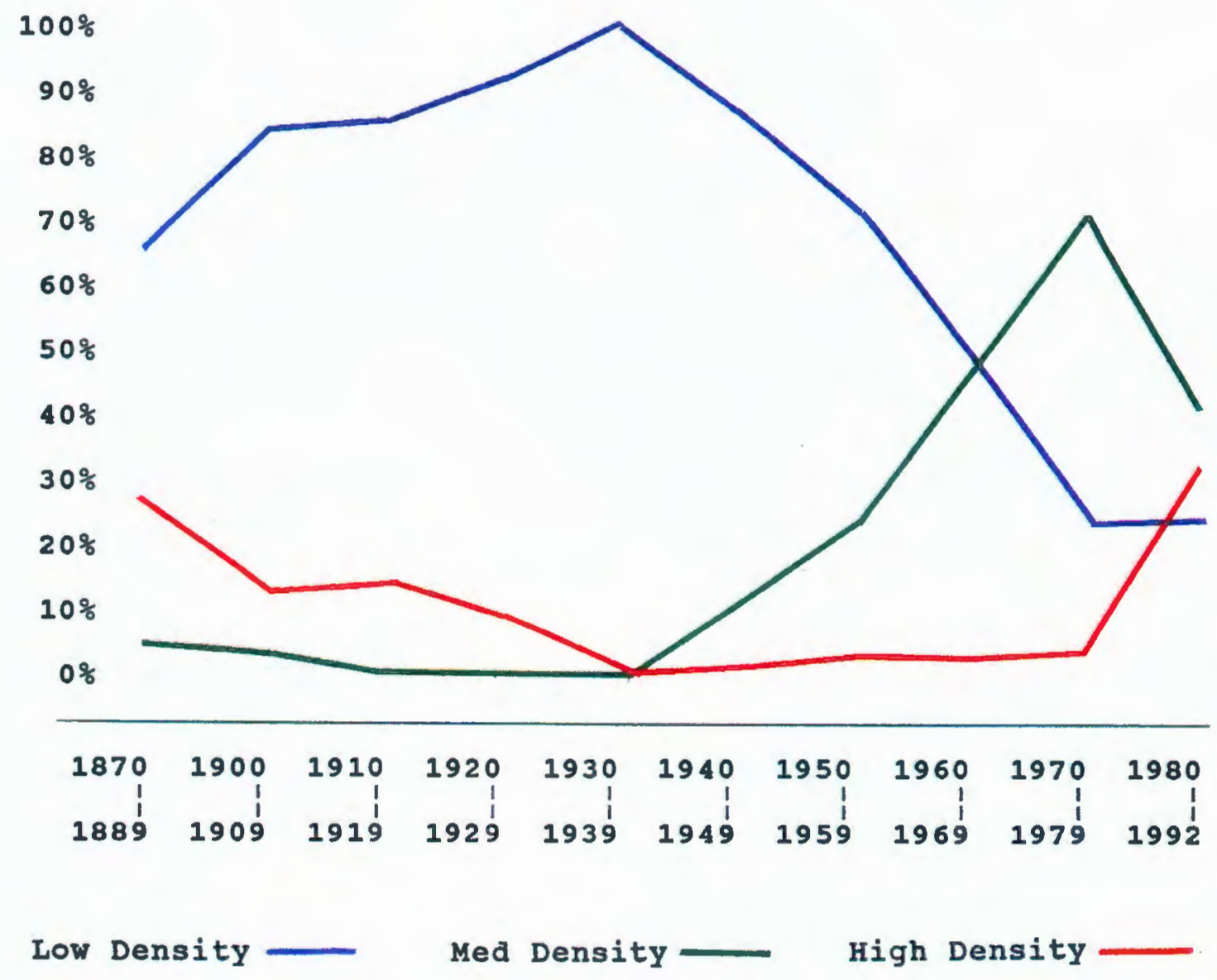

Figure 14. Percentage of Low, Medium, and High Density Subdivisions in Washington County: 1870-1992.

necessitated a scaling down of the average Washington County lot. The rising cost of land dictated that developers build houses on lots ranging from 7,500 to 20,000 square feet, a substantial reduction from the pre-World War II era average of 88,000 square feet. The previous standard one to ten acre lots became increasingly rare, and were generally reserved for only the wealthiest subdivisions. And although most subdivisions built during the late 1940 s remained at extremely 
low densities by 1992 standards, it was during this period that the middle-sized lot first began its inexorable climb to dominance. By the 1975-1979 period, over seventy percent of Washington County's subdivisions were being built at middle density levels.

Although the size of the average Washington County subdivision lot shrunk considerably in the late 1940s and 1950s, they were still quite large by 1992 standards. The typical post-war subdivision consisted of single-level ranch style houses set on large expanses of yard (Figure 15).

One of the largest series of subdivisions built during this era was Cedar Hills in the Beaverton area (Figure 16). From 1946 to 1961 there were several thousand homes built in 26 different Cedar Hill subdivisions. The homes in these subdivisions typified the building styles characteristic of the post-war era. The lots ranged from 8,000 to 10,000 square feet, the ranch-style houses were set well back from the street, and the streetscape was dominated by the houses' front-yard landscape.

For over forty years after World War II, middle-density subdivision developments continued to displace low-density developments as the predominant suburban landscape feature in Washington County. Low density subdivisions which had constituted 85 percent of the pre-World War II total, comprised only 19 percent of the total by the $1980-1984$ period. However, once the Portland area recovered from the economic recession of the early 1980s, large lot subdivisions 
A.

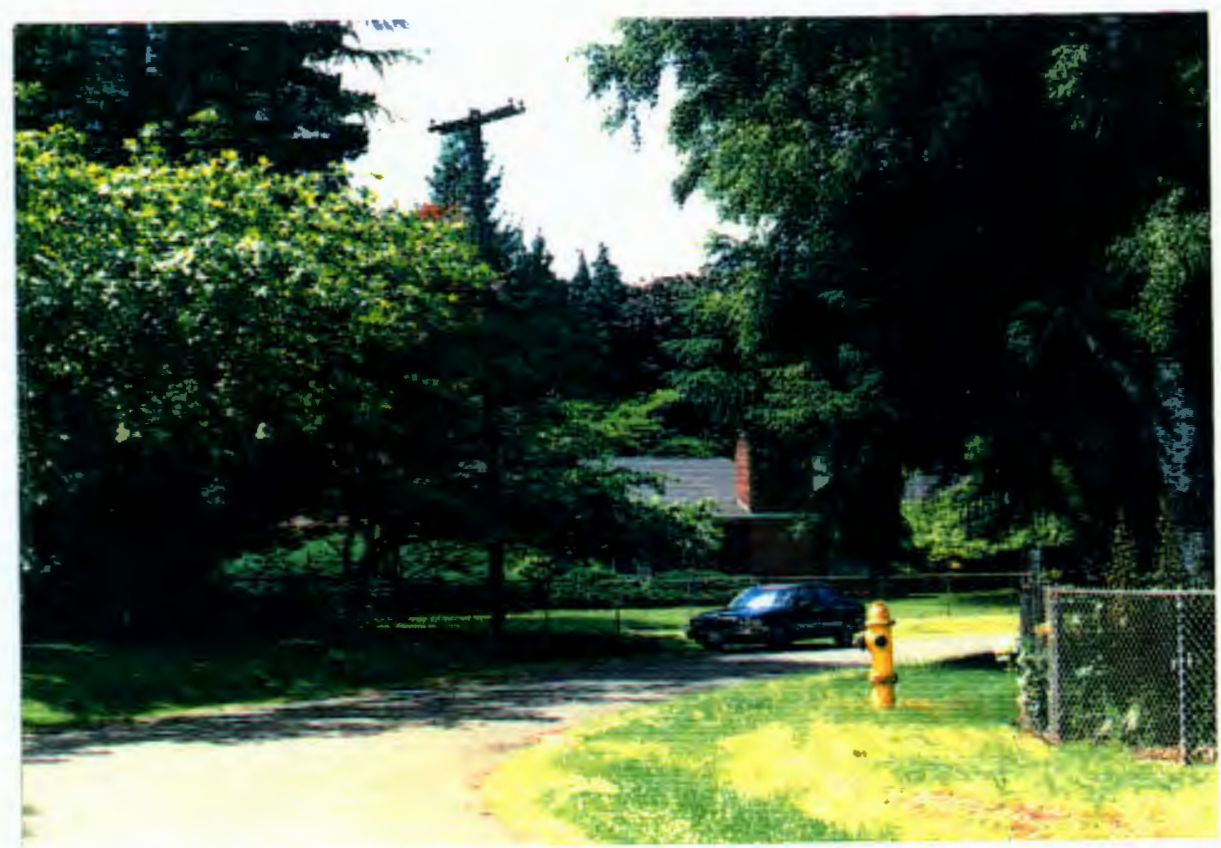

B.

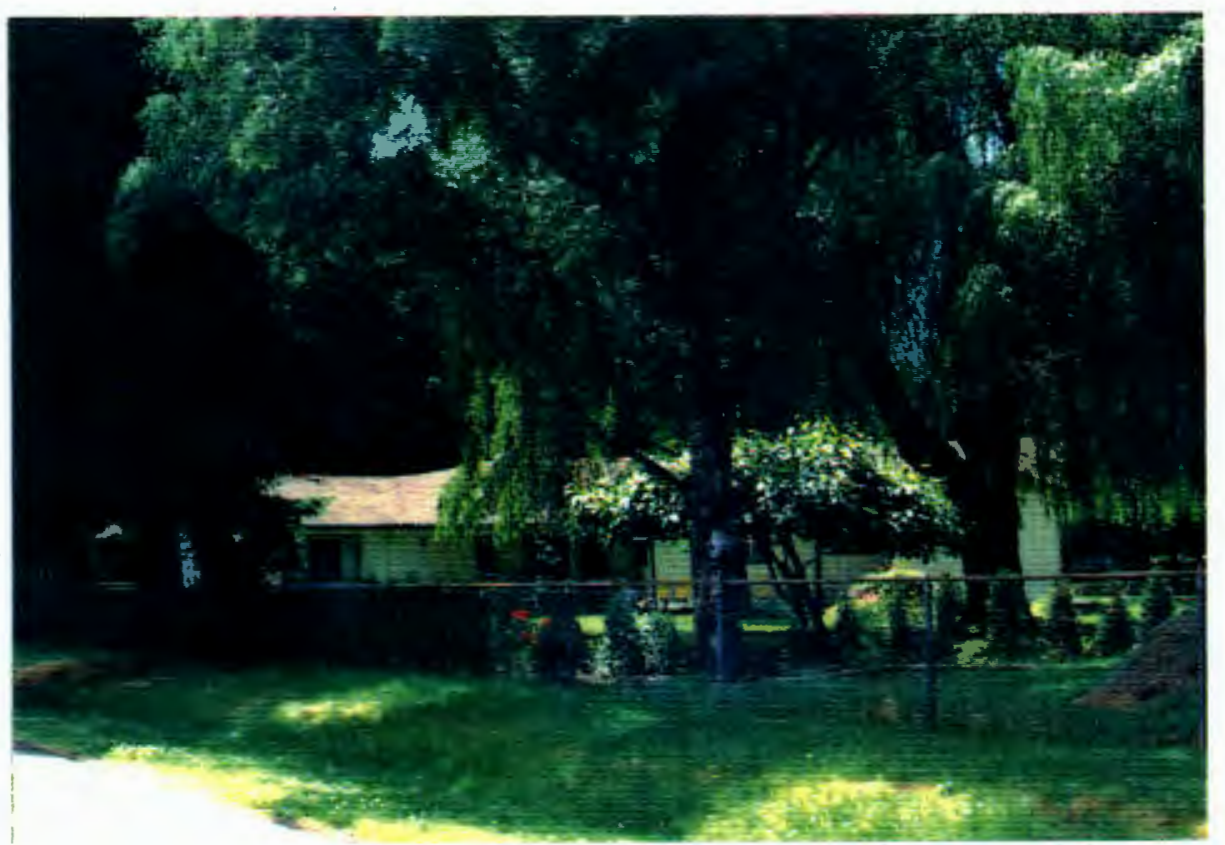

Figure 15. Birchwood Park Subdivision in Hillsboro, surveyed in 1946, 123 units, average lot size $75 \times 120,(9,000$ sq. ft.). 
A.

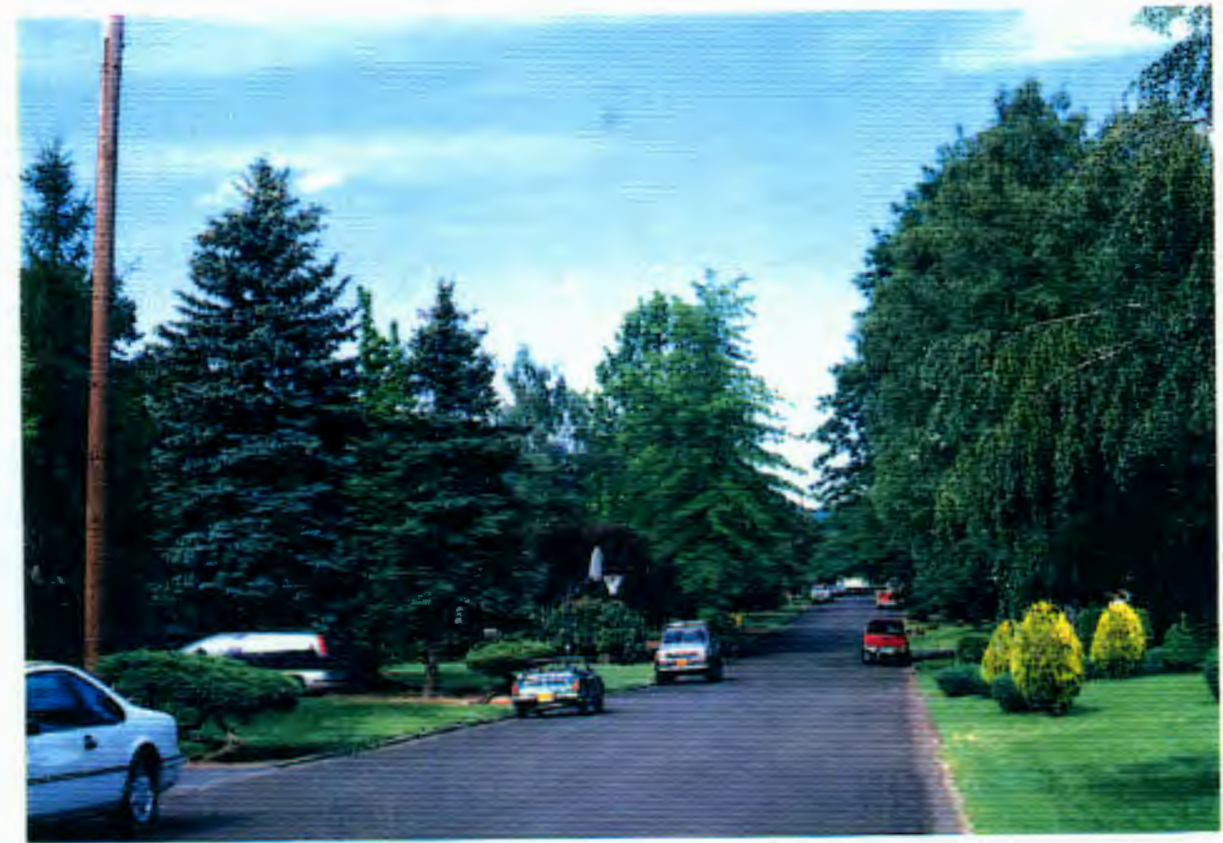

B.

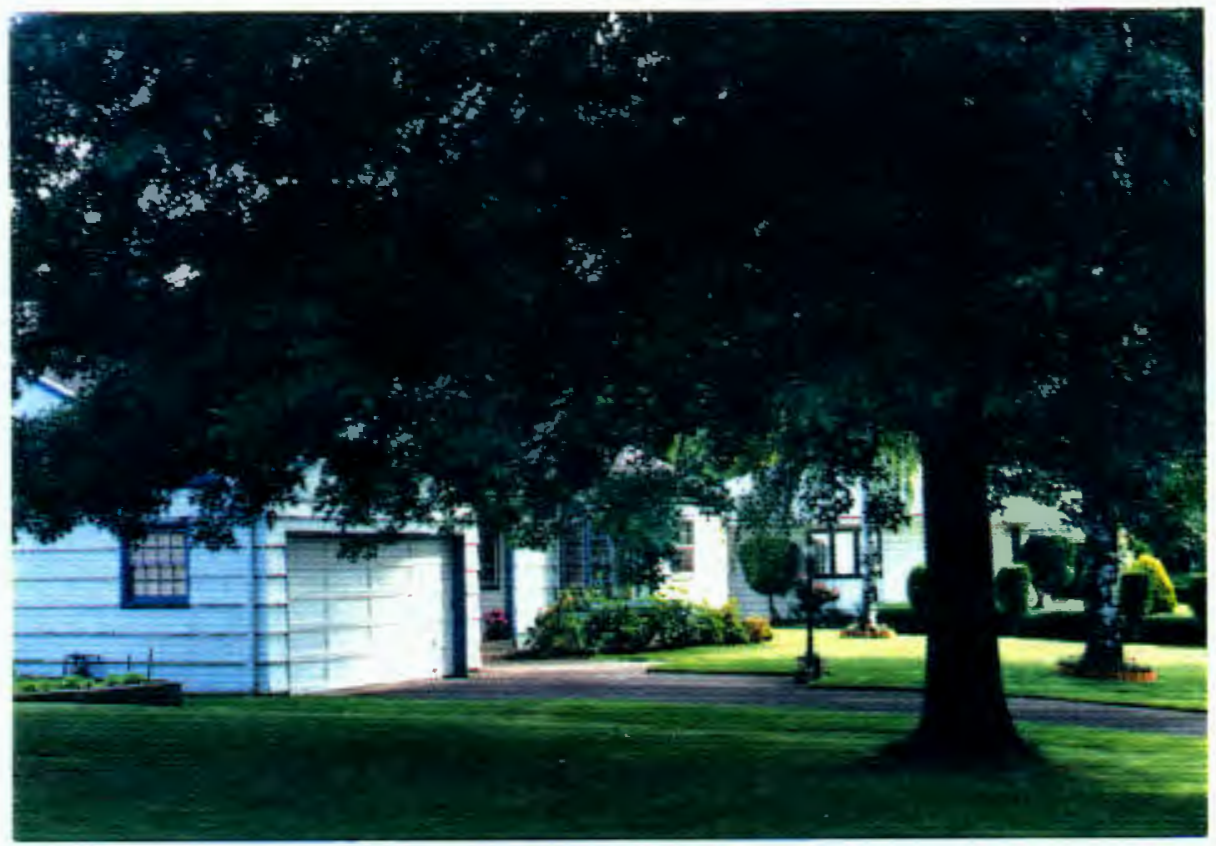

Figure 16. Cedar Hills Subdivision in Beaverton, surveyed in 1946 253 lots, average lot size $80 \times 120$ (9600 sq. ft.). 
began to make a comeback. Low density subdivisions increased to 27 percent in the 1985-1989 period, and maintained a comparable 26 percent in the 1990-1992 period (Figure 14). Generally the size of these low density subdivision lots were substantially smaller than the pre-World War II average lot size, but they were still usually over twice the size found in high density developments. The increase in percentage of these low density subdivisions during the 1985-1992 period is a reflection of the lingering demand for large lots by high-income homebuyers (Figure 17), as well as an indicator of the relative economic health of the Portland metropolitan era.

One of the most conspicuous changes in building patterns in the 1980s and 1990s, is the increase in two-story houses (Figure 18). The substantial decrease in average lot width has made sprawling house designs impractical, and has spelled the demisc of the traditional ranch-style home. In its place has emerged the twostory contemporary, a design which maximizes house square footage while consuming a minimum amount of yard space. The success of this housing style suggests that while consumers seem willing to accept diminished yard space, they are unwilling to accept reductions in the size of their homes.

Except for a few brief flurries of development in the late nineteenth century, high density subdivisions were not built in large numbers until the 1980s (Table V). This was the decade in which the urban growth boundary (UGB) was implemented in the Portland metropolitan area. The UGB confined development to infill areas between the already urbanized sections of the metropolitan region. 
A.

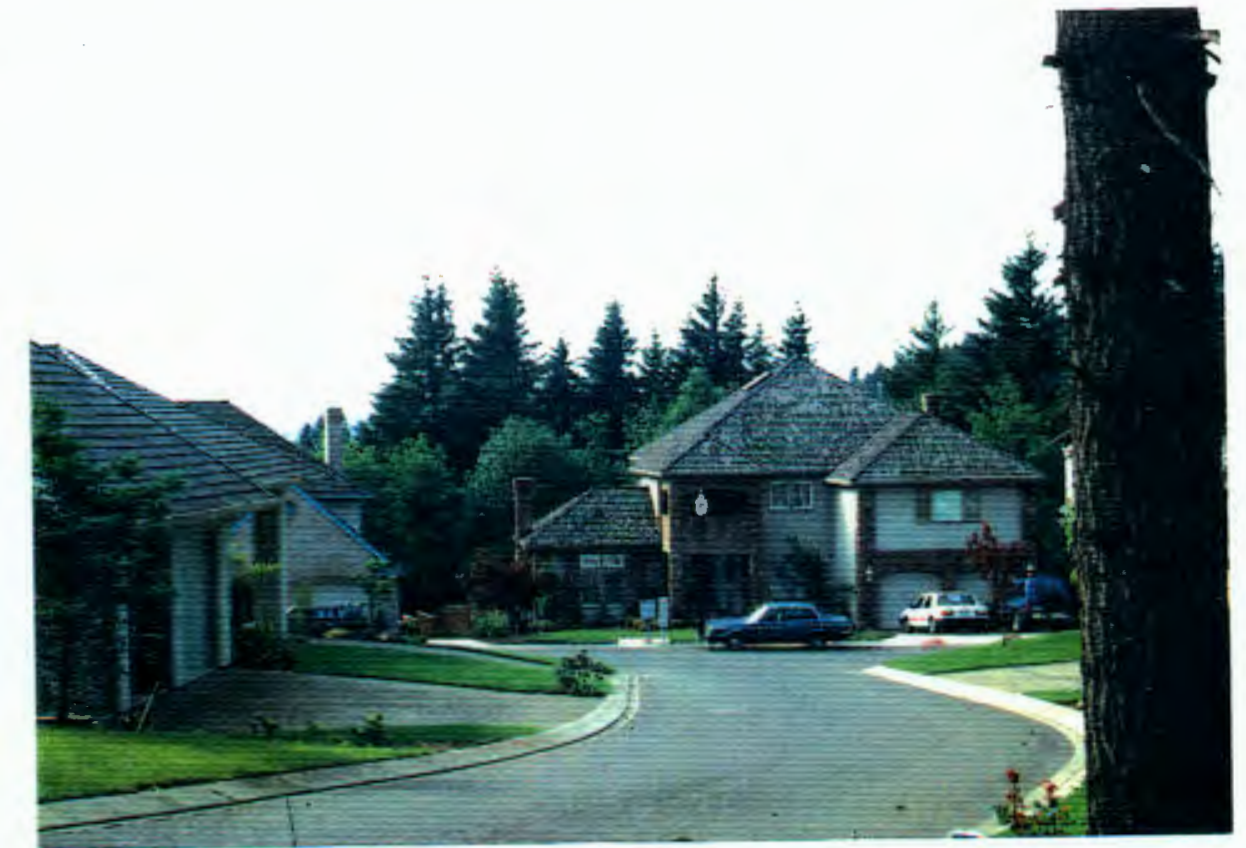

B.

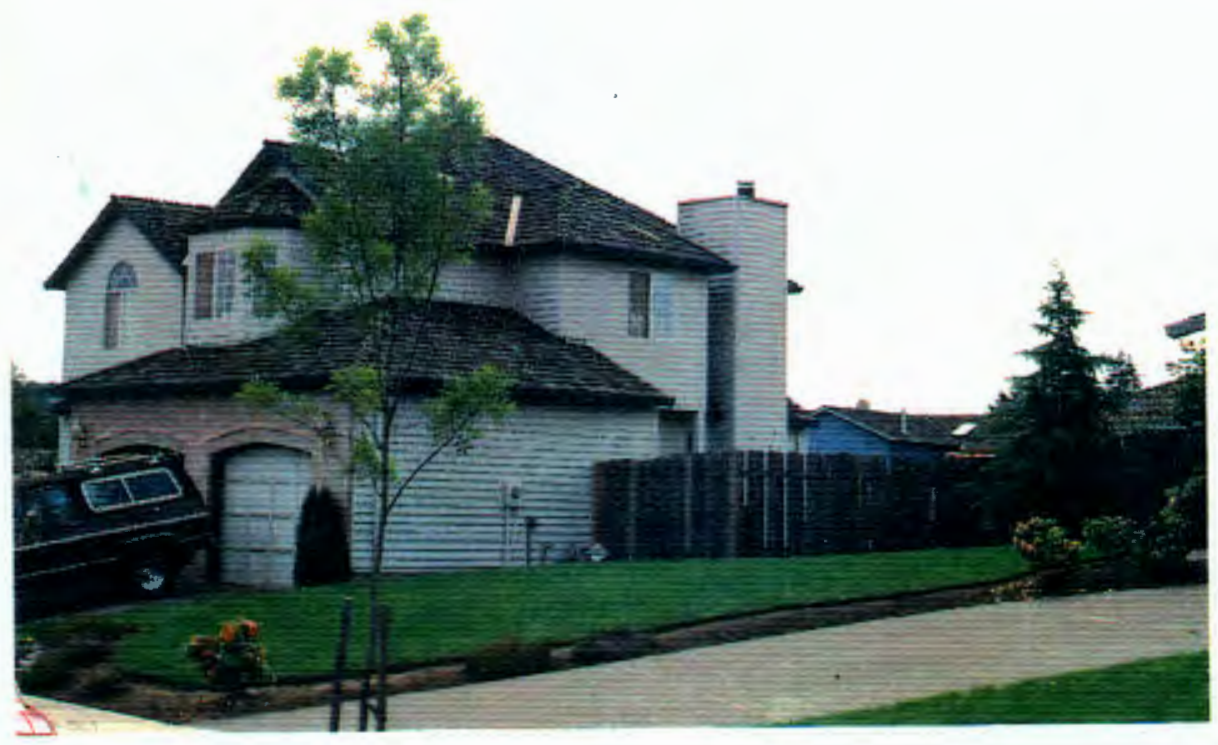

Figure 17. Catlin Crest 2 Subdivision. Near intersection of Miller Rd. and Barnes Rd. Surveyed in 1988, 85 lots, UPA Density: 1.9: average lot size: 15,000 sq. ft. Example of contemporary high-income housing on large lots. 
A.

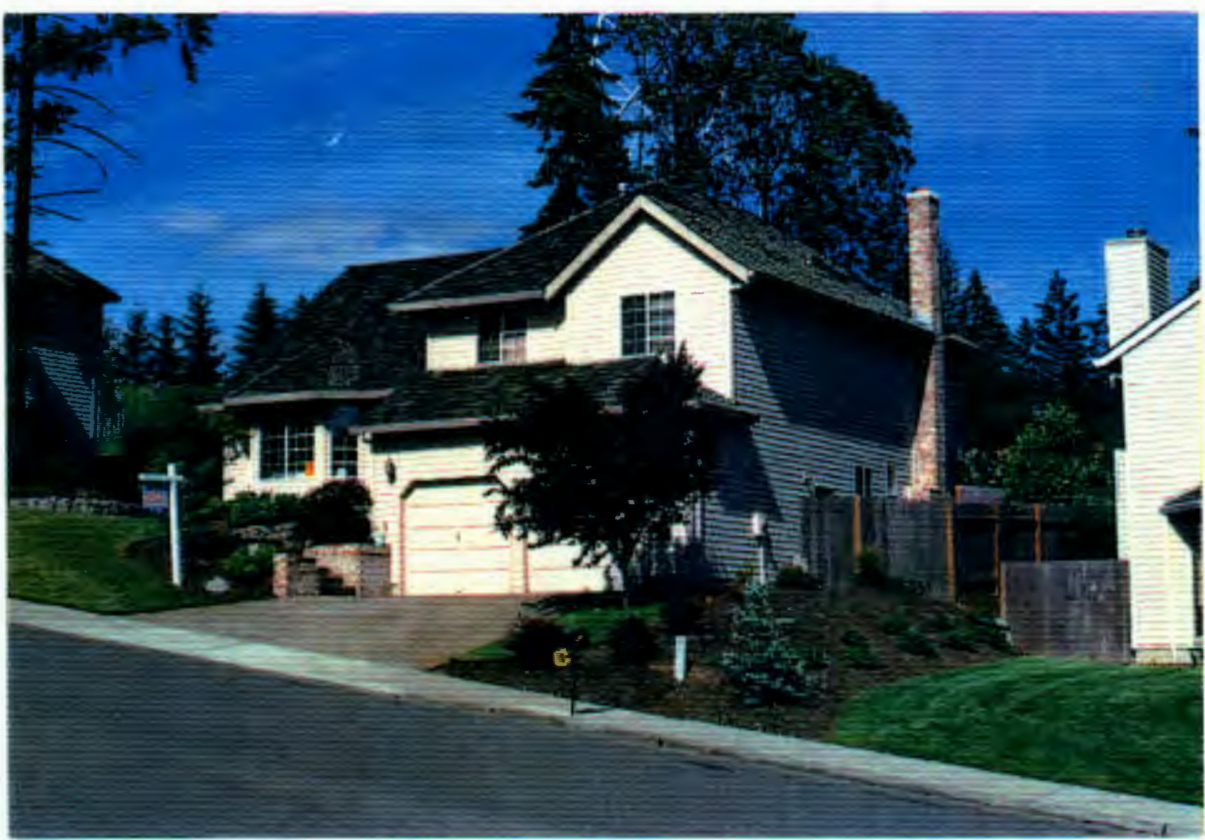

B.

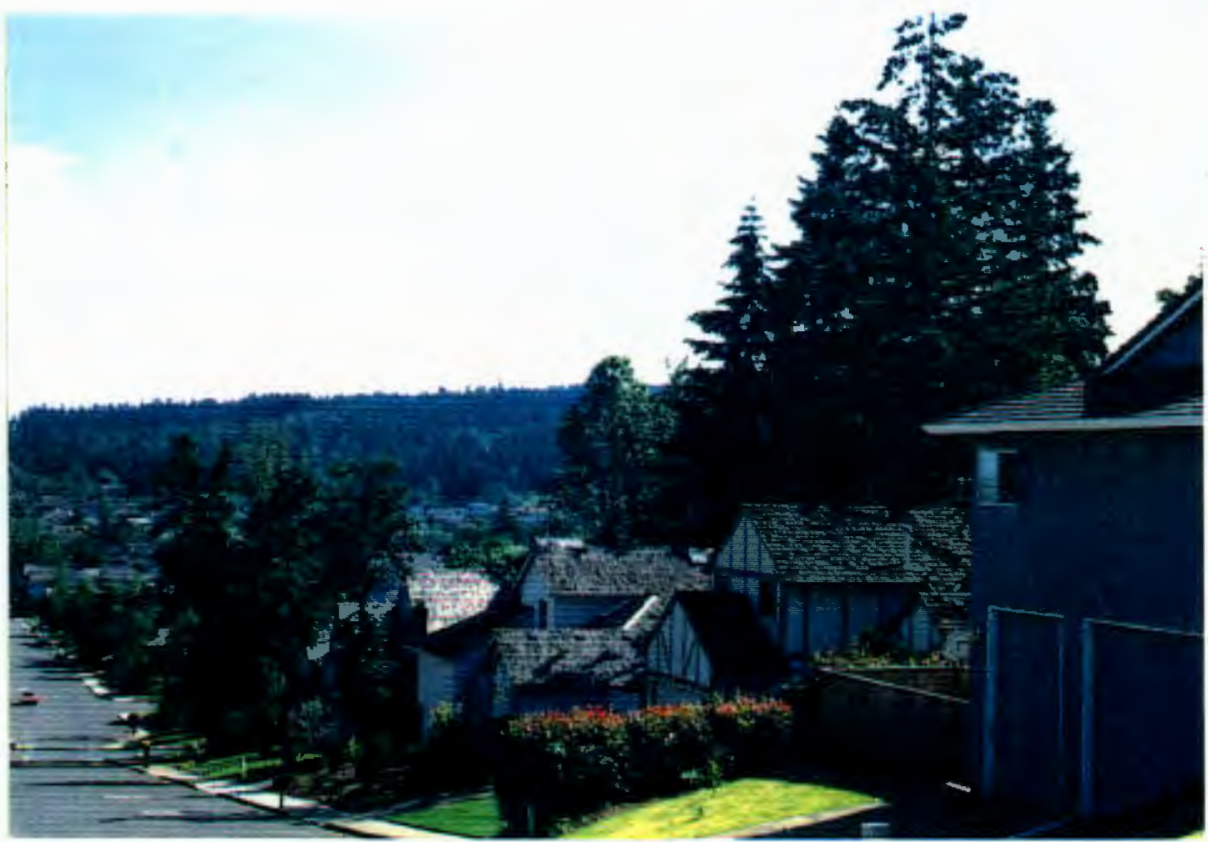

Figure 18. Burntwood 2 Subdivision, west of Beaverton. Surveyed in 1983, 35 lots, UPA Density: 4.0: Average lot size: 7500 sq. ft. Example of contemporary housing set on medium-sized lots. 
By restricting the amount of developable land, the UGB assured that land prices would rise and that developers would be induced to build at increasingly higher densities. In Washington County, where population pressures were already driving up the price of land, the UGB created a powerful additional impetus to the development of high-density subdivisions.

The implementation of the UGB in the early 1980 s was accompanied by a relaxing of minimum-lot-size zoning laws in Washington County. According to Washington County Associate Planner, Robert Cone, the zoned minimum lot size in the county was 7,000 square feet throughout the 1960 s and 1970s. In 1981, however, a new code was adopted which allowed single-family residential development on lots as small as 5,000 square feet (Cone, 1994). This opened the door for high-density developers, and marked the beginning of high-density subdivisions' emergence as a defining force in the county's suburban landscape. The rise in percentage of high density subdivisions since 1980 has indeed been phenomenal. Prior to 1980 , less than six percent of all subdivisions fell into the high density category. From 1980 to 1992, however, 32 percent of all subdivisions built in Washington County were high density, second only to middledensity developments in total numbers (Table V). 


\section{CHAPTER VI}

\section{WASHINGTON COUNTY HIGH-DENSITY RESIDENTIAL DEVELOPMENT}

Large-scale high density residential development is a relatively recent phenomenon in Washington County. Nearly 70 percent of Washington County's high density subdivisions have been built since 1980 , and nearly 50 percent have been built since 1985 . Population pressures, land scarcity, and the relaxing of zoning regulations have all contributed to a dramatic increase in the county's highdensity development in recent years.

\section{Spatial Distribution of High-Density Subdivisions}

Much of Washington County's high-density development encircles the western perimeter of the city of Beaverton and the southern perimeter of the city of Tigard (Figure 19). Beaverton is surrounded by clusters which extend southward from the area north of Highway 26 to the area west of Tigard. The city of Tigard is flanked by a concentration of high-density clusters in the area located between Tigard and Tualatin.

High-density development in the areas surrounding Beaverton and Tigard, has been spurred by a high level of demand and a diminishing level of supply of developable land. According to Washington County Associate Planner, Robert Cone, the Tigard and Beaverton areas will be among the first in Washington 


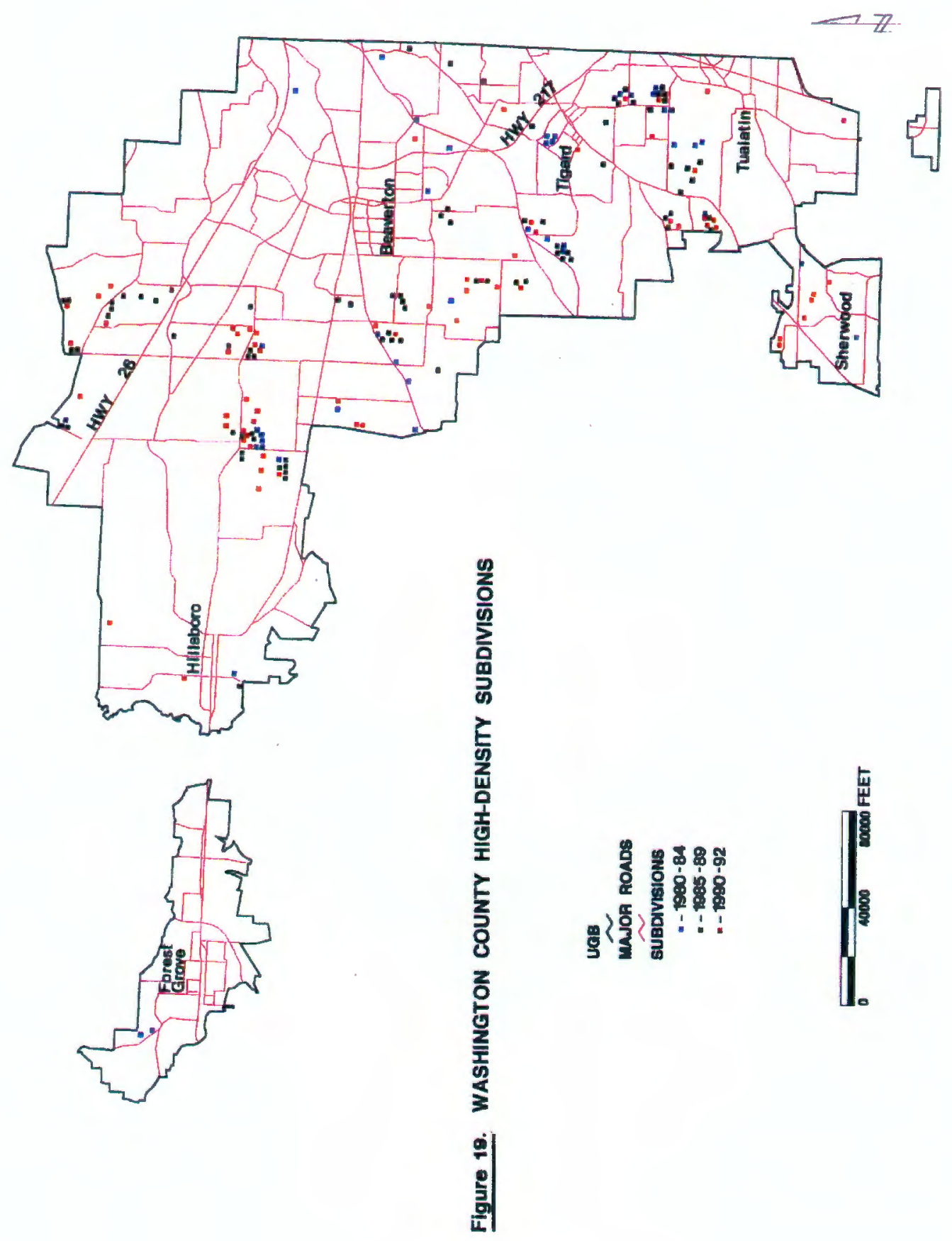


County to use up their remaining developable land. Current demand is so high that land zoned for apartments is being developed for single-family housing in these areas (Cone, 1994). Lot sizes in these apartment-zoned developments sometimes average as small as 4,000 square feet, or approximately one-third the size of the typical 1950's subdivision lot.

An analysis of areas which lack high-density subdivisions can often provide insight on what factors discourage high-density development in one area, and encourage it in another. There are several areas in Washington County which have conspicuously few high-density residential developments. These include Hillsboro, Forest Grove, and the area north of Beaverton (Figure 18).

The Hillsboro area has only two percent of the county's high-density subdivisions. This, despite the fact that Hillsboro has experienced a 146 percent growth rate in the last twenty years, and was the chosen site for the hightechnology giant, Intel, in the late 1970s.

Hillsboro's lack of high-density development can be attributed to two major factors. The first is that the Hillsboro area has far more undeveloped vacant land available than other cities in Washington County. According to Robert Cone, the abundance of land in the East Hillsboro Community has encouraged development of high-end, large-lot subdivisions in that area (Cone, 1994). The Hillsboro area has yet to experience the type of land scarcity which drove up land costs and encouraged high-density development in other parts of Washington County. 
Hillsboro's distance from Portland is the second major factor which has contributed to lower land costs and discouraged high-density development. Hillsboro is located twenty-five miles from downtown Portland, and the city is not directly served by a major freeway. Most Hillsboro residents have a minimum of a forty-five minute commute to downtown Portland, a time-cost premium which many people are unwilling to pay.

Forest Grove's lack of high-density development is also likely attributable to its distance ( 35 miles) from Portland's central business district. However, if land costs continue to escalate in areas closer in, the Forest Grove and Hillsboro areas could become increasingly attractive to people seeking more affordable housing. Like their counterparts in Los Angeles and the Bay area, commuters in Washington County may eventually accept a two hour round trip commute as an acceptable cost for entering the housing market. This would translate into an increasing demand for land in the Hillsboro and Forest Grove areas, and would likely prompt development of higher-density subdivisions.

Another area with a notable lack of high density development is the area located north of Beaverton. Much of the area immediately north of the city of Beaverton was developed prior to 1980 , and is characterized by middle-income low-density developments such as Cedar Hills. The Cedar Hills subdivisions, built in the 1950s and 1960s, are comprised of over 2000 homes and make up a sizable portion of the area located north of the Beaverton business district and south of Highway 26. 
The area north of Sunset Highway has been the site of more recent development which has consisted primarily of high-end types of housing subdivisions. This is an area of rolling hills which offer good view site opportunities for developers. The Bethany Community typifies the development pattern found in this area. According to Robert Cone, the Bethany Community is currently being developed almost exclusively low-density, with large, expensive houses built on large, expensive lots being the normal development pattern (Cone, 1994). The view site opportunities and the already established presence of exclusive housing developments, suggests that the low-density development pattern will likely continue to predominate in this area.

\section{Types of High-Density Subdivisions}

Although there is a general similarity in the lot size and configuration of Washington County high-density subdivisions, there is a great deal of variation in appearance of the individual developments. Generally, the lot-sizes range from 4,000 to 6,000 square feet, with typical configurations of 50 to 60 feet wide by 90 to 100 feet deep. Unlike the more forgiving medium and large lots, small lots require more careful consideration for placement of homes, landscaping, and utilities (Figure 20). While some high-density subdivisions reflect an apparent disregard for design considerations, others manage to impart a sense of integration with the natural environment. The developers of these integrated subdivisions usually incorporate some of the original foliage into each lot in the development, 
Typical Low Density Lot $(85 \times 130 \mathrm{ft}$.

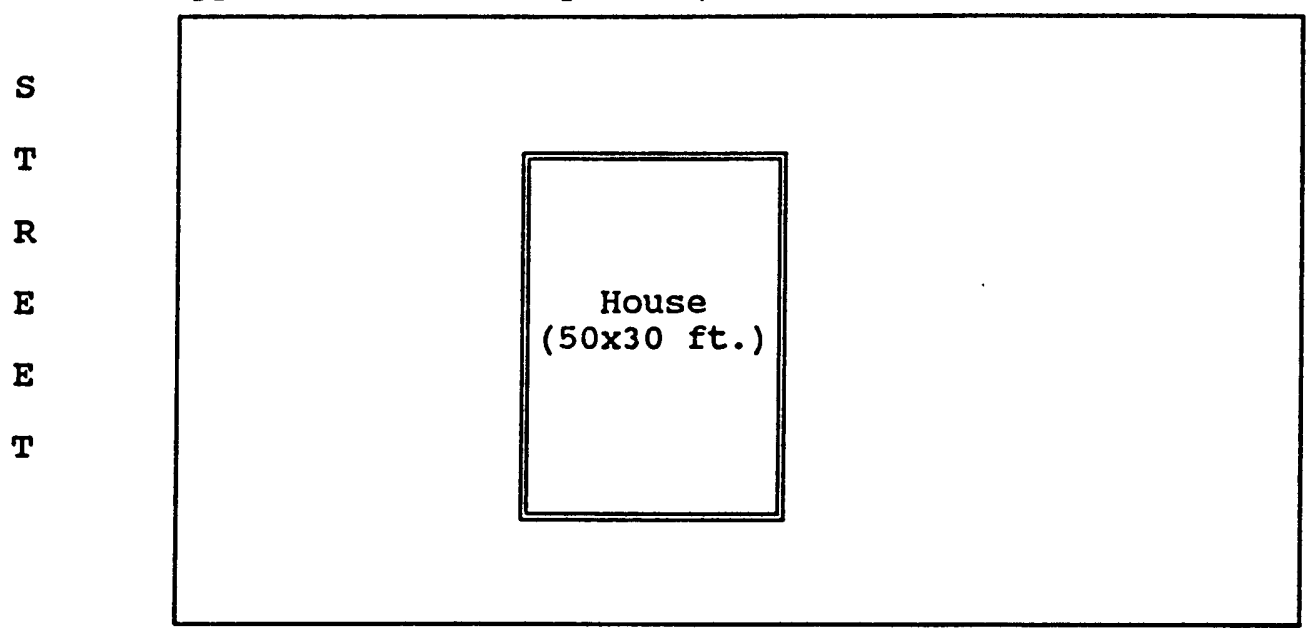

Typical Medium Density Lot $(75 \times 100 \mathrm{ft}$.

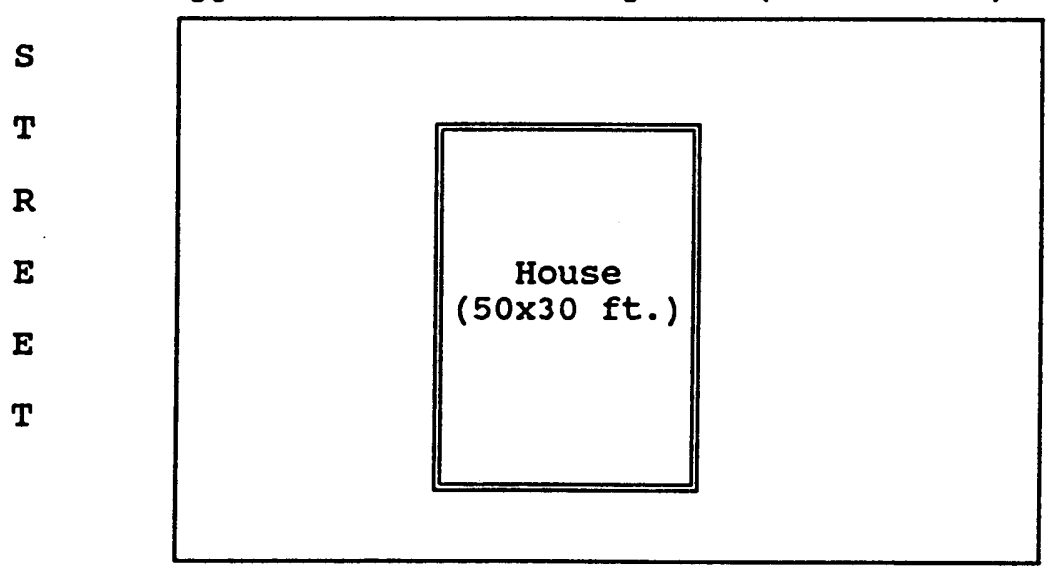

Typical High Density Lot (60x90 ft.)

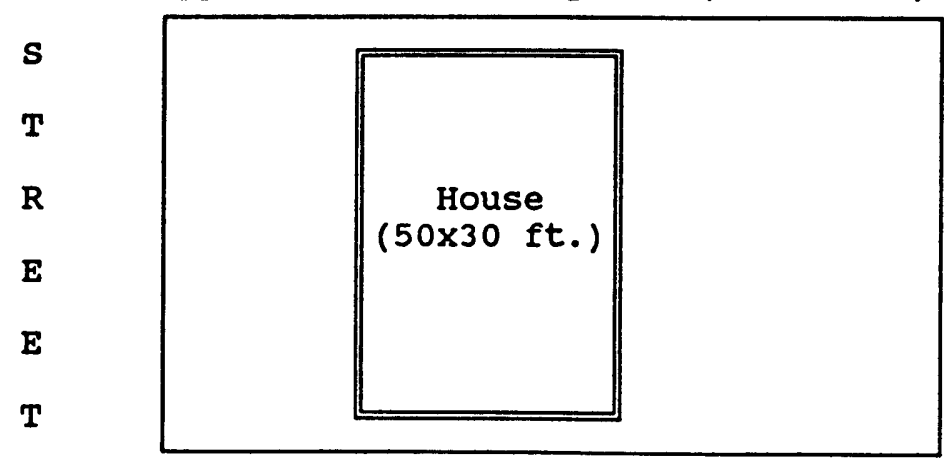

Figure 20. Lot-Size Comparison. 
and in subdivisions such as Summerlake, create large open common spaces for the residents.

The Summerlake development represents an example of high-density subdivisions which are effective in retaining the "garden setting" aspect of the traditional suburban ideal. Located at the center of the Summerlake developments is Summerlake Park, a common space surrounded by high-density residential single-family housing. The park offers a lake, green spaces, a walking trail, and a large playground area (Figure 21), all within walking distance for Summerlake residents. The open nature of the park creates a sense of it being a natural part of the developments' landscape, rather than a private enclave. The overall impression is of heightened livability and a successful integration of housing with the natural environment.

Unfortunately, not all developable land has the natural advantages present in the Summerlake area. Some subdivisions are built on former pastureland which has already been cleared of natural vegetation. In these areas, there are no trees or other foliage to help create a more private and integrated appearance. Residents in developments built on pastureland have to rely on their own landscaping to create privacy and a more natural setting. Often this can take many years to have much effect, and in the meantime many high-density subdivisions look more like apartment complexes or row house than embodiments of the suburban ideal. 
A.

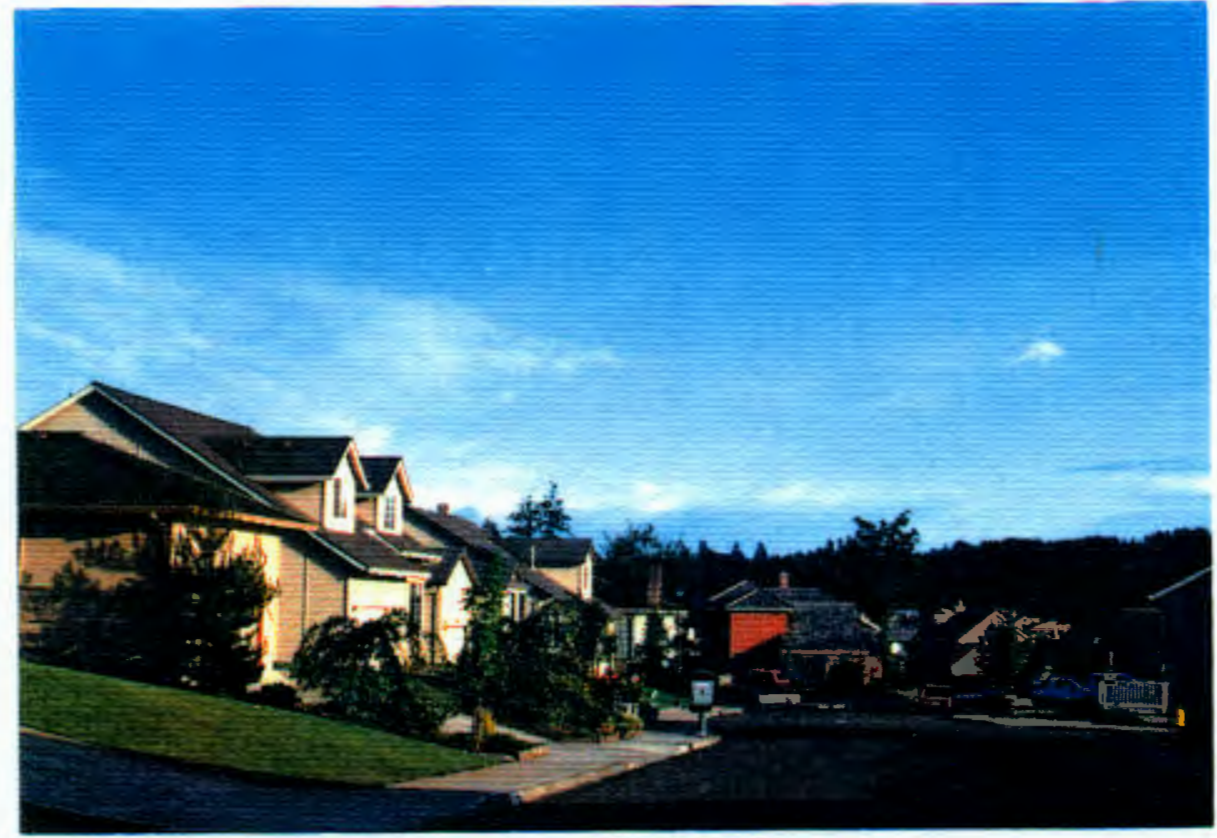

B.

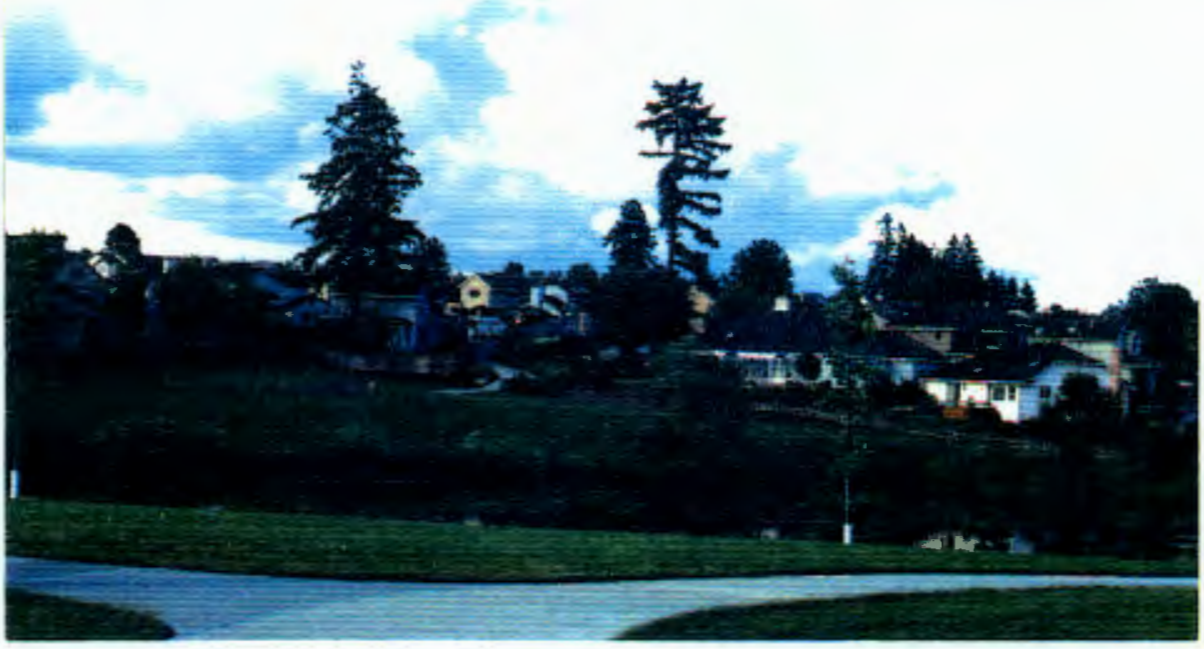

Figure 21. Amart Summer Lake Subdivision located in Tigard. Surveyed in 1979, 135 lots, average lot size: $40 \times 115$ (4600 sq. ft.). 
A.

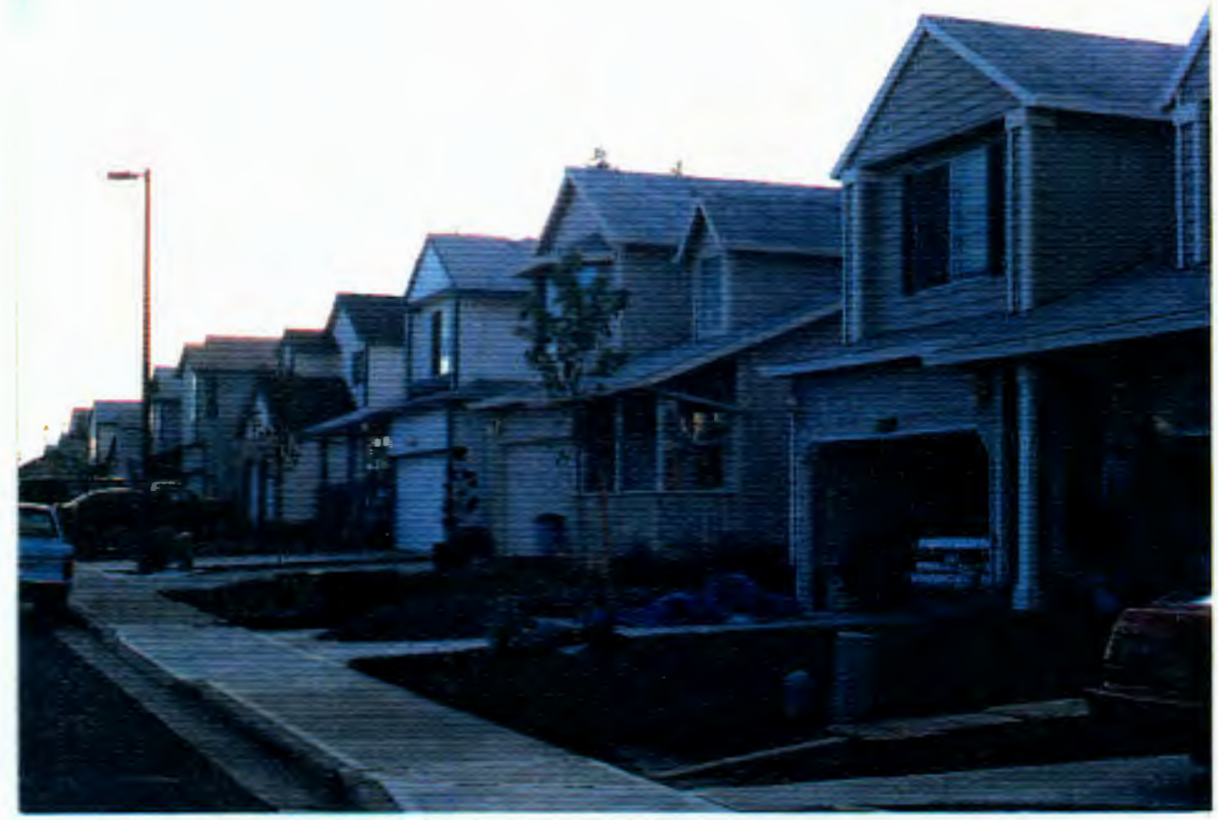

B.

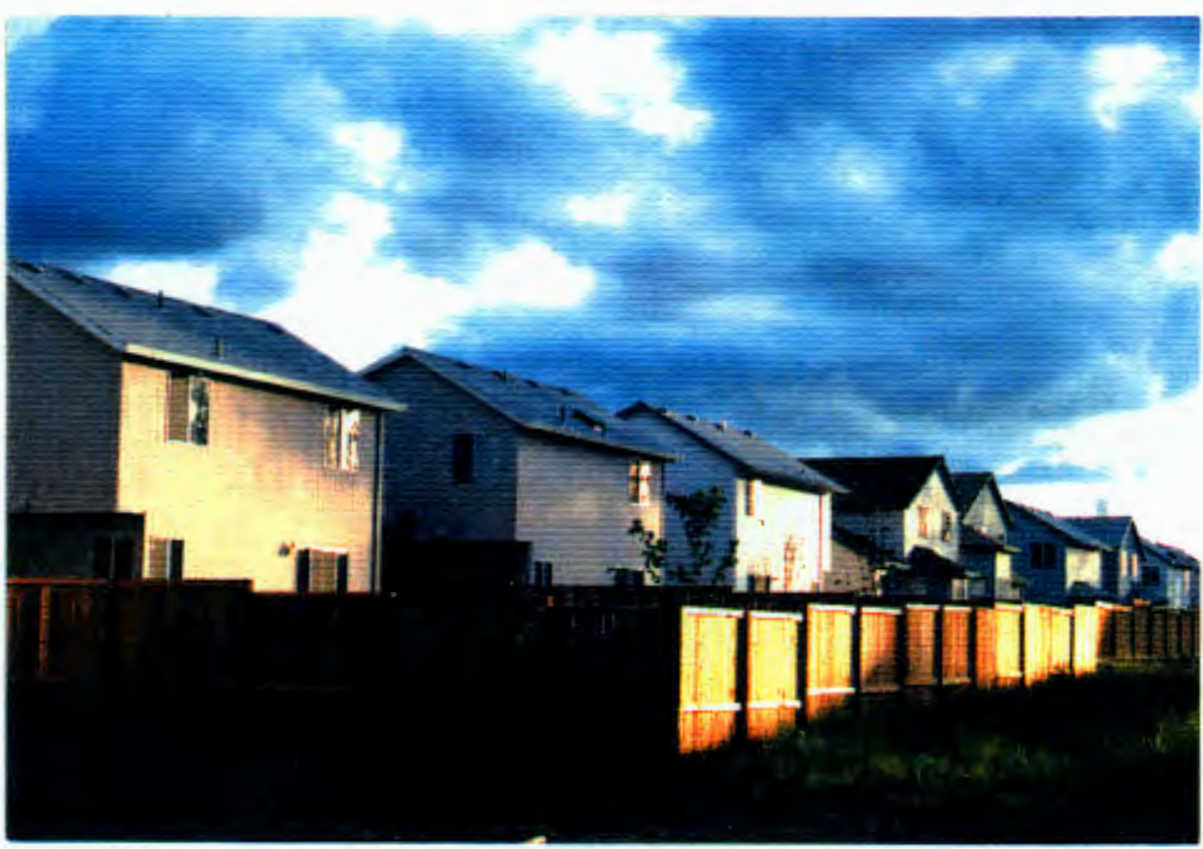

Figure 22. Deerfield Subdivision in Rock Creek area. Surveyed in 1989, 99 lots, average lot size: $45 \times 95$ (4275 sq. ft.). 
A.

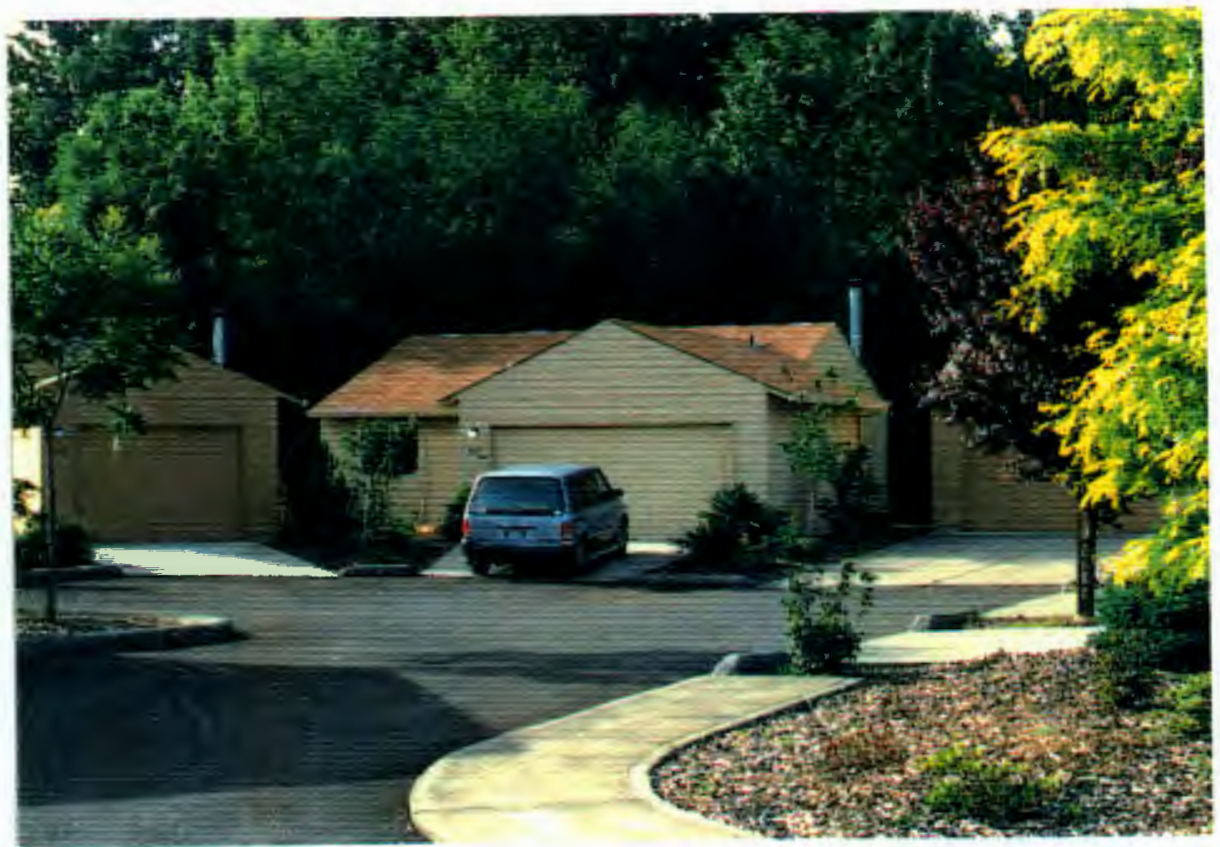

B.

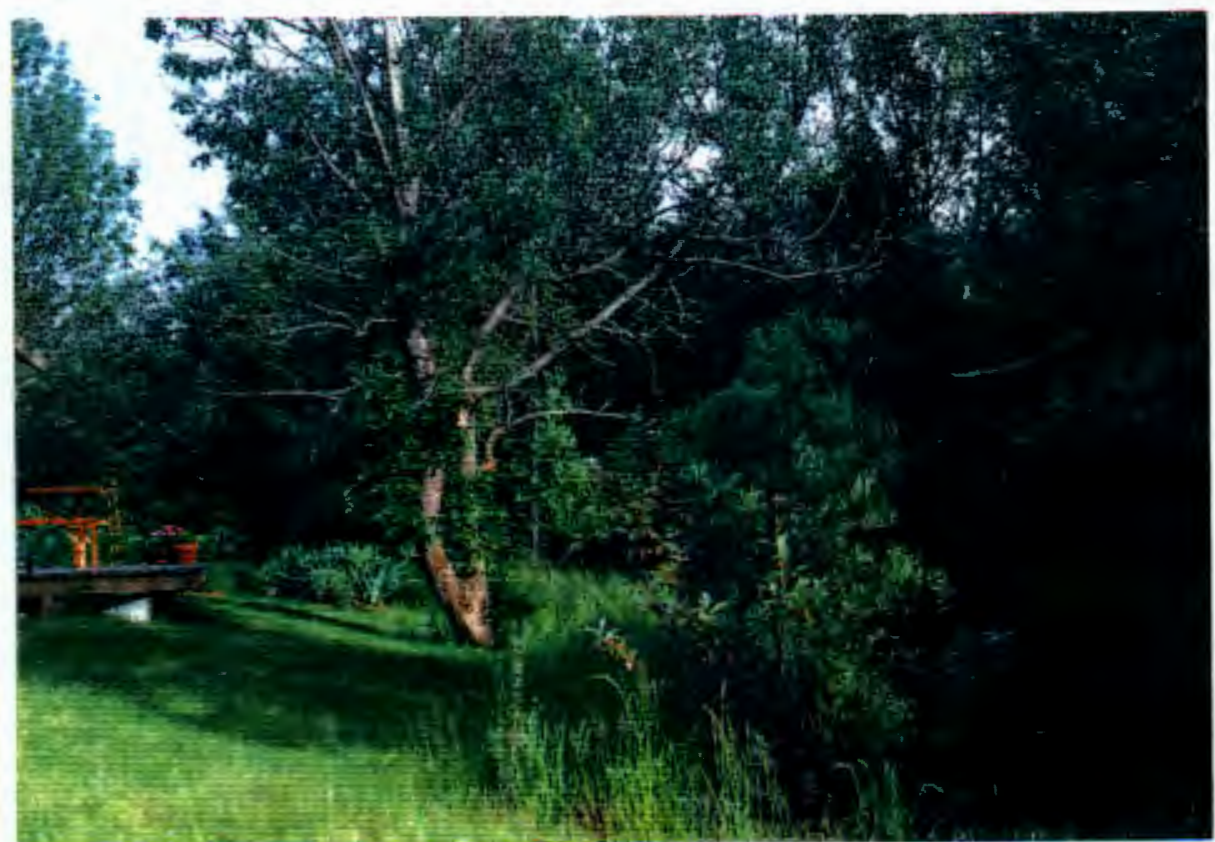

Figure 23. At the Brooks Bend PUD Subdivision. Surveyed in 1984, 20 lots, UPA Density: 5.0: Average lot size: 3900 sq. $\mathrm{ft}$.

Example of PUD subdivision incorporating common space around the perimeter of the development. 
The Deerfield Subdivision in the Rock Creek area is a good example of a high-density subdivision built on former pastureland. The lack of foliage between the houses creates a landscape more reminiscent of dense inner city residential development than that of a suburban environment (Figure 22). The two-story houses completely dominant the landscape, and there is little sense of living in a natural setting. These types of subdivisions represent a return to traditional urban patterns of development, where emphasis is placed on housing and little consideration is given to the aesthetics of yard space. Residents of these developments are, in effect, living in urban-type neighborhoods set in suburban locations.

In many respects, subdivisions like Deerfield represent the antithesis of the suburban ideal. For an average purchase price of $\$ 120,000$ for a 1600 square foot home, Deerfield residents receive all the crowding disadvantages of an inner city environment, combined with all the time/cost disadvantages of being located ten miles from Portland's city center. For many people, however, this is an acceptable trade-off for living in a modern, amenity-laden home. In subdivisions like Deerfield, the traditional suburban ideal of a "garden setting" has been displaced, a victim of the economic realities of the 1990s. In its place has emerged a new middle-income suburban conscienceness, one that emphasizes interior amenities and comfort rather than yard-space and outdoor activities. 
An alternative to the Deerfield type of subdivision are developments which incorporate common-space into the high-density concept. These planned-unitdevelopments (PUD's) usually have lot sizes ranging from 3,000 to 4,000 square feet, with open green spaces available for common use. The common space helps contribute to a sense of spaciousness in the PUD's, and allows for a greater integration with the surrounding natural environment (Figure 23).

PUD developments offer overall higher densities, more affordable housing, and a more integrated setting than most conventional high-density subdivisions. However, many PUD's have homeowners' associations which define appropriate property usage and enforce PUD covenants. This type of restrictive control may discourage some prospective homebuyers as they resent losing individual control over their property. This may explain why despite their advantages, PUD's are still quite rare in Washington County, comprising only one-quarter of one percent of the subdivision developments. 


\section{CHAPTER VII}

\section{THE FUTURE OF SINGLE-FAMILY RESIDENTIAL DEVELOPMENT IN WASHINGTON COUNTY}

Traditionally, developers have viewed couples with children as the primary market for suburban housing. The housing styles, lot configurations, and development layout in most suburban subdivisions have generally been oriented toward the spatial needs of growing families. The phenomenal demand for suburban housing in the post-World War II baby boom era served to solidify this family marketing bias. The large lots and ever-increasing house sizes in the 1950 s and 1960 s reflected both the country's growing prosperity and its perceived need for additional housing and yard space.

Despite continual increases in the number of singles and single parents in recent years, the couple/family marketing bias still predominates in suburban land development. However, by the year 2000,47 percent of the country's households will be made up of singles and single parents, 28 percent will be married households without children, and only 24 percent will be married families with children (German, 1992, p. 36). These projections suggest that developers may need to reassess their family marketing bias if they hope to expand their customer base into the twenty-first century. 
Although singles will constitute nearly half of the household population in 2000, their generally lower incomes will preclude many of them from homeownership. However, it is projected that by 2000 , there will be 14 million single homeowners in the United States, compared to an estimated 45 million homeowners comprised of married families (German, 1992, p. 38). This means that there will be nearly one-third as many single homeowners as married family homeowners, certainly a statistically significant total. Based on the sheer numbers of the ever growing single homeowner segment, it seems reasonable to expect developers to eventually begin to tailor their housing product to this market niche.

The burgeoning single and empty-nester homeowner segments offer the most promise for the expansion of innovative high-density developments. These groups require less house and yard space than families, and their lower incomes often preclude them from affording conventional types of new housing. There has been a tendency in the past to assume these non-family segments of the population preferred attached dwellings such as apartments, condominiums, and townhouses. Although it can be expected that the majority of non-family households will continue to reside in attached dwellings, the demographic trends argue that there is considerable potential in the detached high-density housing market. 


\section{Alternative High-Density Development Options}

The development of innovative high-density subdivisions is not a new concept. As discussed in chapter II, PUD's, zero-lot-line, and Z-lot designs have been used in areas of high housing cost in California for almost three decades. These types of developments have not, however, had much of an impact on the Portland area housing market. The past relative affordability of the area's housing, combined with a conservative building industry, has translated into a traditional adherence to conventional subdivision development.

In recent years, however, there have been several new types of high-density development concepts introduced, some elements of which may prove to have more appeal for the Portland area market. Some of these subdivisions, such as courthomes and cluster developments, offer enhanced affordabilty through extreme high density development. Others, such as traditional neighborhood developments (TNDs), are patterned after older American villages and offer a sense of community reminiscent of an earlier era.

The CourtHome concept was created by RGC (RecreActions Group of Companies) to create affordable detached housing in the high-cost housing market of Orange County, California. CourtHomes are 860 to 1900 square foot houses with two car garages which are built at densities of 10 to 18 an acre. Individual lots are 1200 to 2000 square feet and irregularly shaped to allow for an interlocking of building footprints. The lots have short driveways, and setbacks 
and side yards are eliminated. This allows for a rear yard that is at least 10 feet by 25 feet (Bradford, 1993, p. 148).

CourtHomes are built on land already zoned for multifamily development. The houses are grouped in small cul-de-sacs around shared auto courts (Figure 24). Although the houses are within ten feet of each other, the windows are arranged so that none look directly into a neighbor's house or yard. Privacy is further enhanced by extensive fencing of yard space (Bradford, 1993, p. 148).

The CourtHome concept allows for a significant reduction in new housing cost in areas where land is extremely expensive. In Orange County, land sells for $\$ 550,000$ an acre and a median new-home price is $\$ 298,000$. CourtHomes range in price from $\$ 130,000$ to $\$ 160,000$, or approximately half the cost of the median new home (Bradford, 1993, p. 148). By virtue of its innovative, highly landefficient design, the CourtHome concept provides an attractive alternative to attached housing at a relatively affordable price.

The concept of clustering houses around an auto court has recently surfaced in a somewhat different form in the Seattle area. The development firm, Sherron \& Associates, is building a 10 unit-per-acre detached community on a multifamily-zoned Canyon Creek infill parcel in the city of Bothell. The plan clusters 40 houses around a single auto court (Figure 25), with one-car detached garages and carports accessed by alleys. Pedestrian paths connect the garages to the houses. The 1100 square foot houses, priced in the $\$ 90,000$ range, are quite affordable by Seattle standards (Bradford, 1993, p. 151). 

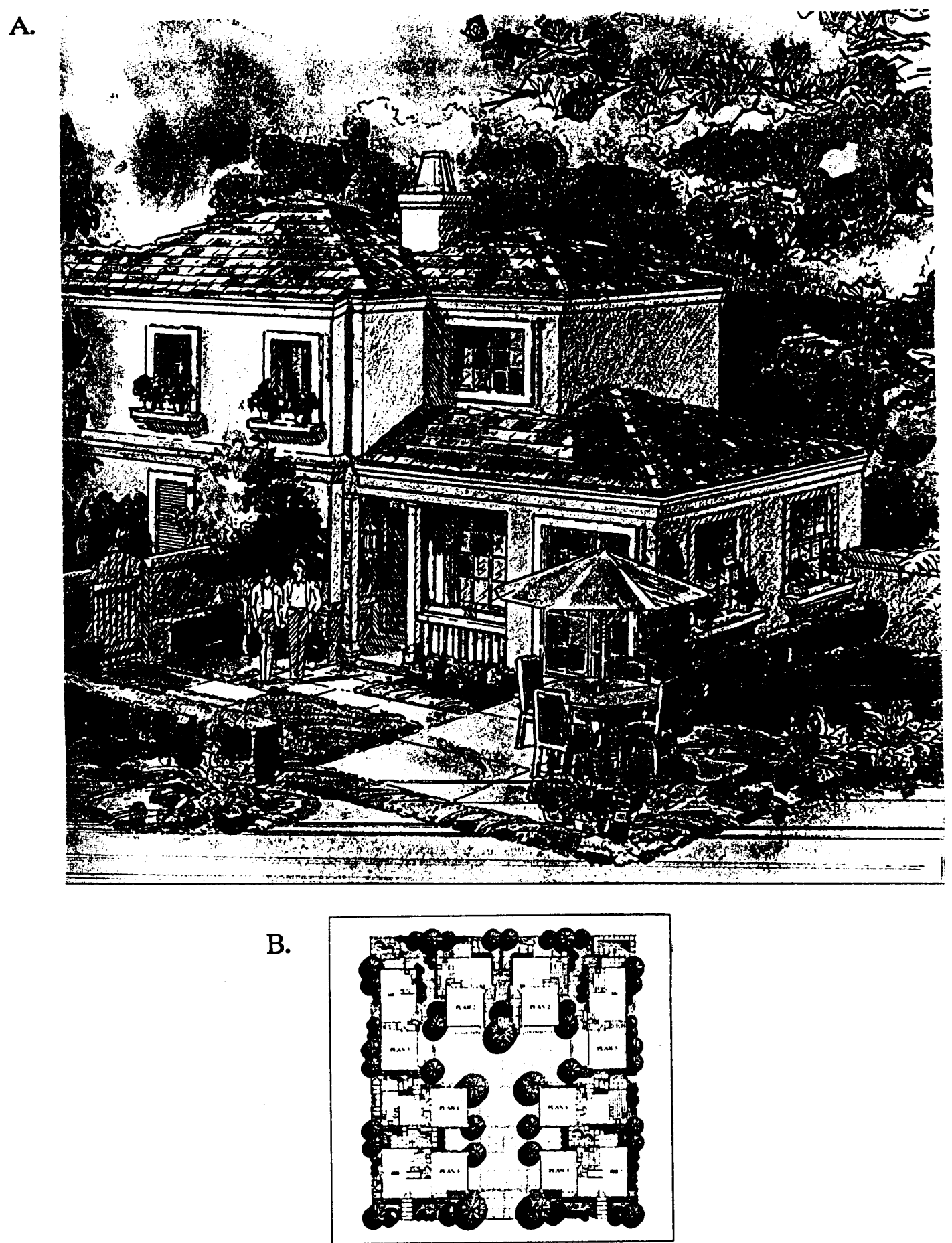

TOWN COURT COLLECTION

Figure 24. RGC's Town Court Collection at Rancho Santa Margarita, Calif. (Source: Bradford, Feb. 1993). 


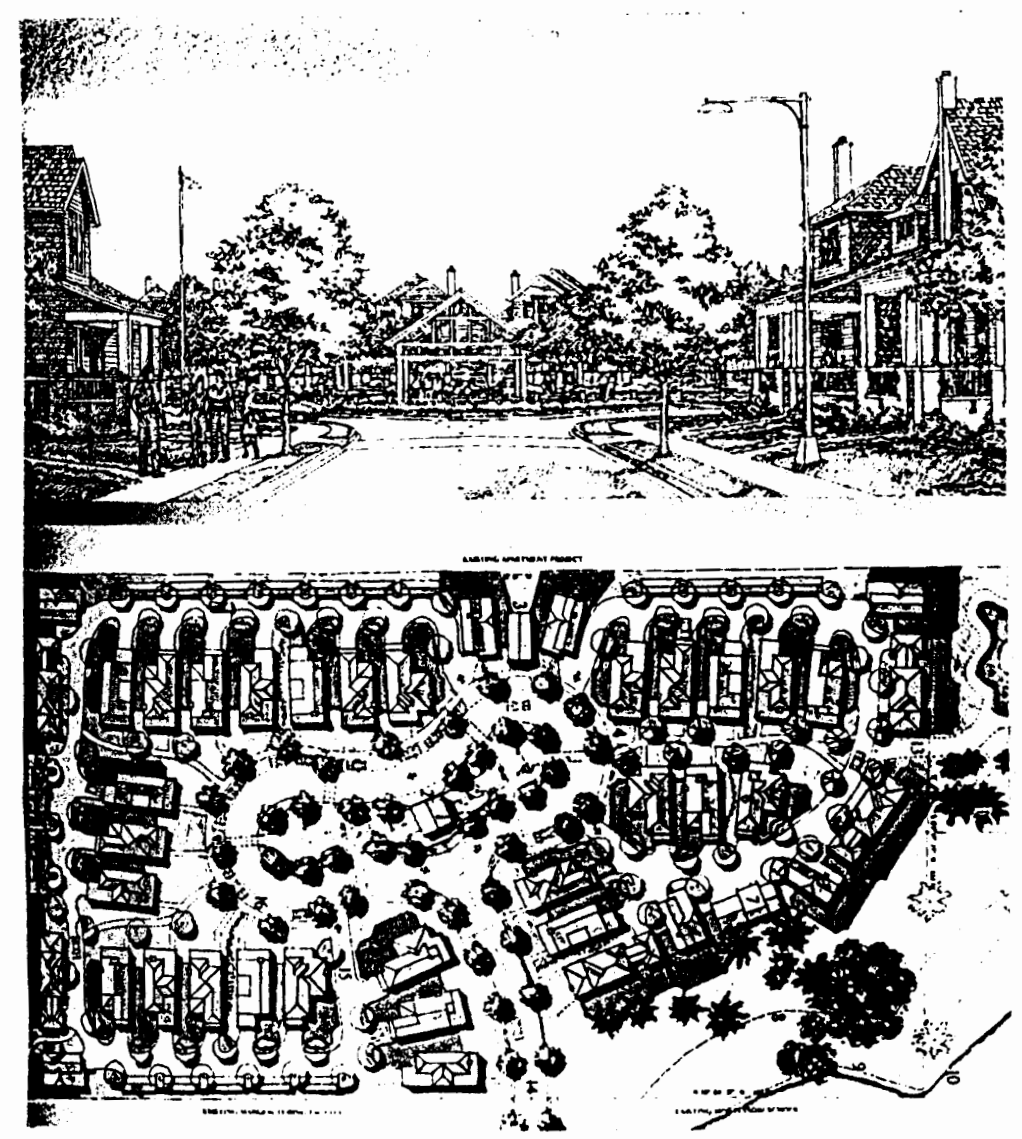

Figure 25. Canyon Creek courtyard development in Bothell, Wa. (Source: Bradford, Feb. 1993).

The designer of the Canyon Creek site plan, Gregory S. Hackworth, views the Canyon Creek project as "something between multifamily and conventional detached." Hackworth contends that most of the people who will buy these houses will be former apartment dwellers who will already be accustomed to having to walk to get to their units (Bradford, 1993, p. 151). By targeting the multifamily household segment, and offering affordable prices, the Canyon Creek project should enable many first-time buyers to enter the housing market. 
A new high-density concept which has made some inroads in the Portland area housing market is the traditional neighborhood development (TND). This type of development is patterned after 18th and 19th century villages with the intent of creating a sense of community among its residents. The design generally includes street layouts that encourage walking with houses located within a fifteen minute walk to schools, parks, and commercial centers. The houses are set on small lots with reduced setbacks, with garages often located in the rear of the properties. The design is intended to create a more pedestrian oriented streetscape which fosters interaction between neighbors (Bradford, Aug. 1993, p. 76).

The TND concept has been implemented in the Portland area in the Rose Lane subdivision in West Linn. The Rose Lane homes have traditional facades and are set on small lots arranged to impart an old-fashioned sense of neighborhood (Figure 26). Like most TNDs, the garages are situated at the rear of the homes and are accessed by a common alley (Peschiera, 1993, p. H1).

The Rose Lane development is similar to other TNDs in that its increased densities do not translate into increased affordability. The 2078 to 2438 square feet homes range in price from $\$ 225,735$ to $\$ 245,000$ (Peschiera, 1993, p. H2), which is well out of the reach of the average homebuyer. According to Von Summers, marketing director for the Homebuilders Association of Metropolitan Portland, it generally costs more per unit to build TND's than for conventional 


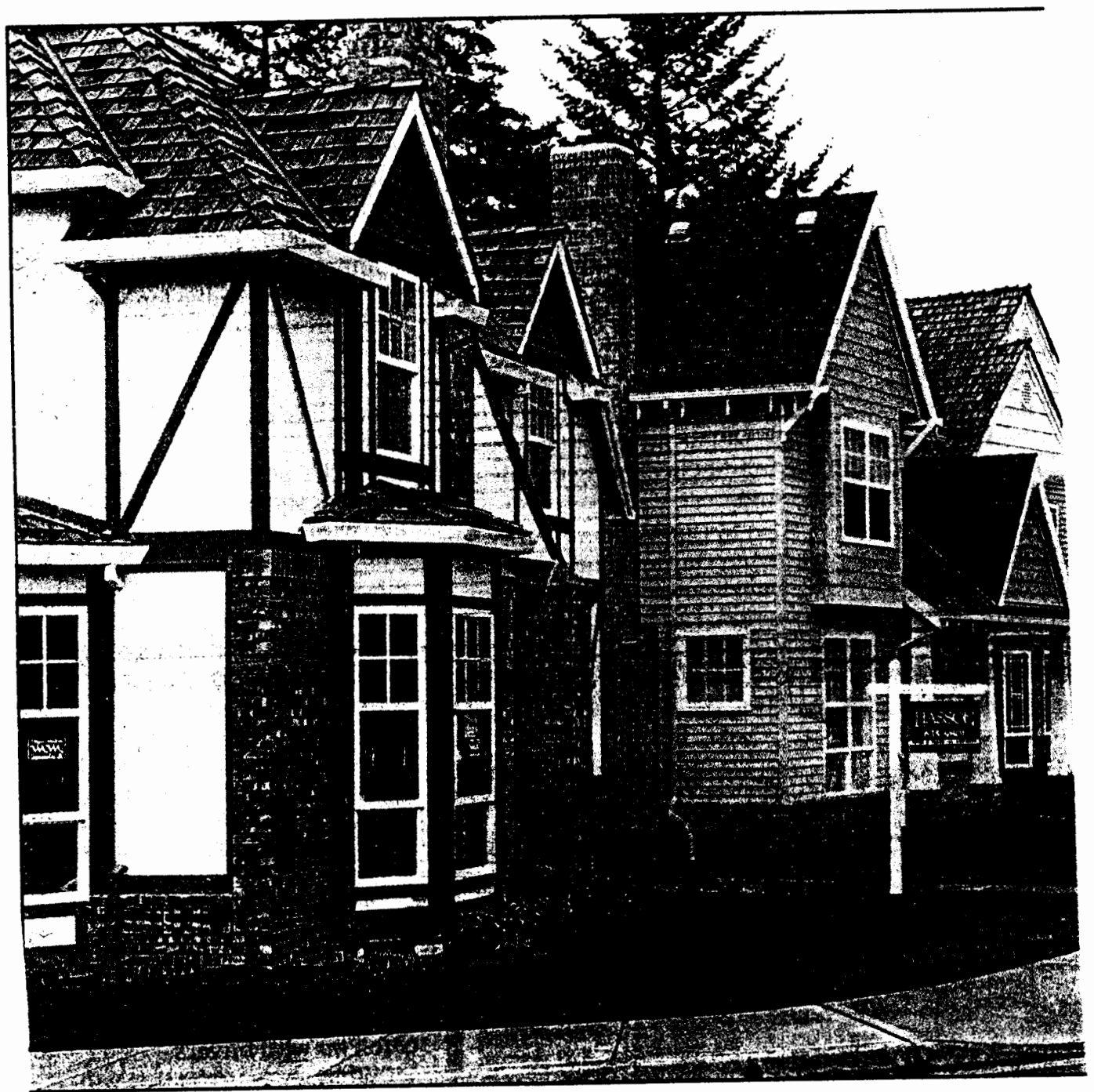

Figure 26. Rose Lane TND subdivision in West Linn, Or. (Source: Peschiera, 1993). 
subdivisions. The costs of building alleyways and rear garages more than offset any cost savings incurred by building at higher densities. Summers contends that when the original traditional neighborhoods were built, the cities provided the streets, alleyways, and other improvements. Now the developer is responsible for providing these improvements and this adds substantially to the cost of building the TND type of development (Summers, 1994).

Recently, a large-scale TND project was approved by the Clackamas County commissioners. The 368 acre East Sunnyside Village will be a neotraditional development designed to encourage a lifestyle less dependent on the automobile. The community will be built around a village green and will have a retail and professional center within walking distance of the residences. The homes will be built on lots smaller than traditional zoning would permit, and the county is requiring that at least half the homes have garages in the back (Pescheria, 1993, p. H2).

Although TND developments do not generally enhance housing affordability, they do represent a more efficient utilization of land than do conventional subdivisions. With their community centers, pedestrian friendly streets, and traditional charm, they represent a refreshing alternative to the conventional car-oriented suburban development. Equally important is the fact that TNDs seem to strike a responsive chord among today's homebuyers. Their increasing popularity should translate into greater receptivity among surrounding neighborhoods, and facilitate approval for future TND development. 
The appeal of traditional types of neighborhoods is well documented in a recent visual preference survey sponsored by several Portland area governmental agencies. The highest rated neighborhood image in the survey consists of traditional Northwest Craftsman homes with short front yard setbacks and covered porches (Figure 27). The neighborhood depicted has rear yard garages which are accessed by alleyways, thus allowing the sidewalk to remain uninterrupted by driveway openings (A. Nelessen Associates, Inc., 1993, p. 30).

The visual preference survey revealed a pronounced disdain for conventional garage-dominated suburban developments. The wide streets and driveways, combined with the visual dominance of the garage over the front door entry, create the impression that these sudivisions were designed more with cars in mind than people (Figure 28). The wide sireets also tend to encourage drivers to drive at higher speeds than on narrower residential streets, thus further compromising pedestrian activity (A. Nelessen Associates, Inc., 1993, p. 32).

\section{The Region 2040 Plan}

The type of future residential development we can expect to see in Washington County will be strongly influenced by Metro's Region 2040 study. The study examines the future shape and design of the entire Portland urban area, with the intention of developing strategies to effectively deal with the regions growth for the next 50 years.

Metro's "Recommended Alternative Decision Kit" published in September 1994, calls for the setting aside of "urban reserve" areas. These reserves will 


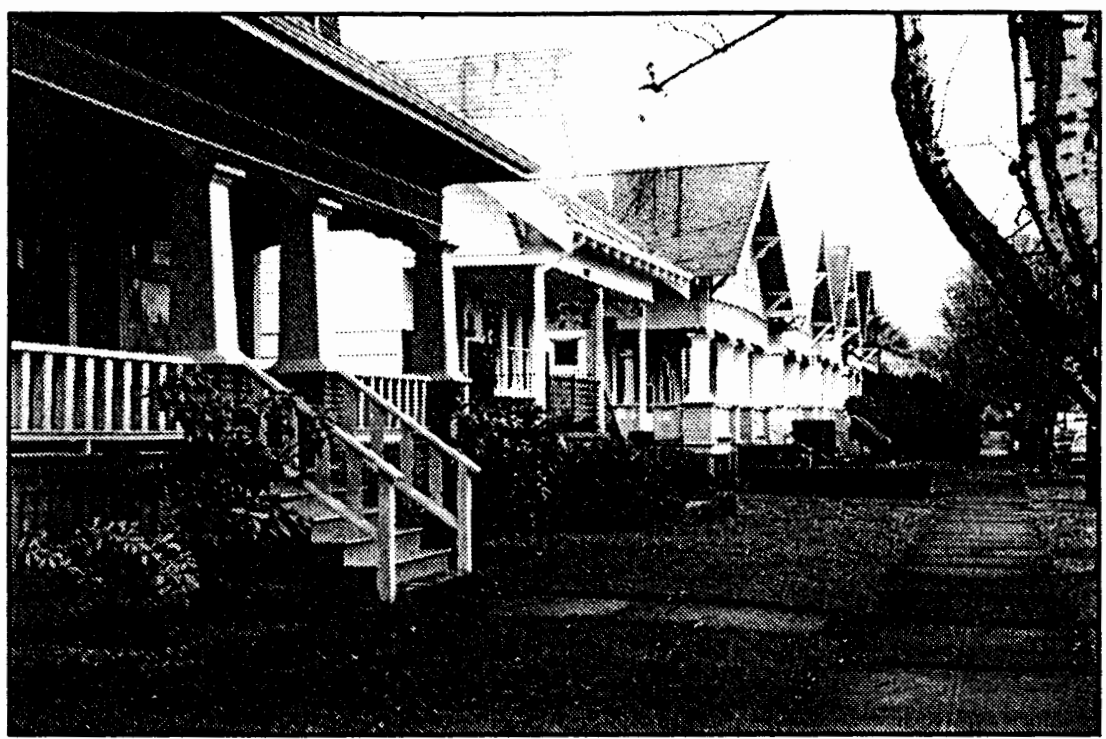

$A$ desirable residential neighborhood.

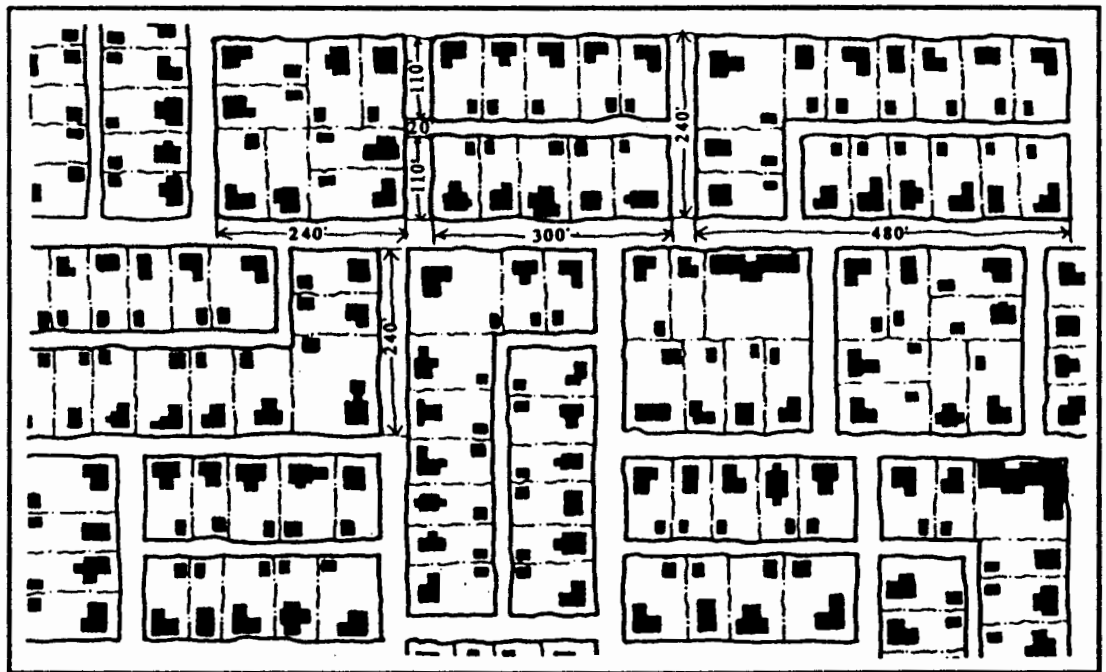

A figure ground plan of a neighborhood similar to the desirable image. Overall density is appraximately 6-8 units per acre.

Figure 27. Highest rated single-family image in the Visual Preference Survey (Source: A. Nelessen Associates, Inc., 1993). 
A.

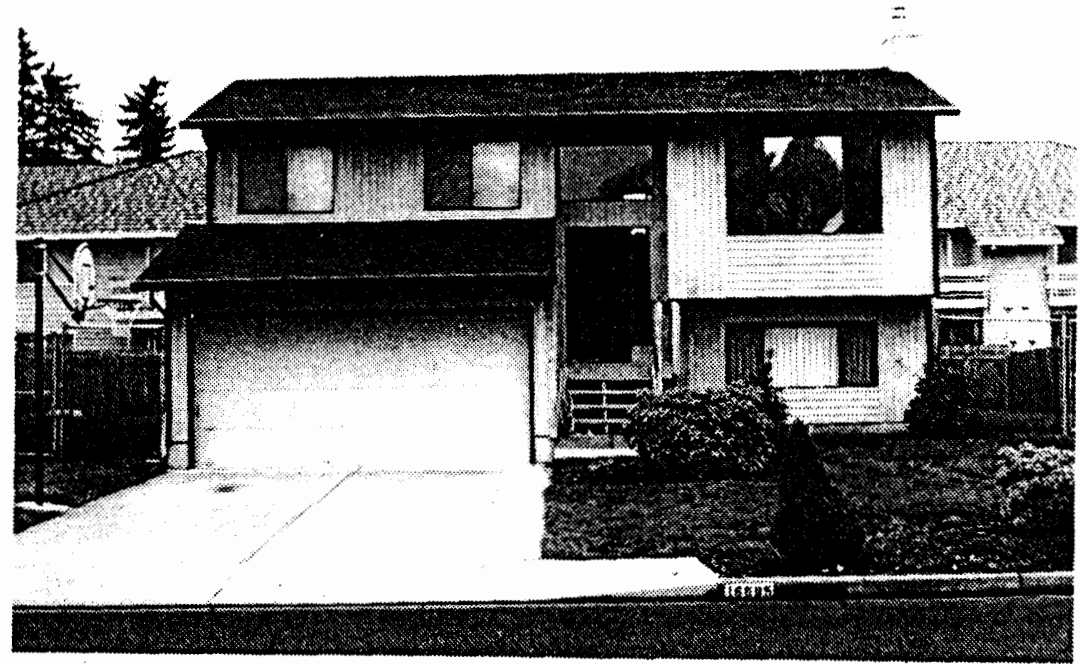

B.

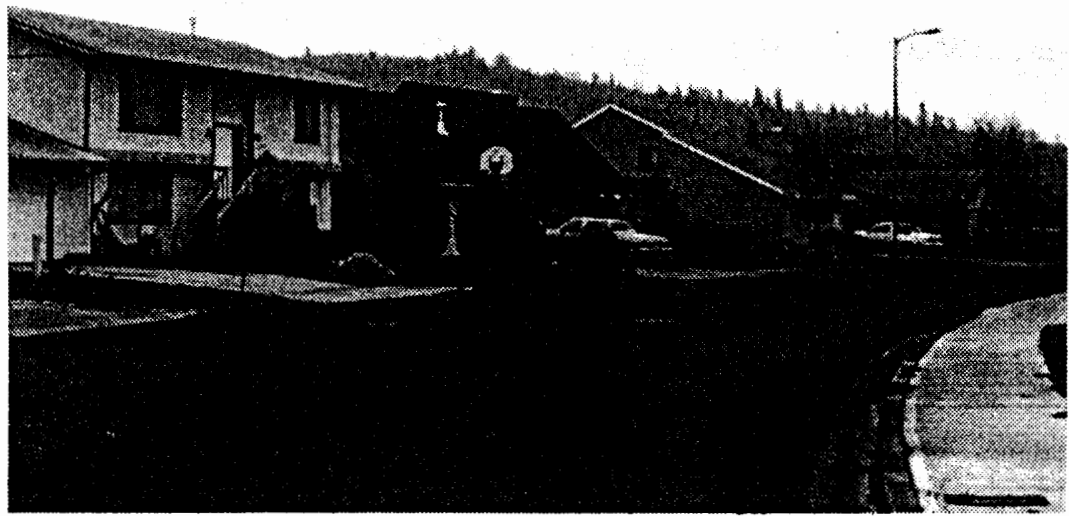

Figure 28. Typical car-dominant suburban development (Source: A. Nelessen \& Associates, Inc., 1993). 
consist of land outside the present urban growth boundary which can be eventually used to accommodate future growth (Figure 29), (METRO, Sep. 1994). This land will likely become developable only after the infill areas within the existing UGB have been largely depleted.

The urban reserves will represent a relatively modest $(14,500$ acres) expansion of the urban growth boundary during the next 50 years (METRO, Sep. 1994). This will translate into only a six percent increase in the total area within the UGB. Since Metro's is predicting a 70 percent increase in the Oregon metropolitan population from the current 1.1 million to about 1.85 million in 2040 (METRO, Sep. 1994), it would seem inevitable that the Portland area will experience a long-term increasing demand for developable land and a continued escalation of housing costs.

In Washington County, approximately 4200 acres are being allocated for urban reserve areas (METRO, Sep. 1994). This represents only a four percent expansion of the Washington County UGB within the next fifty years. Washington County's planning department projects that the county's population will increase from 311,550 in 1990 to 439,500 by 2010 (Washington County Department of Land Use and Transportation - Planning Division, 1992). This means that by 2010, the county will need to accommodate a 40 percent increase in its population within a developable area which will increase by no more than four percent.

Despite the fact that Washington County is the fastest growing area in the metropolitan area, it received only 29 percent of the regions' urban reserves. 


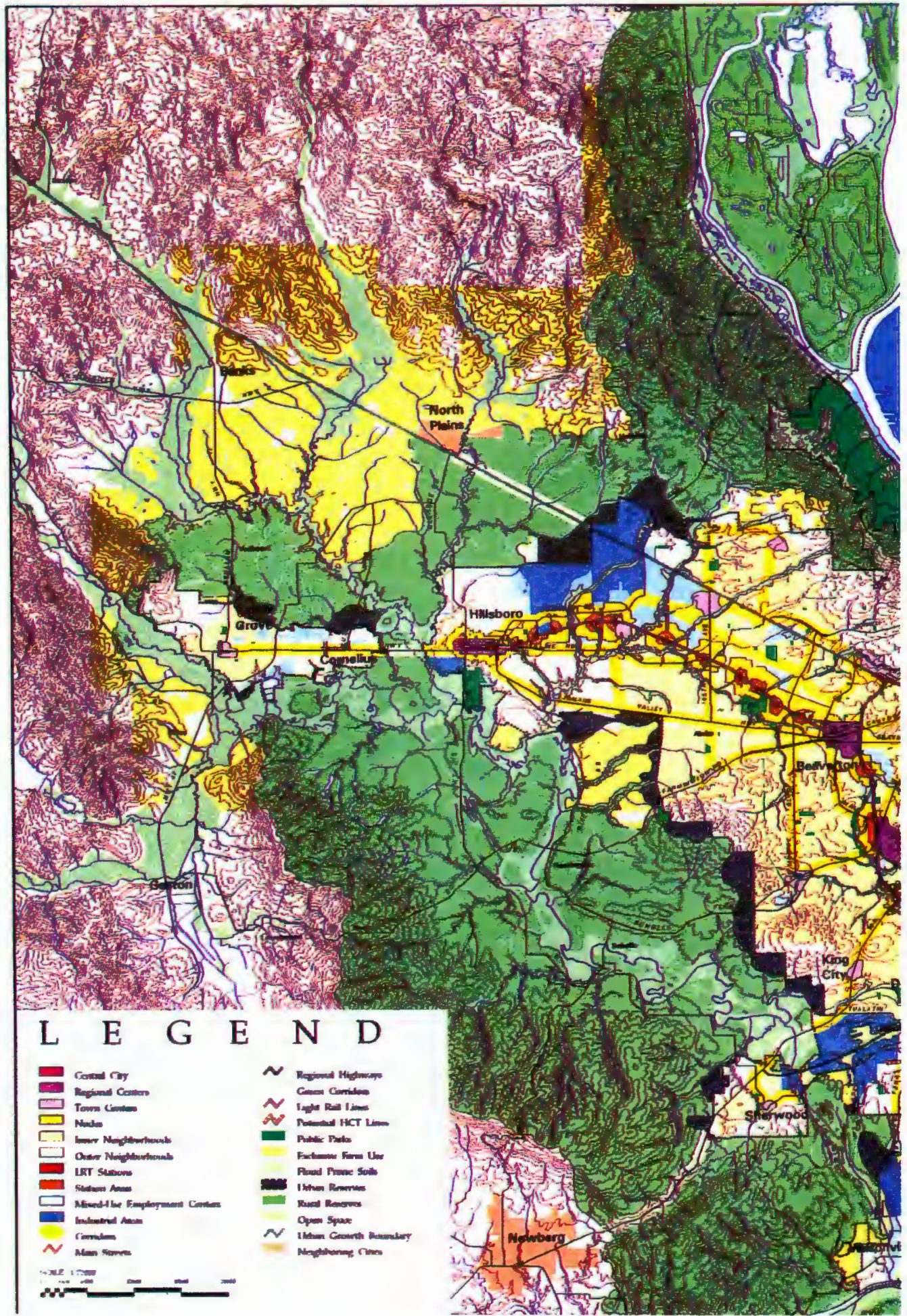

Figure 29. Metro's Region 2040 Analysis of Growth Concept (Source: METRO, Sep. 1994). 
Clackamas County, in contrast, has 58 percent of the regions's urban reserve areas (METRO, Sep. 1994). The relatively low percentage of urban reserves in Washington County, combined with the fact that many areas are already reaching development saturation levels, suggests that future demand for land in Washington County will likely be higher than for other areas in the metropolitan region. This should translate into increasing higher subdivision densities and possibly result in the implementation of more innovative development strategies.

Although rising land costs should provide the impetus for new types of high-density development, there are still many deterrents to unconventional subdivision development in the Portland area. Mark Turpel, Metro senior regional planner, maintains that since most Portland area builders are small-scale, they do not have the resources available to build large master-planned highdensity developments. According to Turpel, small-scale builders tend to stay with projects with which they feel comfortable, and shy away from less conventional development strategies (Turpel, 1994).

In addition to the marketing risks associated with unconventional subdivision development, there are also disincentives posed by restrictive zoning regulations. According to Von Summers, it generally takes longer and costs more to get an unconventional subdivision approved than it does for a conventional subdivision. These "up-front" costs often more than offset any cost advantage gained by building at higher densities, and provide further justification for adhering to a conservative development strategy (Summers, 1994). 
Developers also have to deal with the often negative connotations associated with "alternative" high-density developments. Mark Turpel contends that neighboring residential areas often view unconventional types of developments as a threat to their property values. Just the fact that a development is different than the surrounding neighborhoods is often sufficient motivation for lobbying aggressively against the project. Most builders are not willing to risk this type of resistance, and gravitate toward development styles which are more in keeping with the surrounding neighborhoods (Turpel, 1994).

The general consensus among Portland area planners and developers is that alternative types of developments generally require larger tracts of land to be cost-effective. According to Von Summers, the Portland market has relatively small parcels compared to other cities, and many of these are spot lots or properties that have been passed over in the past because of building difficulties (Summers, 1994). This lack of suitable building sites suggests that future prospects for large-scale master-planned communities within the existing urban growth boundary are limited.

The proposed urban reserve areas in the Region 2040 plan, offer the greatest potential for implementing large-scale alternative types of subdivision development. The opening up of these urban reserves will allow for the acquisition of large contiguous parcels of vacant developable land. However, current land ownership and density patterns in these areas could pose serious obstacles for prospective developers. Mark Turpel contends that since most of the 
land in the urban reserves is comprised of relatively small parcels owned by many different landowners, developers will need to assemble their developable sites by inducing each of the individual owners to sell their property (Turpel, 1994).

Even if developers are successful in acquiring sufficient property to build a large-scale development, they still face the prospect of resistance from neighboring landowners. Since the urban reserve areas have traditionally been developed at extremely low densities, surrounding landowners could very well view high-density developments as a threat to their property values (Turpel, 1994). This perception could spawn an anti-development lobbying campaign which could seriously delay or cancel a high-density project.

It is clear that currently in the Portland area there are a myriad of deterrents and disincentives for building alternative types of high-density developments. There is an entrenched conservatism among builders, homebuyers, and current homeowners which will ensure that conventional patterns of development will continue for some time to come. For the short-term, this conservatism will likely result in the perpetuation of car-dominant type subdivisions built on increasingly smaller lots. Eventually, however, spiraling land costs will necessitate more efficient, intensive and creative types of land development strategies.

As discussed in chapter 5, the post-World War II emergence of Washington County as a high-technology and suburban center, resulted in dramatically rising land costs and a continual increase in single-family residential densities. If these 
trends continue, and it appears likely that they will, the price of a new house in Washington County's could easily double from approximately $\$ 150,000$ today, to $\$ 300,000$ by the beginning of the next century. This dramatic increase in land costs will likely produce market pressures similar to the type which spurred alternative types of high-density development in Los Angeles and the Bay Area. Ultimately, these market pressures could encourage more intensive and innovative high-density projects in the Washington County area.

As discussed earlier, there appears to be a general acknowledgement by developers and planners of the desirability of alternative types of housing development. Despite this, the prevailing attitude among both these groups is to wait and see if market pressures create a significant market for these types of developments. Currently, the average middle-income family is rapidly being priced out of the Portland area housing market. This is dramatically illustrated by the fact that in 1990, Portland's housing affordability index ranked in it the top 20 percent of major U.S cities (Home Sales, National Association of Realtors, 1990); but only four years later a 1994 survey revealed Portland ranked 163rd out of 185 U.S. cities, a figure which placed it in the bottom 12 percent in housing affordability (Tripp, 1995). Unless developers, planners, and homebuyers respond quickly to this situation and begin to seriously consider development alternatives, prospects for future middle-income housing affordability in the Portland area look extremely bleak. 
The limited proposed expansion of Portland's urban growth boundary assures that there will be a relative scarcity of developable land in years to come. Considering this scarcity, perhaps it would be reasonable for planning agencies to reserve a portion of the urban reserves land for alternative single-family highdensity development. A high-density reserve plan would not only enhance housing affordability for middle-income homebuyers, it would also allow single and retired people to pursue their vision of the American suburban ideal. By anticipating future trends and responding accordingly, planners and developers can encourage the building of a broader range of housing styles and help assure that home ownership remains more affordable for middle-income Portland area residents.

Although increased densities will be critical for enhancing housing affordability in the future Portland area market, development design needs to be given equal consideration. Privacy, yard space, and a "garden setting" have been central to the suburban ideal for over a century. Creative design allows for retention of these elements even in extreme high-density developments. The innovative CourtHomes projects in Southern California (10-18 units-per-acre), provide an excellent example of the possibilities in high-density design. These courtyard types of developments, along with zero-lot-line, Z-lot line, and PUD's, represent attractive and affordable alternatives to the traditional car-dominated suburban subdivisions.

The American suburban ideal has been redefined many times since its emergence in the public concienceness in the early nineteenth century. The 
original idea was to create a spacious, private, garden-like setting where people could seek refuge from the noise and turmoil of their central-city workplaces. Initially, only the wealthy were able to realize this ideal. Eventually, however, improvements in transportation technology opened up the suburban landscape to millions of middle-income Americans seeking to define their vision of the suburban dream.

Over the years the original suburban ideal has at times been compromised or redefined to fit the economic realities of the times. The small 3000-6000 square foot lots of the 1890 s' streetcar suburbs, represented a compromise by the middle-class homebuyer of that era. The equally small 3000-5000 square foot lots found in California PUD's in the 1970s and 1980s, represented a similar type of compromise by that era's middle-income homebuyers.

Current trends in the Portland area suggest that the suburban ideal may eventually come full circle and return again to the exclusive province of the wealthy. With median new housing prices rising at a rate where they may reach $\$ 300,000$ by the first part of the twenty-first century, it appears that it will soon be nearly impossible for middle-income homebuyers to afford conventional suburban housing. A new era of compromise may be beginning for the middle-income homebuyer, one that will require acceptence of a dramatic reduction in residential lot size. Whether or not they will even have that option, however, depends on planners, developers, and homebuyers having the foresight to begin exploring housing development alternatives now. If they wait too long, it is conceivable that 
the vast majority of middle-income homebuyers could be priced completely out of the Portland area housing market. 


\section{REFERENCES}

A. Nelessen Associates, Inc., Picture This...The Results of a Visual Preference Survey, (Princeton, New Jersey and Seattle, Washington, June 1993).

Adams, John S., "Residential Structure of Midwestern Cities," Annals of the Association of American Geographers, 60 (1970), pp. 37-62.

Alexander, Ernest R., "Density Measures: A Review and Analysis", Journal of Architectural and Planning Research, 10:3 (Autumn 1993), pp. 181-202.

Bradford, Susan, "Pushing the Density Envelope," Builder, Feb. 1993, pp. 148-152.

Bureau of Labor Statistics, "Builders of I-Family Houses in 72 Cities," U.S.

Department of Labor, Monthly Labor Review, 51:3, September 1940, p. 735.

"Census of Population (1980): Number of Inhabitants, Oregon," (U.S. Department of Commerce, 1981).

"Census of Population and Housing (1990): Summary Population and Housing Characteristics, Oregon," (U.S. Department of Commerce, 1991).

Clark, Jr., Clifford E., The American Family Home 1800-1960, (Chapel Hill, NC; University of North Carolina Press, 1986).

Clay, Grady, "The Coming Struggles Over Density," Landscape Architecture, (May, 1982), pp. 72-73.

Cone, Robert, Washington County Associate Planner, Interview conducted by author, Nov., 1993.

Dodds, Gordon R., and Wollner, Craig, Silicon Forest. (Portland, Oregon; Oregon Historical Society Press, 1990).

Dodge, N.P., "Report of the Committee on Legislation," Annals of Real Estate Practice, 1925, pp. 302-3.

Donaldson, Scott, The Suburban Myth, ( New York; Columbia University Press, 1969). 
Dotterer, Steve, "Cities and Towns," Space, Style and Structure: Building in Northwest America, Vaughan, Thomas, ed., (Portland, Oregon; Oregon Historical Society, 1974).

German, Brad, "Spotting Trends," Builder, July 1992, pp. 35-41.

Hamilton, F.E. Ian, "Silicon Forest," Portland's Changing Landscape, Price, Larry, ed., (jointly published by the Dept. of Geography, Portland State University and the Association of American Geographers, 1987).

Hare, S. Herbert, "Federal Housing Administration Standards for Land Subdivision," The Planners' Journal, 5:1, January-March 1939,

Hayden, Delores, Redesigning the American Dream: The Future of Housing, Work, and Family Life, (New York; W. W. Norton \& Company, 1984).

Heidel, F.M., "Oregon Farms - Partial List of Washington Co. Farms - For Sale By F.M. Heidel," (Hillsboro Independent Print, 1904).

"Home Sales, National Association of Realtors," Vol. 4, No. 12, (December, 1990).

Jackson, Kenneth T., Crabgrass Frontier: The Suburbanization of the United States, (New York; Oxford University Press, 1985).

Langdon, Phillip, "The American House," The Atlantic Monthly, (September, 1984), pp. 45-73.

Marcus, Clare Cooper, Carolyn Francis, and Colette Meunier, "Mixed-Messages in Suburbia: Reading the Suburban Model Home," Places, Vol. 4, No. 1, (1987).

Meinig, Donald W., "Symbolic Landscapes: Some Idealizations of American Communities," in Donald W. Meinig, ed., The Interpretation of Ordinary Landscapes: Geographical Essays (New York; Oxford University Press, 1979, pp. 164-192.

METRO, Region 2040 Recommended Alternative Decision Kit, (Portland, Or: METRO, September 1994).

Mooberry, Lester C., "Housing Problems Found Different; Early Ads in Argus Show Changes," Hillsboro Argus, Jan. 5, 1961.

Muller, Peter O., Contemporary Suburban America,(Englewood Cliffs, N.J; Prentice-Hall Inc., 1981). 
1000 Friends of Oregon and The Home Builders Association of Metropolitan Portland, Managing Growth to Promote Affordable Housing: Revisiting Oregon's Goal 10, (Portland, Oregon; 1000 Friends of Oregon, 1991).

Ottensmann, John R., "Urban Sprawl, Land Values and the Density of Development," Land Economics 53:4, (November 1977).

Peiser, Richard B., "Density and Urban Sprawl," Urban Economics 65:3 (August, 1989).

Peschiera, Barbara, "Modern Meets Traditional," The Oregonian, Nov. 7, 1993,

Popenoe, David, The Suburban Environment, (Chicago, Ill; University of Chicago Press, 1977)

Portland Metropolitian Services District (METRO), Urban Growth Management, 1989.

Potter, Connie, "Cost Conscious: New home prices double in five years," Oregonian, April 25, 1993.

Richardson, Walter J., "Designing High-Density Single-Family Housing: Variations on the Zero-Lot-Line Theme," Urban Land, (February, 1988).

Robbins, Steven, Planning and Adoption Process of the Land Use Framework Element of the CRAG (Portland, Oregon; Portland Metropolitan Services District, 1977).

Rosenbaum, N., "Growth and its discontents: Origins of local population controls," in The Policy Cycle, J.V. May and A. B. Wildarsky, Eds., (Beverly Hills, Calif: Sage Publishers, 1978).

Rowe, Peter G., Making a Middle Landscape, (Cambridge, Mass: Massachusetts Institute of Technology, 1991).

Schwartz, Seymour I., and David E. Hansen, and Richard Green, "Suburban Growth Controls and the Price of New Housing," Joumal of Environmental Economics and Management, (Volume 8, 1981).

Schwartz, Seymour I., and David E. Hansen, and Richard Green, "The Effect of Growth Control on the Production of Moderate-Priced Housing," Land Economics, 60:1 (February, 1984), pp. 110-114. 
Shoppell, Robert W., Modern Houses; Beautiful Homes (New York; Cooperative Building Plan Association, 1887).

Southworth, Michael, and Peter M. Owens, "The Evolving Metropolis: Studies of Community, Neighborhood, and Street Form at the Urban Edge," Journal of the American Planning Association, (Summer, 1993), pp. 271-287)

Stacey, Jr., Robert, "Mapping Metro's Urban Growth," Landmark, (Spring, 1987). State and Metropolitan Area Data Book 1991, (U.S. Department of Commerce, 1991).

Summers, Von, Marketing director of Metropolitan Homebuilders Association of Portland. Interview with author, November, 1994.

Tarr, Fred, senior planner, City of Petaluma. 1978. Interview with Maureen Newby.

Tripp, Julie, "Survey homes in on high Portland prices," Oregonian, Jan 5, 1995.

Tuan, Yi-Fu, Topophilia: A Study of Environmental Perception. Attitudes, and Values, (Englewood Cliffs, NJ; Prentice-Hall, Inc., 1974).

Turpel, Mark, Metro Senior Regional Planner. Interview with author, November, 1994.

Washington County Department of Land Use and Transportation - Planning Division, Information Sheet, 1992.

Washington County Planning Department, Map, 1981.

Weiss, Marc A., The Rise of the Community Builders: The American Real Estate Industry and Urban Land Planning, (New York; Columbia University Press, 1987).

Zelinsky, Wilbur, The Cultural Geography of the United States, (Englewood Cliffs, NJ; Prentice-Hall, 1973). 
APPENDIX

WASHINGTON COUNTY SUBDIVISION DATA

(Source: Washington County Assessors Office) 
The Appendix consists of sample pages of the Washington County subdivision data tables. The full data set is available in the Portland State Geography Department.

Tables are organized in reverse chronological order, and include names of subdivisions, number of units, acreage, units-per-acre (UPA), and location. For subdivisions without available acreage information, a sample lot size, and sample lot number is listed. For some subdivisions, both UPA and sample lot data was obtained with the latter being listed after the locational reference.

For high-density subdivisions, sample lot information is routinely included and is listed immediately below the acreage and UPA figures. To aid in mapping highdensity subdivisions, street names and township-range coordinates are listed after the locational reference.

The abbreviation "Irreg" refers to subdivisions with irregular shaped lots which were excluded from the analysis. The abbreviation "al $/ \mathrm{ml}$ " is used to indicate subdivions which have lot sizes that deviate from the UPA high/medium/low density classification. An example would be a subdivision with a 4.6 UPA (high-density classification) but all lots falling within the 7,000-8,999 square foot range (medium density classification). In this instance, al-md would be used to indicate that the subdivision had "all lots-medium density" and should be classified as a medium density subdivision. The "ml" designation is also used to indicate subdivisions which have lot 
sizes which deviate from the UPA classification. The "ml" indicates that "most-lots" fall within a different density classification than the UPA figure would suggest, and should be re-classified according to the "ml" designation.

The following is the Locational Reference Key:

bv: Beaverton cor: Cornelius fg: Forest Grove kc: king city

hb: Hillsboro she: Sherwood tig: Tigard tua: Tualatin

wc: unincorporated Washington County 
adams acres alex estates anton park 2

arch knoll 3 arch knoll 4 asbury park

aspen park aspen ridge autumn glen avery estates bany view estates

baseline village bauer crest beacon hill est 2 belmont estates berkley estates

bull mtn est. burk's place

burntwood west 4 burntwood west 5 burton cntry est. capstone cascade view est. castle hill cedar creek park

claremont 2

cloverdale

colony cr est 5

dakota ridge

drake est emerald acre finis acres gallaway est glencoe west

glencoe west 2 grenelefe 3 hart's landing
$21 / 5.4 / 3.8$

$4 / 1.3 / 3.1$

$42 / 7.7 / 5.5$

$8 / 1.9 / 4.2$

$6 / 1.5 / 4$

$22 / 4.7 / 4.7$

7020 (16)

$40 / 10.5 / 3.8$ bv

$46 / 17.1 / 2.7$

$11 / 7001$ (9)

$6 / 1.7 / 3.5$

$7 / 1.3 / 5.4$

$13 / 3.2 / 4.1$ wC

$52 / 7245$ (16) wC

$34 / 10.6 / 3.2$ bv

$67 / 15.2 / 4.4 \mathrm{hb}$

$24 / 5.3 / 4.5$ tig $\mathrm{sw} 108$ th ave ne $1 / 415$ 6840 (7)

$41 / 12.2 / 3.4$ wC

$4 / .8 / 5$

5274 (4)

$45 / 13.8 / 3.3 \mathrm{bv}$

$33 / 8.8 / 3.8$ bv

$13 / 7.3 / 1.8$ wC

$16 / 5.0 / 3.2$ tig

$34 / 8.5 / 4.0$ she

$62 / 15.4 / 4.0$ tig

$45 / 8.8 / 5.1$ she

$5700(25)$

$60 / 12.9 / 4.7$ wC 6960 (107)

$23 / 4 / 5.8$

5000 (2)

$13 / 2 / 6.5)$

4840 (120)

$4 / 1.1 / 3.6$ tig

$9 / 3.2 / 2.8 \quad \mathrm{hb}$

$4 / 1 / 4.0$ wC

$4 / 39.8 / 0.1$ wC

$6 / 2.6 / 2.3$

$12 / 2.4 / 5.0 \mathrm{hb}$

6017 (2)

$10 /$ irreg

$41 / 10.6 / 3.9$

$34 / 7.7 / 4.4$ hb

wc

tig

sw titan in t2s riw

sw blanton st nw 1/4 17

sw 162nd pl tis riw

Sw scholls sherw ne $1 / 4$

sw lynnly wy 30 t2s riw

nw clrmnt dr. Sw 1/420

nw canterwood wy tin riw

sw 211th ave se 1/4 2

sw cloverdale wy tis $r 2 w$

sw fanno or ct ne $1 / 411$

sw hall nw 1/4 12 t2s riw

$10 a c(2)$

17,769 (2)

nw 1st pl. nw 1/4 31

north first ave tin $\mathrm{r} 2 \mathrm{w}$

hb

wC 7000 (77)

wC 7400 (10) 


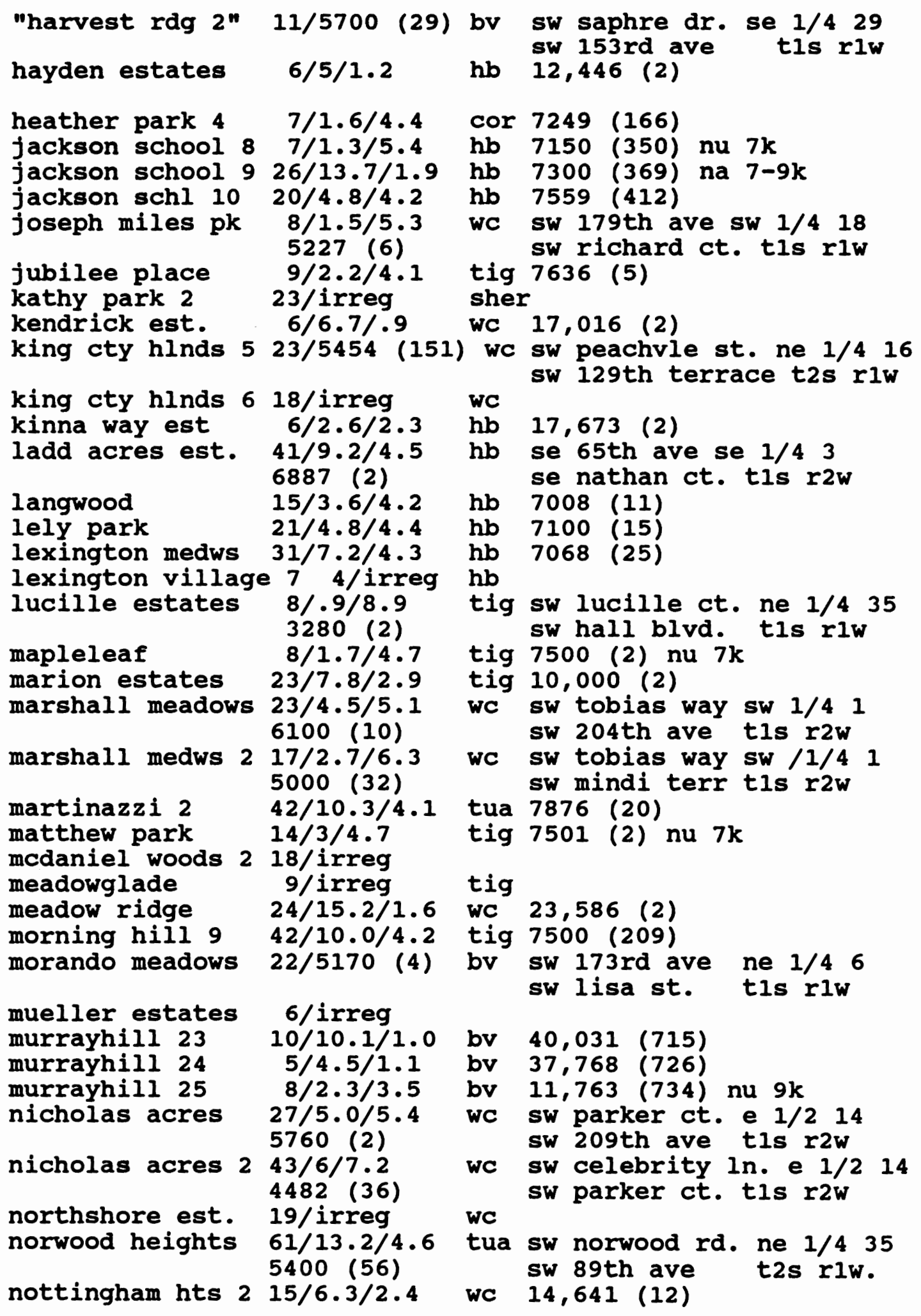




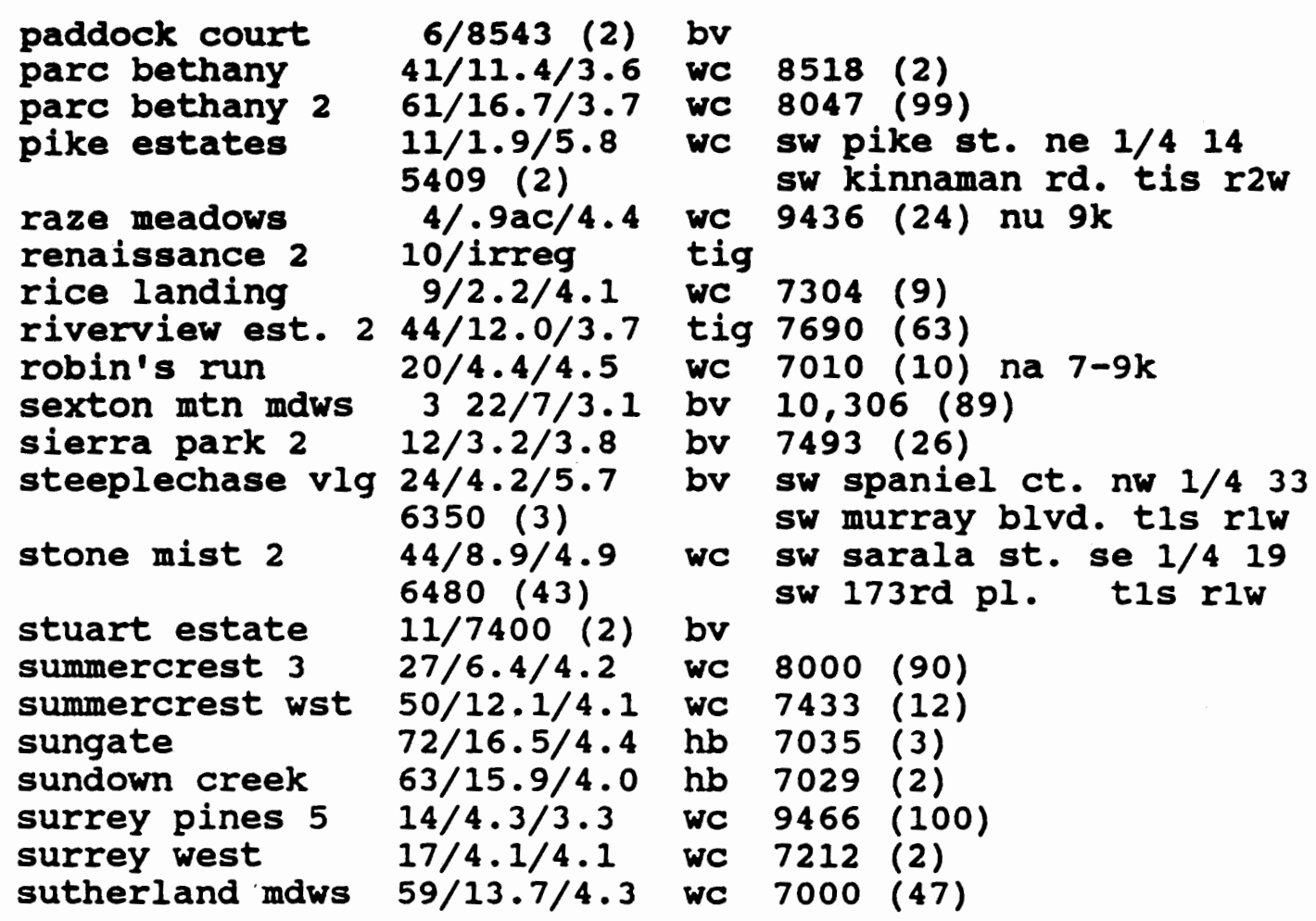

